INSTITUTO DE PESQUISAS ENERGÉTICAS E NUCLEARES

Autarquia associada à Universidade de São Paulo

DESENVOLVIMENTO DE SISTEMA PARA SEGUIMENTO DE PRODUTO E AQUISIÇÃO DE DADOS DO PROCESSO DE IRRADIAÇÃO EM IRRADIADORES DE GRANDE PORTE.

JOSÉ ROBERTO SOARES

Tese apresentada como parte dos requisitos para obtenção do Grau de Doutor em Ciências na Área de Tecnologia Nuclear - Aplicações.

Orientador:

Prof. Dr. Paulo Roberto Rela

SÃO PAULO

2010 
Aos meus pais Jandira das Dores Zoia Soares (em memória) e José Soares (em memória) pela minha existência, à minha amada esposa Rosana Melachos Kozonara Soares e aos meus queridos filhos Alouete Melachos Kozonara Soares e Alexandre Melachos Kozonara Soares pela infinita paciência e atenção, aos amigos pelo incentivo. 
Agradecimentos

Ao Dr. Paulo Roberto Rela pela orientação, amizade, apoio, compreensão e incentivo nesta jornada,

À Dra. Luci Diva Brocardo Machado pelo acolhimento, amizade, incentivo, encaminhamento inicial como orientadora que culminou nesse trabalho,

Ao Dr. Fábio Eduardo da Costa pelas discussões sobre a melhor maneira de lidar com informações do Irradiador Gama Multipropósito,

À M.Sc. Yasko Kodama pelas horas de trabalho na definição desse sistema,

Aos professores, pessoal administrativo, técnicos, comissão de pós graduação do Instituto de Pesquisas Energéticas e Nucleares pela dedicação incansável aos alunos e pesquisadores,

À direção da Bull Ltda na cooperação inicial dos trabalhos com treinamentos nos softwares Bonita e Jonas,

Aos colegas e amigos da Universidade Presbiteriana Mackenzie pelo apoio e incentivo,

Ao Instituto de Pesquisas Energéticas e Nucleares pela oportunidade. 


\title{
DESENVOLVIMENTO DE SISTEMA PARA SEGUIMENTO DE PRODUTO E AQUISIÇÃO DE DADOS DO PROCESSO DE IRRADIAÇÃO EM IRRADIADORES DE GRANDE PORTE.
}

\author{
José Roberto Soares
}

\section{RESUMO}

A esterilização utilizando a radiação ionizante é uma técnica consolidada para o processamento de produtos médicos descartáveis. No Brasil há irradiadores gama em operação com capacidade entre 0.37 PBq (10kCi) a 185 $\mathrm{PBq}(5 \mathrm{MCi})$ utilizando radioisótopos ${ }^{60} \mathrm{Co}$ como fonte de radiação. $\mathrm{O}$ trabalho desenvolvido proporciona um controle e registro apurado da aplicação das Boas Práticas de Fabricação (BPF), durante todas as fases de um processo de irradiação, requeridos pelas normas da ANVISA, ISO e recomendações técnicas da AIEA durante o tratamento de alimentos e produtos médicos. Todas as etapas envolvidas no tratamento por irradiação estão mapeados em fluxos de processos (workflow) onde cada agente (participante) tem suas tarefas sistematizadas. A aquisição de dados do processo, o acompanhamento e controle, estão baseados em um conjunto de ferramentas (software livre de licenças) integradas por uma rede de comunicação eficiente, inclusive, utilizando-se recursos da WEB. O desenvolvimento foi realizado para uma unidade com capacidade de processamento a nível industrial, utilizando-se o Irradiador Gama Multipropósito do IPEN/CNEN/USP. O sistema permite a rastreabilidade do processamento, em tempo real, a qualquer participante e também o armazenamento dos registros correspondentes para serem auditados.

Palavras Chaves: Irradiação, GMP, BPF, Workflow, Código Aberto, ZigBee. 


\title{
DEVELOPMENT OF SYSTEM FOR PRODUCT TRACKING AND DATA ACQUISITION OF DATA IRRADITION PROCESS IN LARGE GAMMA IRRADIATORS
}

\author{
José Roberto Soares
}

\begin{abstract}
The sterilization of medical care products using ionizing radiation is a consolidated technique. In Brazil there are in operation gamma irradiators with capacity between $0.37 \mathrm{PBq}(10 \mathrm{kCi}) 185 \mathrm{PBq}(5 \mathrm{MCi})$ using radioisotopes ${ }^{60} \mathrm{Co}$ as radiation source. The developed work provides an accurate control anda data acquisition for the application of Good Manufacturing Practices during all fases of an irradiadiation process, required by the standards of ANVISA, ISO and IAEA technical recommendations for the treatment of foods and medical products.. All the steps involved in the irradiation treatment are mapped into process flow (workflow), where each agent (participant) has its systematized tasks. The data acquisition process, monitoring and control, are based on a set of tools (free software licenses) integrated by a network of efficient communication, including the use of Web resources. Using the Gamma Irradiator Multipurpose IPEN/CNEN/USP all the development was performed to be applied in irradiators facilities operating in industrial scale. The system enables a complete traceability of the process, in real time, for any participant and also the storage of the corresponding records to be audited.
\end{abstract}

Keywords: Irradiation, GMP, Workflow, Open Source, ZigBee. 


\section{LISTA DE FIGURAS}

FIGURA 2.1 - Ilustração do efeito radiação gama num microorganismo (RELA, 2006)..19

FIGURA 2.2 - Gráfico $D_{10}$ : quantidade de radiação necessária a ser absorvida pelo produto para permitir que a população inicial tenha uma redução de $90 \%$, ou seja, reduzida de uma magnitude na escala logarítmica (RELA, 2006;

ISO 11137-1:2006).... 19

FIGURA 2.3 - Comparativo entre um tubo de imagens de um televisor e um acelerador de elétrons industrial (RELA, 2006)..................................................21

FIGURA 2.4 - Fóton de Raio-X produzida pelo efeito Bremsstrahlung (KARAN JUNIOR, 2000)......

FIGURA 2.5- Hierarquia de comunicação do padrão IEEE 802 para comunicação sem fio (Adaptado VRIES - 2008)............................................................... 31

FIGURA 2.6- Topologias de redes suportados pelo padrão ZigBee (Adaptado VRIES 2008).

FIGURA 2.7- Process Virtual Machine como núcleo do Bonita(LACY, 2008). ................36

FIGURA 2.8- Diagrama Funcional do Bonita (LACY, 2008) ............................................

FIGURA 2.9 - Tela de Login da Console do Bonita: o administrador do sistema (root) faz o seu login para acessar o sistema. .....................................................38

FIGURA 2.10 - Tela de Console do Bonita com diversos widgets (objetos de tela). O widget selecionado é para fazer a manutenção dos usuários ou grupos de usuários.

FIGURA 2.11 - Página do Bonita que o usuário root poder escolher entre cadastrar um novo usuário ou incluir um novo relacionamento.

FIGURA 2.12 - Página do Bonita para o Administrador faz acesso ao sistema para fazer a manutenção de funcionalidades. .......................................................40

FIGURA 2.13 - Página do Bonita para o Administrador do sistema fazer a manutenção dos processos do sistema - aba Processes.

FIGURA 2.14 - Página do Bonita para o Administrador do sistema fazer a manutenção dos processos do sistema - aba Instances.

FIGURA 2.15 - Página do Bonita para o Administrador do sistema fazer a manutenção dos processos do sistema - aba Activities.

FIGURA 2.16 - IDE Eclipse com as classes JAVA de um processo no qual é configurado uma tarefa "chamar" um método (hook) quando a tarefa terminar..........44

FIGURA 2.17 - IDE Eclipse-Proed mostrando um processo, atividades e transições..... 45

FIGURA 2.18 - IDE Eclipse-Proed mostrando as propriedades de um processo.............46

FIGURA 2.19 - IDE Eclipse-Proed mostrando as variáveis globais de um processo......47

FIGURA 2.20 - IDE Eclipse-Proed exibe as propriedades de uma atividade do processo iniciada por um usuário. .....................................................................48

FIGURA 2.21 - IDE Eclipse-Proed exibe a lista de formulários utilizados pelas atividades

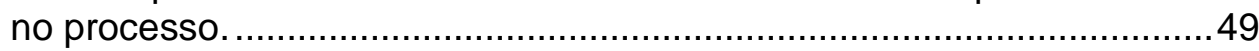

FIGURA 3.1 - Modelagem UML do fluxo do processo de Solicitação de Serviço. ...........58

FIGURA 3.2 - Diagramas de Casos de Uso de Serviço de Irradiação de Produto............60

FIGURA 3.3 - Casos de Uso de Pedido de Serviço de Irradiação de Produto. .................64

FIGURA 3.4 - Irradiador Compacto Multipropósito do IPEN. (Fotos: Paulo Roberto Rela).

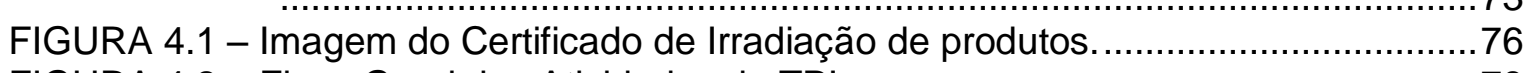

FIGURA 4.2 - Fluxo Geral das Atividades do TPI. ........................................................... 78

FIGURA 4.3 - Tela do Bonita com os processos do TPI disponíveis aos usuários (Apêndice E1 mostra a tela aumentada)............................................. 82

FIGURA 4.4 - Modelo de Dados do Projeto TPI (APÊNDICE F1- Modelo de Dados do

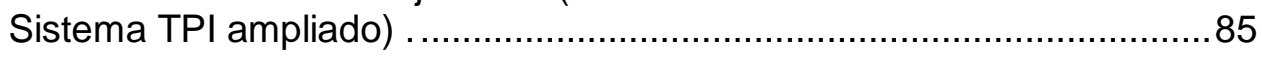

FIGURA 4.5 - Hierarquia de tracking ou relacionamento contém-contido. ........................87 
FIGURA 4.6 - Infra-estrutura de escrita e coleta de código de barras e posicionamento das fontes de irradiação.

FIGURA 4.7 - Arranjo típico da rede de comunicação de coleta e escrita do ambiente do irradiador gama.

FIGURA A1.1 - Página do Bonita que o usuário palmer faz acesso à página do sistema para iniciar a solicitação de Orçamento

FIGURA A1.2 - Página do Bonita que o usuário palmer faz acesso à página do sistema para iniciar a solicitação de Orçamento.

FIGURA A1.3 - Tela que o Cliente faz acesso à página do sistema para iniciar a Solicitação de Orçamento.

FIGURA B1.1 - Fluxo do processo de Emitir Instrução de Irradiação. .104

FIGURA B1.2 - Tela do processo de Emitir Instrução de Irradiação (visão parcial). .......105

FIGURA B1.3 - Tela do processo de Emitir Instrução de Irradiação (visão parcial). .......106

FIGURA C1.1 - Fluxo do processo de Cadastrar Dosímetros no editor Proed...............107

FIGURA C1.2 - Tela do processo de Cadastrar Dosímetros.........................................108

FIGURA C1.3 - Tela do processo de Cadastrar Dosímetros Individualmente................108

FIGURA C2.1 - Fluxo do processo de Leitura de Dose no editor Proed..........................109

FIGURA C2.2 - Tela de registro de Leitura de Dose. .....................................................109

FIGURA C2.3 - Tela mostra o posicionamento e a situação do dosímetro. ...................110

FIGURA C2.4 - Tela mostra a dose acumulada no dosímetro e as quantidades de doses realizadas.

FIGURA C3.1 - Fluxo do processo de Consultar Dosímetro no editor Proed.

FIGURA C3.2 - Tela de Consulta do Dosímetro.

FIGURA C3.3 - Tela mostra o estado atual do dosímetro.

FIGURA C4.1 - Fluxo do processo de Colocar Dosímetro no editor Proed.

FIGURA C4.2 - Tela de Colocar do, referente ao posicionamento do dosímetro....

FIGURA D1.1 - Fluxo do processo de Carregar Caixas de Irradiação.no Proed.............114

FIGURA D1.2 - Tela de Carregar Caixa de Irradiação com itens de lotes.......................114

FIGURA D1.3 - Tela mostra a efetivação da carga do item de lote na Caixa de Irradiação.

FIGURA D2.1 - Fluxo do processo de Consultar Caixa de Irradiação.no Proed

FIGURA D2.3 - Tela mostra a efetivação da carga do item de lote na Caixa de Irradiação.

FIGURA D3.1 - Fluxo do processo de Carregar Caixa de Irradiação na Posição do Irradiador no editor Proed.

FIGURA D3.2 - Tela de carregar caixas nas posições do irradiador.

FIGURA D4.1 - Fluxo do processo de Carregar Posição do Track no ambiente do irradiador no editor Proed.

FIGURA D4.2 - Tela de carregar posições de track nas posições do irradiador.

FIGURA D5.1 - Fluxo do processo de Consultar Lote de produto para irradiar no editor Proed.

FIGURA D5.2 - Tela de Consultar Lote e seus itens.

FIGURA D5.3 - Tela de Consultar Lote e são detalhados os seus itens. 
FIGURA D5.4 - Tela de Consultar Lote com o detalhamento do item-1 com seu respectivo tracking. 


\section{Lista de Quadros}

Quadro 1.1 Comparação entre padrões de comunicação sem fio (wireless).............................................................

Quadro $3.1 \quad$ Descrição do Atores do Sistema TPI............................... 61

Quadro 3.2 Descrição das responsabilidades dos atores do sistema 62

Quadro 3.3 Descrição das atividades dos atores na geração do pedido de 65

Quadro 4.1 Estimativa de horas de desenvolvimento dos processos do TPI 89

Quadro 4.2 Estimativa de horas de desenvolvimento da biblioteca TPIUTIL 90

Quadro 4.3 Infra-estrutura de escrita e coleta de código de barras e 92 posicionamento das fontes de irradiação 


\section{SUMÁRIO}

1 INTRODUÇÃO

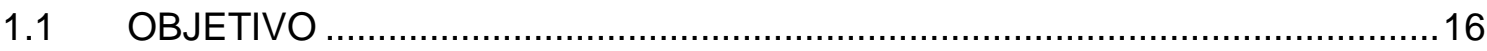

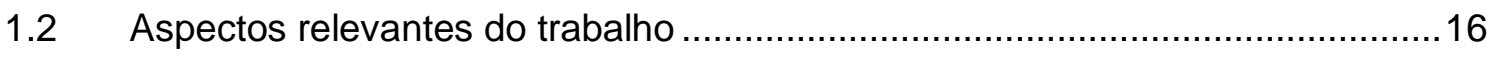

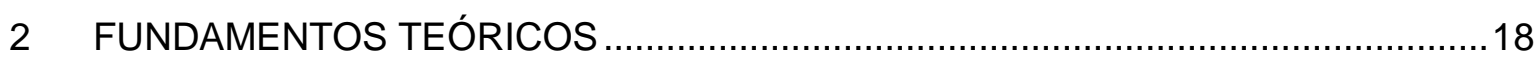

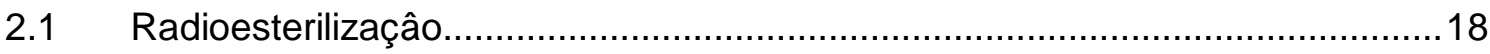

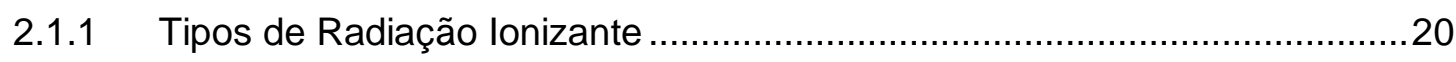

2.1.1.1 Radiação Gama............................................................................2

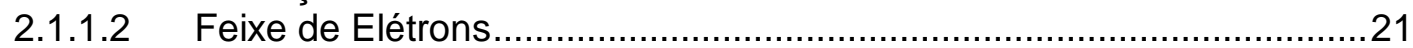

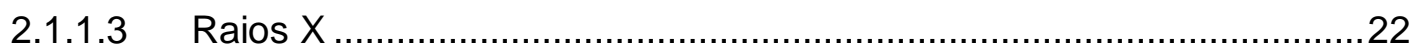

2.2 GMP - Good Manufacturing Pratice ou Boas Práticas de Fabricação ...............22

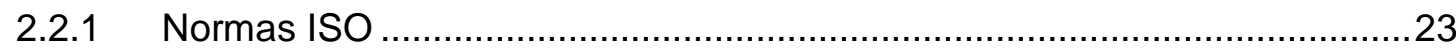

2.2.2 IAEA - International Atomic Energy Agency ..............................................24

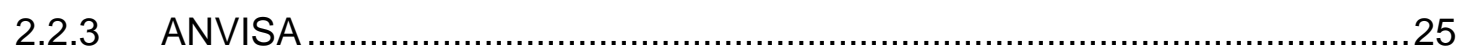

2.2.3.1 Boas Práticas de Fabricação (área de alimentos) ...............................25

2.2.3.2 Boas Práticas de Fabricação (área da saúde) .....................................26

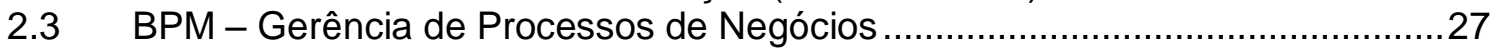

2.3.1 As fases e evolução de processos de negócios ...........................................28

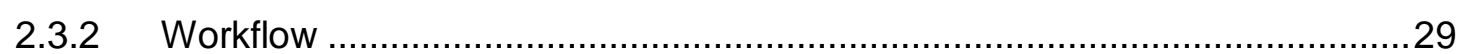

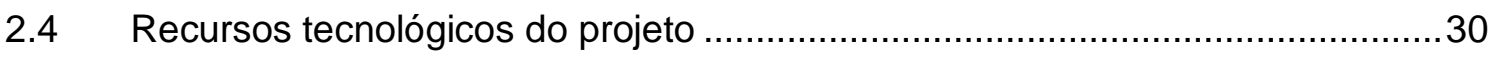

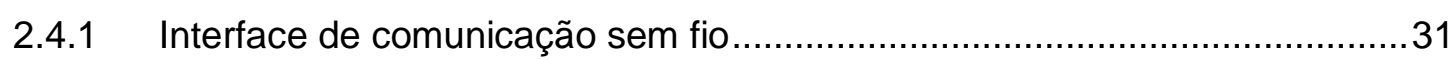

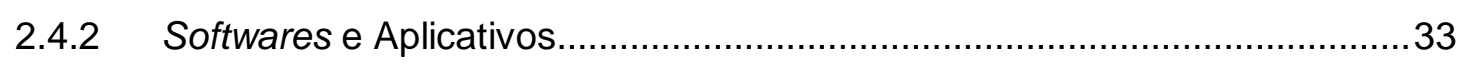

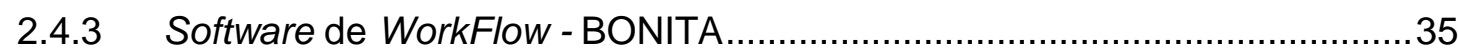

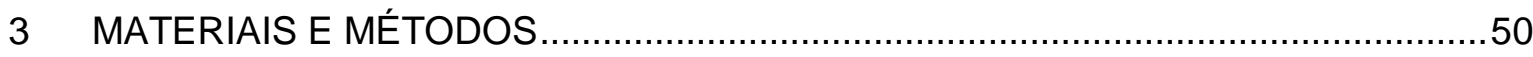

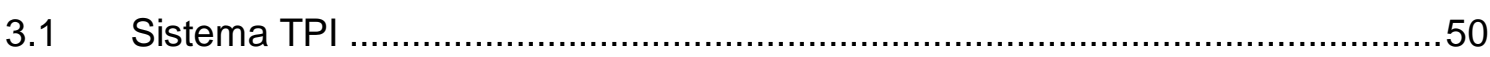

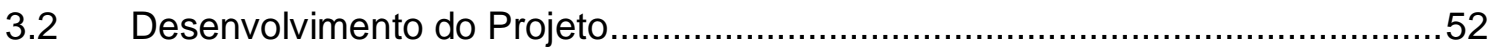

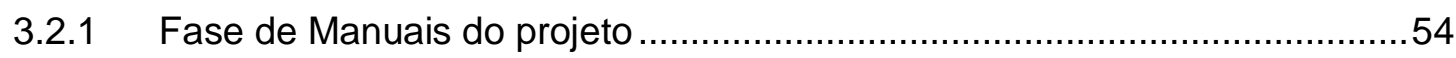

3.2.1.1 Manual de Padronização...................................................................54

3.2.1.2 Metodologia de Desenvolvimento de Sistemas ....................................55

3.2.2 Fase de Gestão de Requisitos do projeto …………..................................56

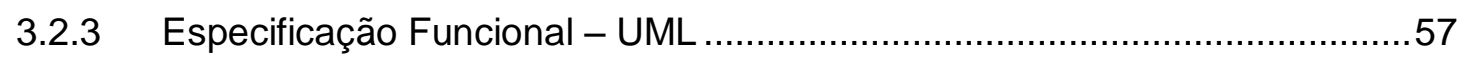

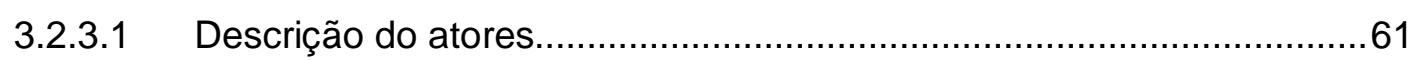

3.2.3.2 Descrição geral das atividades dos atores ..........................................61

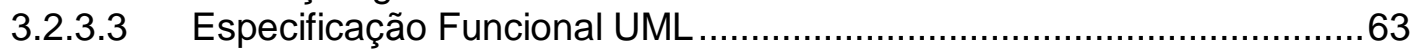

3.2.3.4 Pedido de Serviço de Irradiação .........................................................63

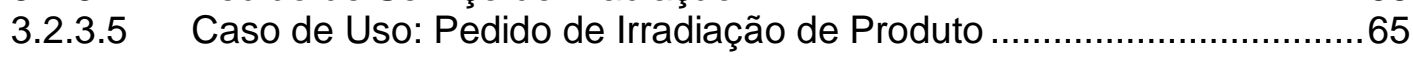

3.2.3.6 Modelos de formulários, etiquetas e relatórios .......................................68

3.2.4 Fase de Formatação e Desenvolvimento ………….....................................68

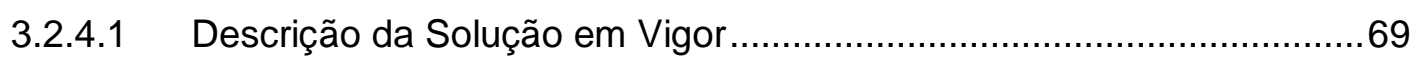

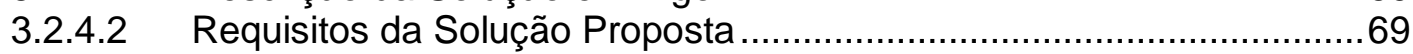

3.2.4.3 Requisitos de Interface do Usuário .....................................................70

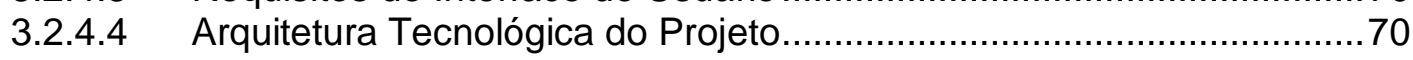

3.2.4.4.1 Irradiador Multipropósito do IPEN ....................................................71

3.2.4.4.2 Interface de aquisição de dados..................................................... 


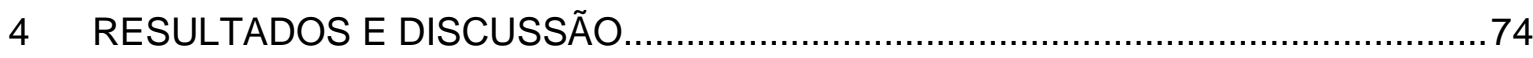

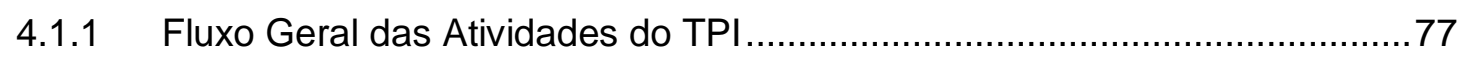

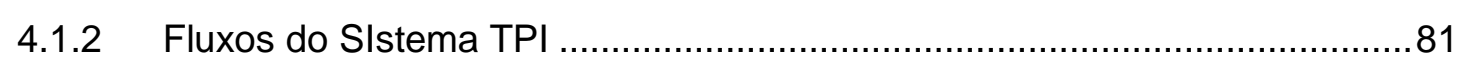

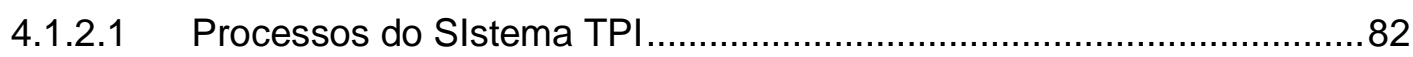

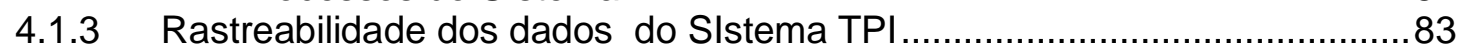

4.1.3.1 Modelos de dados do TPI ..................................................................

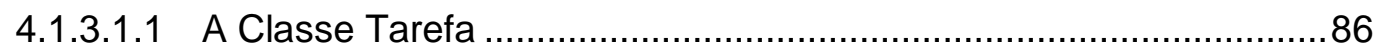

4.1.3.1.2 A Classe Item de Track ............................................................... 86

4.1.3.1.3 Relacionamento do que contem o quê...........................................87

4.1.4 Plataforma de Desenvolvimento do Sistema TPI ........................................ 88

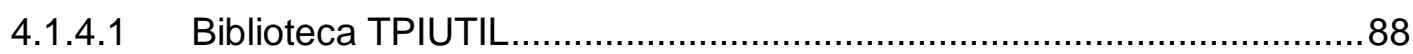

4.1.4.2 Processos desenvolvidos para o TPI................................................ 89

4.1.5 Estimativas de custos de desenvolvimento do sistema TPI .........................91

4.1.6 Rede de coleta/escrita Wireless ZigBee/WiFi.............................................93

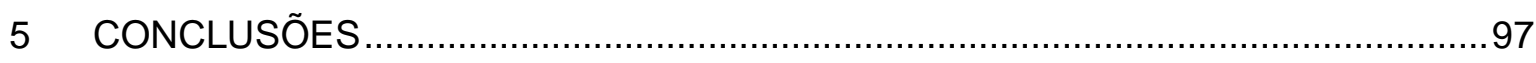

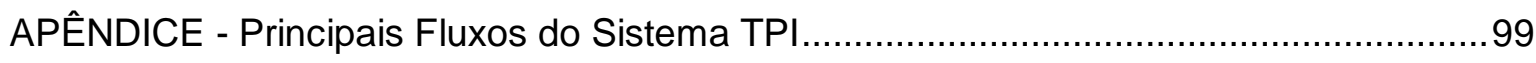

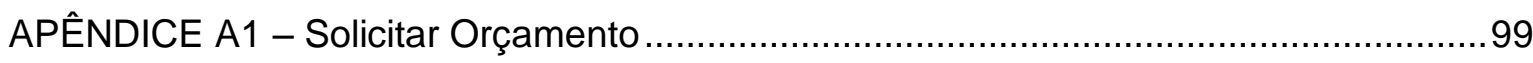

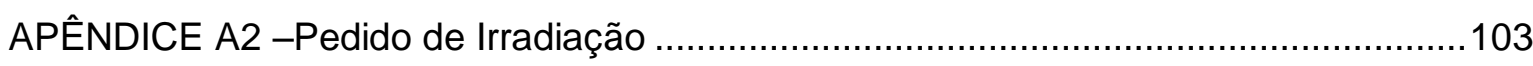

APÊNDICE B1 - Emitir Instrução de Irradiação ..........................................................104

APÊNDICE C1 - Cadastrar Dosímetros .............................................................107

APÊNDICE C2 - Leitura de Dose do Dosímetro ……………........................................109

APÊNDICE C3 - Consultar Dosímetro ……………………....................................111

APÊNDICE C4 - Colocar Dosímetro ……………………….................................113

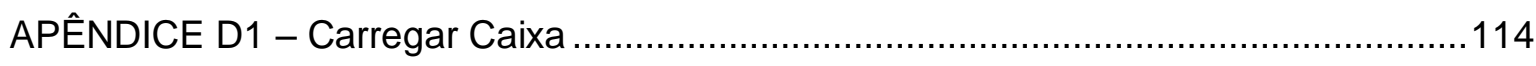

APÊNDICE D2 - Consultar Caixa ........................................................................116

APÊNDICE D3 - Carregar Caixa Posição Irradiador Contínuo .........................................118

APÊNDICE D4 - Carregar Posição do Track ……………………................................119

APÊNDICE D5 - Consultar Lote …………………………………………....122

APÊNDICE E1 - Tela dos Processos do TPI no Bonita.................................................127

APÊNDICE F1 - Modelo de dados do Sistema TPI ....................................................129

APÊNDICE G1 - Modelagem do fluxo do processo de Solicitação de Serviço (FIG.3.1)

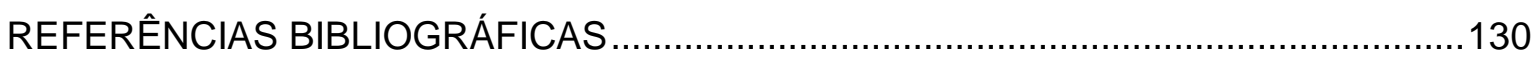




\section{INTRODUÇÃO}

Com o advento da formação da ONU (Organização das Nações Unidas) e da Agência Internacional de Energia Atômica com a criação do Programa Átomo para a Paz, a humanidade, finalmente, começou a vislumbrar uma melhor utilização da energia nuclear como geração de energia, medicamentos e terapias contra diversos males. Outro benefício é a utilização dessa energia na forma de radiação ionizante na esterilização de equipamentos e dispositivos médicos, produtos de banco de tecidos humanos, artigos de higiene, na redução da carga microbiana de ingredientes de alimentos, ração animal, sementes, frutas, na modificação de propriedades de polímeros, na indução de cores de gemas, e tantas outras aplicações.

Entretanto, não é comum ver em embalagens de produtos que foram submetidos ao processo de radiação ionizante qualquer menção do método de esterilização, exceção feita aos produtos médicos. As pessoas leigas têm a falsa idéia de que o material esterilizado por esse método torna o produto radioativo e causaria danos sérios a elas. Mesmo após a explicação que, os níveis de energia utilizados nas aplicações industriais não são suficientes para indução de radioatividade nos materiais processados, as pessoas ainda ficam receosas.

A técnica de radiação ionizante é utilizada comercialmente há mais de 45 anos. Existem mais de 250 plantas em diversos países. Cerca de $55 \%$ dos produtos médicos descartáveis são esterilizados por esse método. Em números, isso representa mais de cinco milhões de metros cúbicos. No Brasil mais de 75 mil metros cúbicos de produtos médicos descartáveis são esterilizados a cada ano (RELA, 2006; comunicação pessoal, 2010).

As atividades do serviço de uma planta de irradiação para fins de esterilização, desinfestação, desinfecção ou outra utilização têm sua qualidade melhor reconhecidas se seguirem Boas Práticas de Fabricação (BPF), Good Manufacturing Practice (GMP).

A norma ISO-11137:2006 trata sobre esterilização de produtos de saúde, enquanto a norma ISO-13485:2003 trata de sistema de qualidade de 
equipamentos médicos, ainda, o documento IAEA-TECDOC-539 é um guia para Boas Práticas de Radiação utilizando fontes de Cobalto-60 como fonte de irradiação.

No Brasil a ANVISA emitiu algumas normas para processamento de produtos tanto na área de alimentos quanto na área de saúde. É interessante salientar que, a responsabilidade final da qualidade do produto esterilizado por processo de irradiação ionizante, é sempre do fornecedor ou fabricante do produto e não de quem presta o serviço de irradiação. Para tanto, quem presta o serviço de irradiação deve assegurar o bom serviço prestado, garantindo a aplicação na dosagem requerida pelo fabricante.

A operação da planta de irradiação normalmente é comandada por dois sistemas automatizados com o propósito de controlar a operação do irradiador assegurando a segurança do mesmo e das pessoas, e também controlar a operação do serviço de irradiação assegurando a eficácia do serviço de irradiação aplicado aos produtos submetidos ao processo. A operação do irradiador é baseada em controladores lógicos programáveis (CLP). O ideal é que as unidades controladoras sejam separadas, onde a operação do sistema responsável pela segurança ocorra de forma independente do sistema de controle do serviço de irradiação. A separação física dos dois sistemas é para garantir que não haja a possibilidade de interferência direta ou remota na operação do irradiador, quebrando dessa forma, o protocolo de segurança do mesmo.

O sistema de gerenciamento do processo de irradiação segue as atividades normais de uma fábrica na qual o cliente solicita o serviço através de um pedido; o setor comercial faz o trâmite do pedido até a abertura de uma ordem de serviço; a gerência da planta verifica se o produto é conhecido ou se necessita de um estudo; a produção faz toda manipulação do produto desde o recebimento até a expedição do mesmo, após o seu processamento; a qualidade inspeciona cada detalhe para certificar a garantia do processo; e a contabilidade lida com os trâmites fiscais e faturamento dos serviços.

Um sistema de gerenciamento baseado em sistema computacional passou por diversas fases e culturas. Atualmente os mesmos são desenvolvidos seguindo às boas práticas de Gerência de Processos de Negócios, ou, Business Process Management (BPM). Esse enfoque é uma evolução da tecnologia da informação, ou seja, na década de 80 o foco era o acesso a dados e informação; 
na década de 90 teve, no seu início, foco em automação e decisões, no final da década, o foco se tornou mais amplo com a introdução da WEB; a partir de 2000 se evoluiu para processos de negócios "uma série de passos repetitíveis adotados por uma organização para produzir um resultado desejável" (BORGES, 2003).

As arquiteturas de sistemas computacionais atualmente estão fortemente baseadas em software livre (open source, freeware). Com o advento da conectividade através da Internet as transações de negócios trouxeram o cliente para "dentro" das empresas. A compra online, na qual o comprador não tem nenhum contato direto com o vendedor, faz o pedido, efetua o pagamento com cartão de crédito, recebe o produto no local onde quiser, é uma realidade irreversível.

Portanto, a concepção de um sistema de controle de produção na qual o cliente ou qualquer outro participante do processo tem a oportunidade de, a qualquer momento, visualizar o andamento do processo, é mais que desejável e aceitável.

O sistema desenvolvido recebeu o nome de Tracking de Produto Irradiado (TPI). Tem o suporte das Boas Práticas de Fabricação para irradiação de produtos médicos e alimentícios.

O sistema tem como base operacional e desenvolvimento o Sistema de Irradiação em um Irradiador Multipropósito de Cobalto-60 Tipo Compacto do IPEN/CNEN/USP construído por RELA e descrito por CALVO (2005). A arquitetura do sistema computacional é baseada na WEB na qual todos os participantes possam se conectar de qualquer local. Bastando para isso ter um login e um password de acesso. Cada participante tem acesso às atividades e informações que o sistema lhe permite "ver". A arquitetura do sistema é baseada num tramitador (workflow) de atividades do processo. São desenhados diversos fluxos de controle dependendo da atividade e do participante do processo. As ferramentas são todas open source (código aberto). O tramitador escolhido é o Bonita $^{1}$ O servidor de aplicação WEB o JONAS $^{2}$. As duas ferramentas são

\footnotetext{
${ }^{1}$ http://forge.objectweb.org/projects/bonita

2 http://forge.objectweb.org/projects/jonas
} 
baseadas na arquitetura JAVA ${ }^{3}$. O banco de dados é o $\mathrm{H}_{2}^{4}$ como base persistente para os dados do processo.

A documentação do sistema segue a metodologia de orientação a objetos. É composta por diversos documentos. O foco deste trabalho é uma tese de doutoramento, o produto final é uma peça de sistema computacional. Portanto, a sua concepção, do ponto de vista de um desenvolvedor de aplicação, atende aos diversos atores (agentes) que participam do desenvolvimento de um sistema onde existe a visão do cliente (patrocinador), a especificação do arquiteto do sistema, a descrição dos processos, teste e base de dados. Estão detalhados os fluxos, formulários, telas e a arquitetura física da instalação.

O seguimento do produto no ambiente do irradiador se dá através da identificação de código de barras do produto. Pensou-se na utilização de etiquetas com Radio Frequency IDentification (RFID), porém, o microchip de mercado não resiste à dosagem acima de 3.000 Gy. A garantia de que o produto foi irradiado é a presença de um leitor, fixo, de código de barras na porta de entrada do irradiador e outro leitor, também fixo, na porta de saída. Portanto, se o produto (dentro da caixa de irradiação) foi identificado entrando no irradiador (o transportador é automático) da próxima vez que o mesmo passar pelo leitor será no leitor da porta de saída. Com isso, fica garantido que o produto percorreu todos os passos internos do irradiador (ao todo 17 posições do modelo adotado).

A única interação do sistema TPI com o sistema de controle do irradiador é através de uma interface sem fio (wireless) para informação da posição das fontes de cobalto-60, "em cima", quando exposta e irradiando radiação gama, ou "em baixo", quando mergulhada na piscina de segurança e armazenamento. A informação "em cima" garante que o irradiador está com a porta trancada e intertravada com o sistema de segurança. Qualquer material no interior do irradiador, nessa condição, receberá radiação ionizante.

\footnotetext{
${ }^{3}$ http://www.oracle.com/technetwork/java/javase/downloads/index.html

${ }^{4}$ http://www.h2database.com/html/main.html
} 


\subsection{OBJETIVO}

O objetivo desse trabalho foi desenvolver um sistema computacional com o propósito de atender às necessidades de realizar o seguimento (acompanhamento, tracking) do produto enquanto submetido ao ciclo do processo de irradiação em uma planta industrial . Como resultado final do processo tem-se a emissão de um certificado de qualidade atestando ao cliente a conformidade do serviço de irradiação com as especificações do produto.

A arquitetura do sistema computacional utiliza ferramentas open source (código aberto) ou softwares livres de licença, de modo, a não depender de uma empresa ou pessoas específicas para seu desenvolvimento e manutenção. A arquitetura do sistema é baseada num tramitador (workflow) de atividades do processo, contendo desenhos de diversos fluxos de controle, na qual todos os participantes possam, por meio da WEB, se conectar de qualquer local, por meio de um login e um password para fazer o acompanhamento do produto num ambiente de irradiação e permitir acesso controlado às atividades e informações de acordo com a sua hierarquia.

\subsection{Aspectos relevantes do trabalho}

Este trabalho tem a novidade de introduzir a tecnologia de seguimento de produto (tracking) no ambiente de produção de serviço de irradiação utilizandose da integração que a arquitetura WEB oferece, concomitantemente, atender às Boas Normas de Fabricação e Irradiação de produtos.

O serviço de irradiação executado seguindo às Boas Práticas de Fabricação e Irradiação é inovador e relevante do ponto de vista do sistema aqui proposto. Estas práticas estão calcadas nas normas ISO-11137:2006 que trata da esterilização de produtos de saúde e ISO-13485:2003 sobre a qualidade de equipamentos médicos. Essas duas normas (ISO-11137 e ISO-13485) estão de acordo com a norma ISO-9001 que governa a elaboração de documentos que atestam a qualidade do processo. Esse processo segue, também, o guia de Boas 
Práticas de Irradiação, IAEA-TECDOC-539, que trata da esterilização industrial por radiação, especificamente por cobalto-60, em produto médico descartável. Estas normas têm abrangência internacional. Em nível nacional a ANVISA emitiu a RDC-275:2002 para a área de alimentos e a RDC-59:2000 para produtos médicos. Também emitiu a RDC-21:2001 que regulamenta a irradiação de alimentos.

O seguimento de produtos é de domínio das áreas de logística e distribuição. É comum encontrarmos nas embalagens dos produtos comprados, quer seja via WEB ou de magazines, etiquetas com uma série de códigos de barras com diferentes identificações cobrindo as fases percorridas pelo produto.

Esse trabalho de desenvolvimento de sistema tem os mesmos propósitos. Com uma novidade, a introdução do uso de softwares livres de licença, conhecidos também por open source ou código aberto. Estes não dependem de uma empresa ou pessoas específicas para seu desenvolvimento e manutenção. São mantidos por comunidades de desenvolvedores ao redor do mundo. As dúvidas são esclarecidas em fóruns apropriados.

Como prova da eficácia e interesse no uso do software livre, o governo brasileiro criou a Comunidade de Software Livre do Governo Federal ${ }^{5}$ e em 2010 promoveu a $11^{\circ}$ Fórum Internacional de Software Livre- A tecnologia que liberta ${ }^{6}$ em Porto Alegre-RS, realizado de 21 a 24 de julho no Centro de Eventos da PUCRS. Para o evento foram inscritos mais de 7.500 pessoas. Esse evento é considerado o maior encontro da América do Sul e um dos mais importantes do mundo (SOFTWARELIVRE, 2010).

$O$ custo de desenvolvimento fica restrito à disponibilidade de tempo dos participantes e na aquisição de equipamentos de mercado. Por ser um projeto baseado em software livre de licença deve-se, obrigatoriamente, estar de acordo com os termos de uso de software livre. Esses termos estão descritos em licenças denominadas GNU Lesser General Public License ${ }^{7}$. Há a garantia de utilização de software livre sem que o mesmo, em dado momento, seja limitado o uso por alguma patente ou direito autoral particular.

\footnotetext{
${ }^{5}$ HTTP://www.softwarelivre.gov.br

${ }^{6}$ http://www.softwarelivre.org/fisl11

${ }^{7}$ http://www.opensource.org/licenses/lgpl-3.0.html
} 


\section{FUNDAMENTOS TEÓRICOS}

Nas seções seguintes estão abordados aspectos teóricos das diversas fases, ferramentas, conceitos que envolvem o desenvolvimento de sistema para atender aos requisitos anteriormente mencionados. Os aspectos abordados estão sucintamente descritos de forma a cobrir a teoria envolvida, sem perder o foco no objetivo que é o sistema propriamente dito.

\subsection{Radioesterilizaçâo}

A esterilização por radiação ionizante é uma técnica altamente eficiente, econômica e segura. A radiação ionizante destrói os microorganismos presentes em produtos médicos, alimentos, próteses, entre outros, quebrando suas cadeias moleculares, reduzindo a carga microbiana dentro de um prazo determinado. A interação pode ser direta, quando a radiação ioniza uma parte do DNA ou outro elemento vital de uma célula levando-a a falência. Ou interação indireta, na qual a radiação provoca nas moléculas de água, presentes nos microorganismos, a formação de radicais altamente reativos $\left(\mathrm{OH}^{-}\right)$e $\mathrm{H}^{+}$ou moléculas como $\mathrm{H}_{2}$, ou $\mathrm{H}_{2} \mathrm{O}_{2}$ que, reage com os componentes vitais das células dos microorganismos, causando a sua morte ou inviabilizando a sua reprodução. A FIG.2.1 ilustra o que acontece com o microorganismo presente no material após sofrer a incidência de radiação gama.

Um produto pode ser considerado estéril, livre de microorganismo viável (em condições de se reproduzir), quando o Nível de Segurança de Esterilidade - Sterility Assurance Level - SAL, ou a probabilidade de sobrevivência do microorganismo, quando submetido a uma quantidade de radiação, for igual $10^{-6}$ (RELA, 2006). 


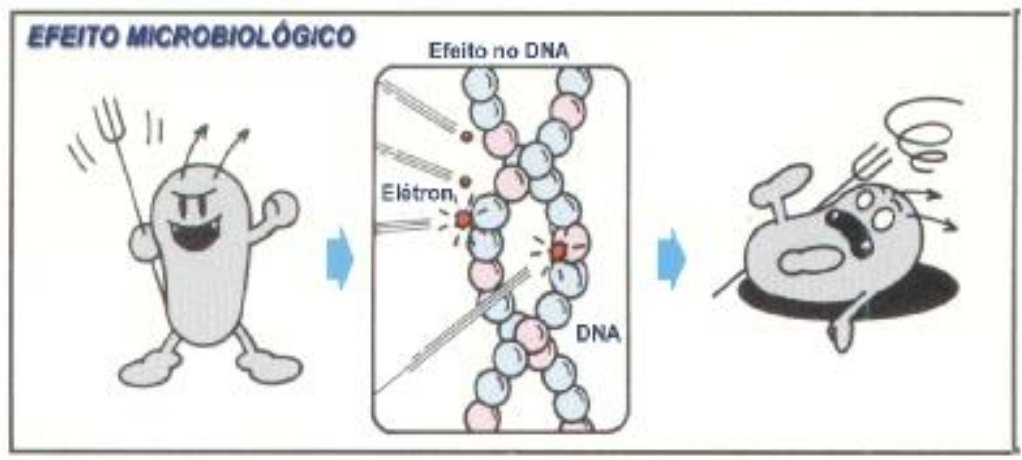

FIGURA 2.1 - llustração do efeito radiação gama num microorganismo (RELA, 2006).

De acordo com a norma ISO 11137-1:2006, existe um valor de dose absorvida, denominado $D_{10}$, para o qual deve ocorrer uma redução de $90 \%$ da contagem inicial da população de microorganismos existente no produto irradiado. De acordo com ilustração da FIG.2.2 quando o produto absorve uma dose de radiação com valor correspondente ao do $D_{10}$ a contagem inicial de microorganismos de uma população de 10.000 elementos, após a irradiação passa para 1.000 elementos.

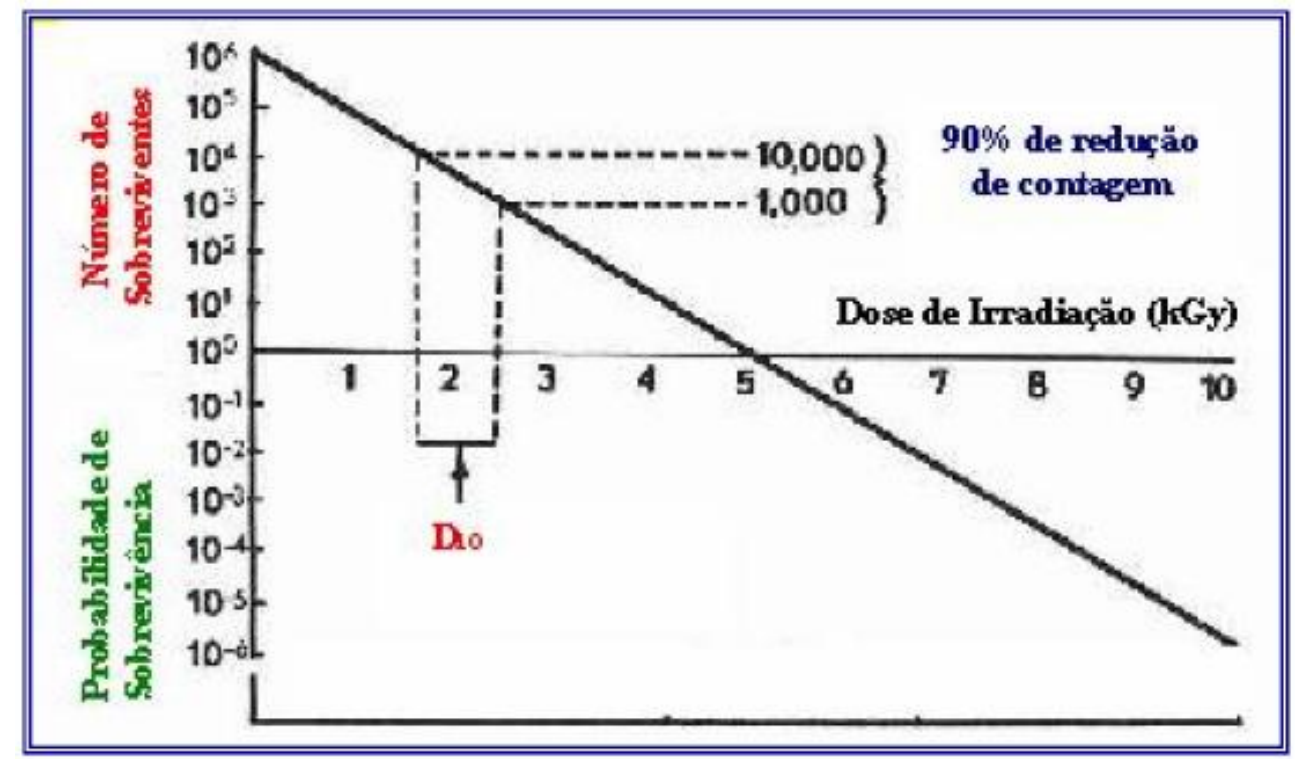

FIGURA 2.2 - Gráfico $D_{10}$ : quantidade de radiação necessária a ser absorvida pelo produto para permitir que a população inicial tenha uma redução de $90 \%$, ou seja, reduzida de uma magnitude na escala logarítmica (RELA, 2006; ISO 111371:2006). 
A redução da carga microbiana faz com que a probabilidade de um novo crescimento da população desses microorganismos seja reduzida, dificultando a recontaminação do produto. Para esse mesmo gráfico (FIG.2.2), partindo-se de uma contaminação inicial de $10^{6}$ unidades formadoras de colônia (UFC) para se atingir o nível de $S A L=10^{-6}$ seria necessária uma dose da ordem de 10 kGy. , usualmente aceito para classificar como estéril. O nível de segurança $S A L=10^{-6}$ é usualmente aceito para classificar o produto como estéril.

\subsubsection{Tipos de Radiação lonizante}

Os tipos de radiações abordadas neste trabalho são radiações com energia suficiente para ionizar o meio onde interagem sendo classificadas como radiações ionizantes.

\subsubsection{Radiação Gama}

A Radiação Gama é uma radiação na forma de onda eletromagnética originadas da transição do núcleo de átomos instáveis. A instabilidade dos átomos é produzida em reatores nucleares.

$$
\begin{aligned}
& { }^{59} \mathrm{Co}+\text { nêutron }={ }^{60} \mathrm{Co} \rightarrow \text { átomo instável } \\
& { }^{60} \mathrm{Co} \text { - elétron }-2 \mathrm{y}={ }^{60} \mathrm{Ni} \rightarrow \text { átomo estável }
\end{aligned}
$$

Existem vários isótopos do cobalto com emissão gama, entretanto o que apresenta uma meia-vida mais longa, 5,2714 anos é o isótopo ${ }^{60} \mathrm{Co}$. A irradiação do cobalto-60 é conseguida de forma artificial. Submete-se o cobalto59, que é estável, a um reator nuclear. Este bombardeia o núcleo do cobalto-59 com um nêutron. O núcleo do cobalto-60 torna-se instável, emitindo um elétron (radiação beta) e duas ondas eletromagnéticas (radiação gama), sendo uma com energia de 1,17 MeV e outra com 1,33 MeV, após o decaimento resulta o níquel60 que é estável. 


\subsubsection{Feixe de Elétrons}

A radiação por feixes de elétrons, com determinada energia, são produzidos em aceleradores de elétrons. A FIG. 2.3 mostra ilustrações de um tubo de imagem de um televisor e um acelerador de elétrons para aplicação industrial. Os elétrons são produzidos termiônico similar ao de uma lâmpada incandescente, depois, são acelerados em um elétrico e a seguir são direcionados por defletores magnéticos para atingir a região que se pretende irradiar. . No tubo de imagens os elétrons se chocam contra uma película de fósforo que faz com que os pontos fiquem iluminados. Num tubo de imagem de TV em cores chega-se a $30 \mathrm{KeV}$ ou 0,03 $\mathrm{MeV}$ (TOMEI, 2009). Num acelerador de elétrons, os elétrons formam um feixe e ao passarem por uma janela são dirigidos contra um alvo externo, a energia do feixe de elétrons para aplicações industriais variam de $0,1 \mathrm{MeV}$ a $10 \mathrm{MeV}$. O acelerador de elétrons do IPEN tem energia de 1,5 MeV (CREDE,2005).

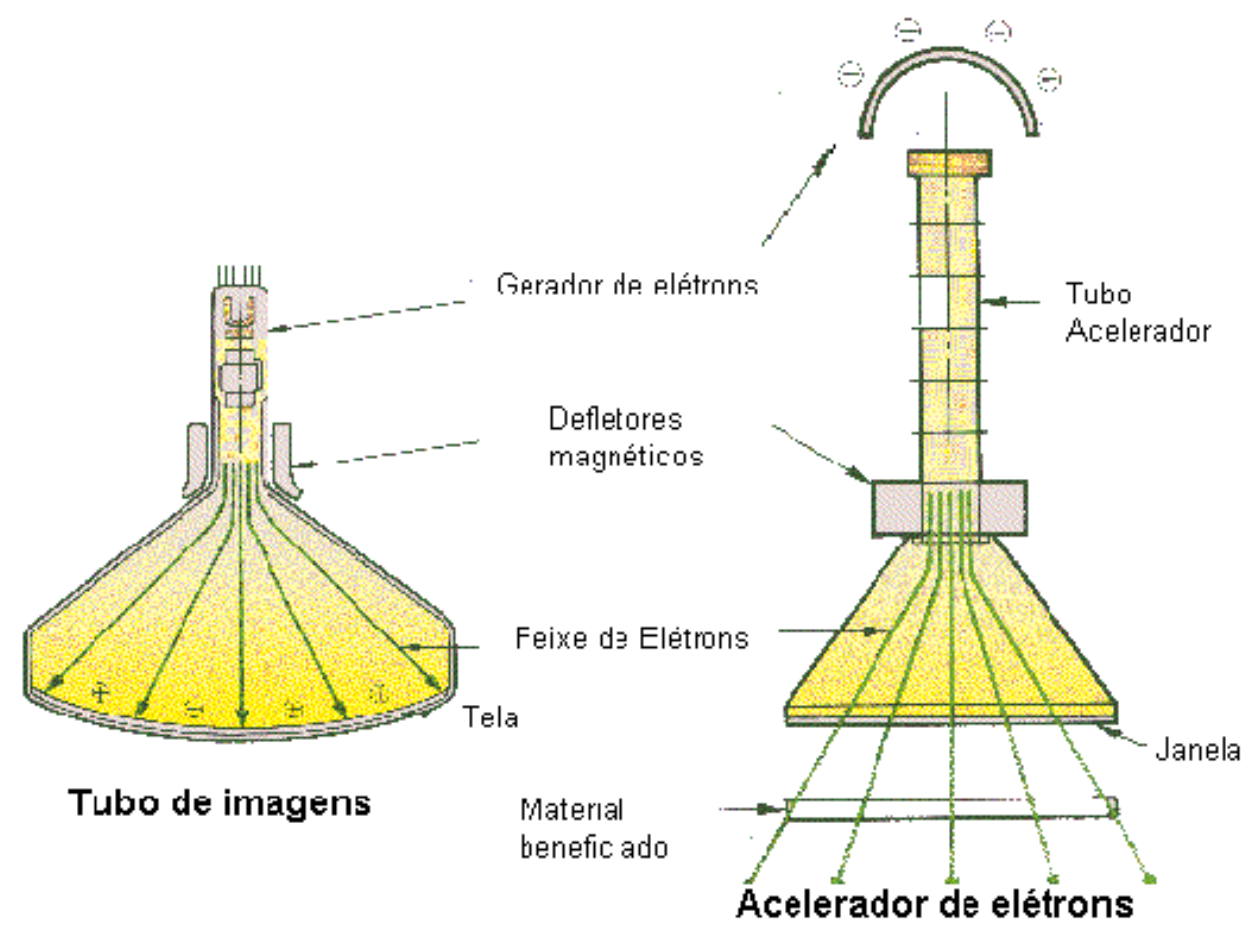

FIGURA 2.3 - Comparativo entre um tubo de imagens de um televisor e um acelerador de elétrons industrial (RELA, 2006). 


\subsubsection{Raios X}

A FIG.2.4 mostra a emissão de um fóton de Raio-X pelo efeito de Bremsstrahlung. Este efeito ocorre quando um elétron incide em um alvo com numero atômico elevado e tem sua trajetória repentinamente desacelerada e desviada pela carga positiva do núcleo, esta variação da energia cinética provoca a emissão de uma onda eletromagnética ou seja um fóton de raio $X$.

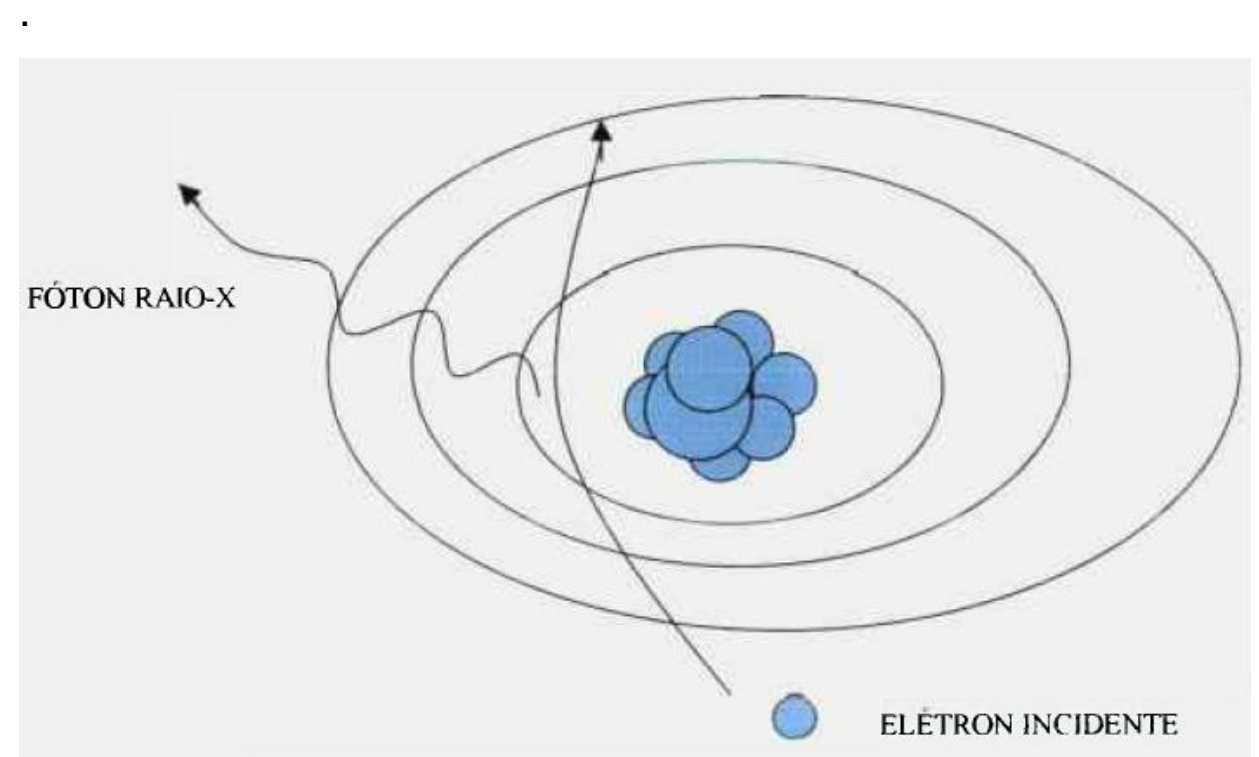

FIGURA 2.4 - Fóton de Raio-X produzida pelo efeito Bremsstrahlung (KARAN JUNIOR, 2000).

\subsection{GMP - Good Manufacturing Pratice ou Boas Práticas de Fabricação}

Boas práticas de fabricação, Good Manufactoring Pratice (GMP), nos tempos atuais, são de vital importância tanto para produtores, distribuidores, comerciantes, consumidores e outros. O Código de Defesa do Consumidor (BRASIL, 1990) adotado no Brasil deslocou o ônus da prova para o fabricante, ou seja, cabe ao fabricante provar que o seu produto tem qualidade. Para tanto, utiliza-se de diversas normas nacionais e internacionais para assegurar que 0 produto tenha a qualidade adequada para utilização ou consumo.

O processo de adoção das normas pelas empresas envolve longos procedimentos que culminam na certificação da mesma. Essa certificação é a 
garantia de que a empresa tenha reconhecimento de suas boas práticas no processo de fabricação de seus produtos. Também, dá reconhecimento público e habilita a sua participação em mercados restritivos do qual somente participam empresas reconhecidamente responsáveis e comprometidas com o bem estar de seus clientes e consumidores. Essa certificação vai de encontro ao movimento mundial no qual se privilegia as práticas que preservam o meio ambiente e o bem estar dos indivíduos.

A Agência de Vigilância Sanitária - ANVISA - é a agência federal brasileira que regulamenta e fiscaliza as atividades ligadas ao setor de alimentos e de saúde. Também define as Boas Práticas de Fabricação para ambos os setores. Essas práticas têm em comum um conjunto de medidas que devem ser adotadas pelas indústrias a fim de garantir a qualidade sanitária e a conformidade dos produtos com os regulamentos técnicos. Essas medidas têm caráter geral, são aplicáveis a todo tipo de indústria de alimentos e produtos de saúde ou a produtos em específicos.

\subsubsection{Normas ISO}

A ISO (International Organization for Standardization) Organização Internacional para Normalização sediada em Genebra, Suíça. Por coincidência, a palavra grega ISO significa igualdade.

O propósito da ISO é desenvolver e promover normas e padrões mundiais que traduzam o consenso dos diferentes países do mundo de forma a facilitar o comércio internacional.

A ISO forma uma rede composta por 157 institutos nacionais de padronização (um instituto por país membro). Por ser uma organização nãogovernamental, faz a ponte entre o setor público e o privado formando um consenso que atenda aos requerimentos de negócios e as amplas necessidades da sociedade.

A norma ISO 11137:2006 é específica para validação do controle de processo e monitoramento de rotinas em processos de irradiação para esterilização de produtos para saúde. É aplicável em processamento contínuo de lotes em irradiadores gama utilizando como fonte o Cobalto-60 e para irradiadores utilizando feixes de elétrons ou geradores de raios-X (ISO 11137: 2006). 
A norma padroniza a documentação de produção que deve estabelecer e manter a descrição da manipulação do produto antes, durante e após o processo de irradiação. Também, estabelece metodologia para definição de dose mínima para esterilização de produtos.

\subsubsection{IAEA - International Atomic Energy Agency}

A Agência Internacional de Energia Atômica (AIEA) é a agência mundial que centraliza a cooperação no campo nuclear. Foi criada dentro das Nações Unidas em 1957 tendo como lema "Átomo para a Paz". A Agência trabalha em cooperação com os Estados Membros e com múltiplos parceiros mundiais para promover segurança e tecnologias nucleares pacíficas.

Dentre as suas diversas atividades existe a seção de publicações. Para o presente trabalho interessa a seção de Documentação Técnica (TECDOC).

No documento TECDOC 539, a planta de irradiação é considerada uma parte do processo de fabricação do produto, e enquanto tal, deve se sujeitar às Boas Práticas de Fabricação, e de forma mais abrangente, às Boas Práticas de Irradiação, Good Radiation Practice (GRP) (AIEA, 1990).

A seguir estão listadas as atividades necessárias para garantir, ao produto fabricado, a sua qualidade, segurança e desempenho. Os procedimentos para irradiação são geralmente elaborados seguindo os seguintes princípios básicos de GMP:

- Um sistema integrado de fabricação e qualidade assegurada;

- Responsabilidades de gerenciamentos distintas para produção e qualidade assegurada;

- Local apropriado para equipamentos e materiais;

- Pessoal treinado;

- Procedimentos documentados para a fabricação e qualidade assegurada;

- Registros apropriados para lotes e produtos;

- Manuseio adequado, transporte e armazenamento;

- Sistemas de recuperação que permite a rastreabilidade do material; 
- Sistema para auditar a operação de GMP.

Dentre outras práticas devem estar incluídas seções que tratem do comissionamento certificação e qualificação do irradiador, da validação dos processos, organização e treinamento de pessoal, controle do processo e manter os registros dos mesmos.

\subsubsection{ANVISA}

A ANVISA é a Agência de Vigilância Sanitária vinculada ao Ministério da Saúde do Governo Federal do Brasil. Tem como missão proteger e promover a saúde da população garantindo a segurança sanitária de produtos e serviços, e participa da construção ao seu acesso.

A finalidade institucional da Agência é promover a proteção da saúde da população por intermédio do controle sanitário da produção e da comercialização de produtos e serviços submetidos à vigilância sanitária, inclusive dos ambientes, dos processos, dos insumos e das tecnologias a eles relacionados. Além disso, a Agência exerce o controle de portos, aeroportos e fronteiras e a interlocução junto ao Ministério das Relações Exteriores e instituições estrangeiras para tratar de assuntos internacionais na área de vigilância sanitária.

\subsubsection{Boas Práticas de Fabricação (área de alimentos)}

A ANVISA definiu um conjunto de regras gerais para as Boas Práticas de Fabricação (BPF), as quais abrangem um conjunto de medidas que devem ser adotadas pelas indústrias de alimentos a fim de garantir a qualidade sanitária e a conformidade dos produtos alimentícios com os regulamentos técnicos. A legislação sanitária federal regulamenta essas medidas em caráter geral, aplicável a todo o tipo de indústria de alimentos e, em específico, indústrias que processam determinadas categorias de alimentos (ANVISA):

- Resolução RDC no 275, de 21 de outubro de 2002. Essa Resolução foi desenvolvida com o propósito de atualizar a legislação geral, introduzindo o controle contínuo das BPF e os Procedimentos 
Operacionais Padronizados, além de promover a harmonização das ações de inspeção sanitária por meio de instrumento genérico de verificação das BPF. Portanto, é ato normativo complementar à Portaria SVS/MS no 0 326/97;

- Portaria SVS/MS no 326, de 30 de julho de 1997. Baseada no Código Internacional Recomendado de Práticas os Princípios Gerais de Higiene dos Alimentos CAC/VOL. A, Ed. 2 (1985), do "Codex Alimentarius", e harmonizada no Mercosul, essa portaria estabelece os requisitos gerais sobre as condições higiênico-sanitárias e de Boas Práticas de Fabricação para estabelecimentos produtores ou industrializadores de alimentos;

- Portaria MS no 1.428, de 26 de novembro de 1993. Precursora na regulamentação desse tema, essa portaria dispõe, entre outras matérias, sobre as diretrizes gerais para o estabelecimento de Boas Práticas de Produção e Prestação de Serviços na área de alimentos;

- Resolução RDC no 21, de 26 de janeiro de 2001. Regulamento técnico para irradiação de alimentos. Estabelece os requisitos gerais para o uso da irradiação de alimentos com vistas à qualidade sanitária do produto final. $O$ processo físico de tratamento que consiste em submeter o alimento, já embalado ou a granel, a doses controladas de radiação ionizante, com finalidades sanitária, fitossanitária e ou tecnológica.

\subsubsection{Boas Práticas de Fabricação (área da saúde)}

Para a área de saúde a ANVISA também definiu um conjunto de regras gerais para as Boas Práticas de Fabricação (BPF):

- Ata de Auto-Inspeção: Documento que o solicitante preenche cumprindo todos os quesitos citados e no final o representante legal da empresa subscreve o documento e a ANVISA dá o parecer pela concessão do Certificado de Boas Práticas de Fabricação de produtos para a Saúde; 
- Documentos necessários para obtenção do Certificado de Boas Práticas de Fabricação de Produtos para a Saúde que inclui as Boas Práticas de Fabricação para Produtos Médicos; Boas Práticas de Fabricação para Kit - Diagnóstico; Boas Práticas de Distribuição e Armazenamento de Produtos para Saúde, Boas Práticas de Fabricação de Produtos para Saúde;

- Portaria no 686, de 27 de agosto de 1998: Determina a todos os estabelecimentos que fabriquem produtos para diagnóstico de uso "in vitro", o cumprimento das diretrizes estabelecidas pelas Boas Práticas de Fabricação e Controle em Estabelecimentos de Produtos para Diagnóstico de uso "in vitro";

- Resolução RDC no 59, de 27 de junho de 2000: Determina a todos fornecedores de produtos médicos, o cumprimento dos requisitos estabelecidos pelas "Boas Práticas de Fabricação de Produtos Médicos".

- Resolução RDC no 331, de 29 de novembro de 2002: Estabelece a auto-inspeção como um dos instrumentos de avaliação do cumprimento das Boas Práticas de Fabricação de Produtos Médicos, para fins de prorrogação da validade do Certificado de Boas Práticas de Fabricação de Produtos Médicos;

\subsection{BPM - Gerência de Processos de Negócios}

BPM, Business Process Management, define, possibilita, gerencia a troca de informações da corporação através da visão semântica dos processos de negócios, que envolvem empregados, clientes, parceiros, aplicações e bancos de dados. A gerência deve ser capaz de modelar um processo, intermediar sua execução, monitorar seus resultados e gerenciá-lo (Borges, 2006).

Processo de negócios pode ser definido como uma série de passos repetíveis adotados por uma organização para produzir um resultado desejável. São aqueles processos voltados para a realização de operações com clientes, parceiros e fornecedores. Devem ser executados de forma bem objetiva e clara. 
Devem ser compreendidos e adotados por todos que lidam com os negócios da corporação. A sua concepção compreende as etapas:

- Modelagem de Processos: separar a lógica do negócio da lógica da aplicação;

- Execução do Processo (Instanciação): gerenciar a execução operacional dos processos;

- Monitoramento dos Processos: acompanhar o status da execução e as estatísticas.

\subsubsection{As fases e evolução de processos de negócios}

Os modelos de processo de negócios evoluíram com o tempo. $\mathrm{Na}$ década de 70 os processos eram modelados por analistas de Organização \& Métodos (O\&M). Mapeavam as atividades de cada departamento e as pessoas que ali trabalhavam. O modelo seguido era o de detalhar funções. Qualquer pessoa poderia assumir um papel designado pela função. Os trabalhos eram entediantes e sem qualquer participação do executor. Bastava que seguissem os cadernos de encargos para a função e estava tudo certo.

Com o advento dos primeiros computadores de dados as funções passaram a ser menos rígidas. Tudo o que se colocava para ser executados nos computadores eram somente as mesmas funções que se faziam manualmente. Essa fase foi denominada de Mecanização dos Processos. Os computadores eram alojados em CPD ou Centro de Processamento de Dados. As tarefas eram mapeadas por Analistas de Sistemas, que definiam uma série de procedimentos computacionais e estes programados para seguir sequências lógicas de processos executadas pelos operadores do computador.

Não se tinha qualquer segurança das informações. Os dados eram copiados de arquivos e sempre havia repetições das informações. Informações desatualizadas eram uma constante. Os antigos Analistas de O\&M ou se convertiam à nova tecnologia ou estavam sem empregos. Foi uma época de grandes erros. O julgamento de que processos poderiam ser facilmente mecanizados e deles extraídos informações que garantiriam o sucesso da empresa foi mal realizado. Mostrou-se que a redundância de informações e 
sistemas confundia os negócios. Empresas perderam suas identidades. Pessoas consideradas ultrapassadas foram despedidas. Com elas se foi o know how da empresa.

$\mathrm{Na}$ década de 80 começaram as integrações dos sistemas. Os processos deixavam de ser vistos como funções independentes e passaram a ser considerados como algo vivo que definiam os papéis dos diversos agentes e as entidades a eles relacionados. Os analistas de sistemas se especializaram e passaram a ser Analistas de Negócios.

Alguns deixaram área de sistemas e foram trabalhar diretamente na área de negócio da qual se tornou um especialista. O profissional abdicou de sua carreira de sistemas, que era impessoal e não dependia da empresa, e passa a se dedicar a especializar o negócio da empresa pela qual era responsável. Os sistemas começam a mapear de forma mais estreita os negócios. Surgem os MRPs (Material Requirement Planning depois Manufacturing Resource Planning).

Os diversos departamentos são integrados pelas funcionalidades. As responsabilidades são compartilhadas. São criados níveis de operação e decisão. Os profissionais são formados para agirem de forma estruturada e integrada. Os analistas de negócios e os analistas de sistemas ganham um novo parceiro, o Analista de Processos. É um resgate dos antigos Analistas de O\&M que não dependem mais dos profissionais de sistemas para criarem os processos das empresas. Eles agora têm os Sistemas de Workflow (fluxo de trabalho) para servirem aos seus propósitos. Entretanto, ainda depende dos profissionais de sistemas para construir a retaguarda dos processos, principalmente, banco de dados e interfaces WEB.

\subsubsection{Workflow}

Workflow, ou fluxo de trabalho, é um termo utilizado para descrever o conjunto de tarefas dos processos, as etapas de procedimentos, a organização ou pessoas envolvidas, as entradas requeridas e as informações de saída. Também está relacionado às ferramentas necessárias para a execução de cada etapa num 
processo de negócio. O workflow engine ${ }^{8}$ é o programa que automatiza e que controla todos os procedimentos, os passos dos processos e as regras de transição para cada etapa (RESHEF, 2003).

Os principais benefícios do workflow (RESHEF, 2003, tradução livre do autor):

- Aumento na eficiência - a automatização de muitos processos do negócio resulta na eliminação de muitas etapas desnecessárias;

- Melhor controle do processo - melhor gerenciamento dos processos do negócio conseguidos com a padronização dos métodos de trabalho e a disponibilidade de trilhas de auditorias;

- Melhor serviço ao cliente - a consistência nos processos conduz a uma possibilidade de previsões maior aos níveis de respostas aos clientes;

- Flexibilidade - o controle do software sobre os processos permite seu re-projeto alinhado com necessidades em mudança do negócio;

- Melhoria no processo do negócio - o foco nos processos do negócio conduz à eficiência e simplificação.

\subsection{Recursos tecnológicos do projeto}

O projeto ou sistema tem como premissa a escolha de tecnologias de comunicação, logística de processo, o desenvolvimento das interfaces a base de dados que sejam livres de custo de licença ou código aberto (open-source). Os equipamentos para acompanhamento dos produtos na área do irradiador o menor custo possível. Todo esse cuidado é para não depender de financiamento das agências de fomento.

\footnotetext{
${ }^{8}$ Em programação de computadores, engine é um jargão para um programa que executa as funções centrais ou essenciais para outros programas. No contexto de workflow, a engine é o centro de todo o processamento, sendo responsável por todo o processo de interpretação de modelos, instanciação e inferência.
} 


\subsubsection{Interface de comunicação sem fio}

Redes de Sensores Sem Fio (RSSF) são cada vez mais frequentes em ambientes industriais ou domésticos. Para os sensores com comunicação sem fio, diversos são os meios de transmissão, os mais comuns são GPRS, WiFi, Bluetooth e mais recentemente, o padrão ZigBee.

O padrão ZigBee (alusão ao movimento das abelhas ao se comunicarem em vôo) é concebido e mantido pela ZigBee Aliance (2008). Reúne dezenas de empresas que desenvolvem seus chipsets (placa de silício com circuitos que implementam certa tecnologia) e distribuem para fabricantes de placas de sensores ou comunicação. A ZigBee Alliance adotou o padrão IEEE 802.15.4 para a camada física (PHY) e o protocolo Medium Access Control (MAC). A FIG.2.5 mostra como são organizados os padrões definidos pelo IEEE grupo 802.

\section{Padrão 802 Espaço Sem Fio}

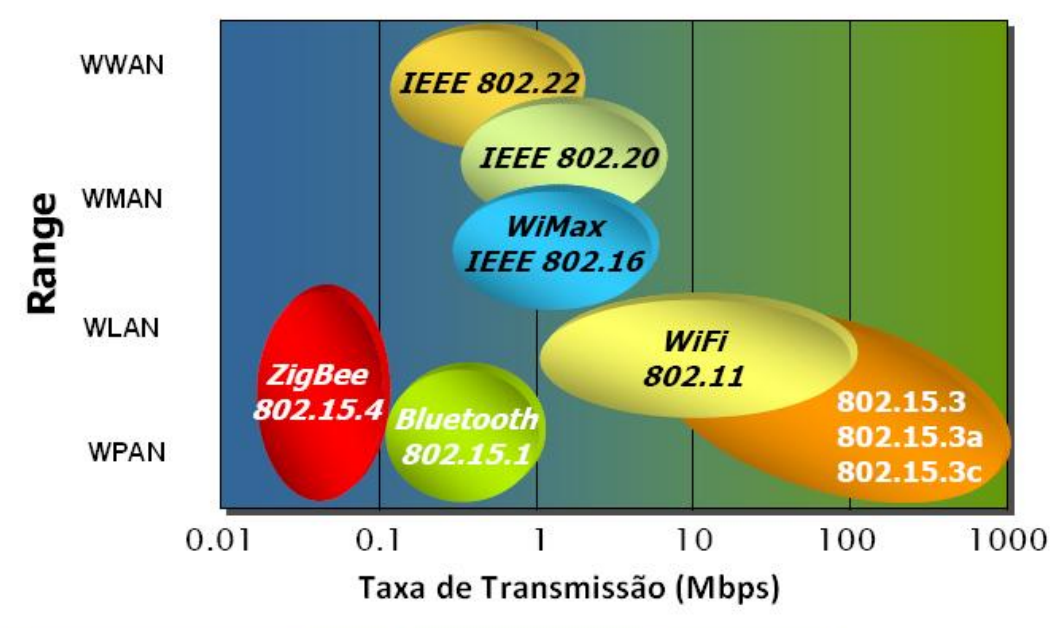

FIGURA 2.5- Hierarquia de comunicação do padrão IEEE 802 para comunicação sem fio (Adaptado VRIES - 2008).

Ainda de acordo com a FIG.2.5, o alcance e a taxa de transferência empregada nas tecnologias sem fio, são agrupadas em quatro grupos, a saber:

- WPAN -Wireless Personal Area Network - São destinadas à utilização de comunicação sem fio de curto alcance (entre 10 e 100 metros) e baixa taxa de transmissão. Esse contexto é destinado às redes que 
interligam dispositivos pessoais ou redes de sensores sem fio, definido pelo IEEE 802.15.

- WLAN - Wireless Local Area Network - São destinadas a interligar redes locais com alcance entre 100 e 300 metros. Muito utilizada para substituir rede cabeada em empresas, escolas, residências (IEEE.802.11)..

- WMAN - Wireless Metropolitan Area Network - São destinadas à interligar redes metropolitanas de banda larga às redes de última milha. Sua abrangência tem alcance em torno de 6 a 8 km (IEEE 802.16);

- WWAN - Wireless Wide Area Network - São destinadas às redes de telecomunicações de longa distância que atendem serviços de voz e dados (IEEE 802.20 e IEEE 802.22).

QUADRO 1.1- Comparação entre padrões de comunicação sem fio (wireless) (adaptado SIQUEIRA CAMPOS - 2006)

\begin{tabular}{|c|c|c|c|c|}
\hline Aspectos & WiFi & Bluetooth & ZigBee & WPAN \\
IEEE 802.11g & 802.15 .1 & 802.15 .4 & 802.15 .4 \\
\hline $\begin{array}{c}\text { Consumo de } \\
\text { Bateria }\end{array}$ & Horas & Dias & Anos & Anos \\
\hline Complexidade & Alta & Média & Baixa & Muito Baixa \\
\hline $\begin{array}{c}\text { Quantidade } \\
\text { de } \\
\text { Dispositivos }\end{array}$ & 32 & 7 & 65.525 & 255 \\
\hline $\begin{array}{c}\text { Alcance } \\
\text { Taxa de } \\
\text { Transmissão }\end{array}$ & 54 Mbps & 1 Mbps & 250 Kbps & 250 Kbps \\
\hline Custo & Alto & Baixo & Baixo & Muito Baixo \\
\hline
\end{tabular}

O Quadro $1.1 \mathrm{faz}$ um comparativo entre as tecnologias usadas para redes de curta distância. O que chama-se a atenção é para a taxa de dados que o ZigBee normalmente trabalha, ou seja, $250 \mathrm{Kbps}$ para freqüência de transmissão de $2.4 \mathrm{GHz}$. Outro aspecto é a duração de baterias. Também a quantidade de 
dispositivos que podem ser conectados. Teoricamente, o ZigBee pode conectar 65.525 nós numa configuração MESH (malha).

A FIG.2.6 mostra as configurações possíveis para interligar os nós de uma rede. O mais simples é o ponto-a-ponto (pear-to-pear). O mais complexo é a configuração mesh (malha).

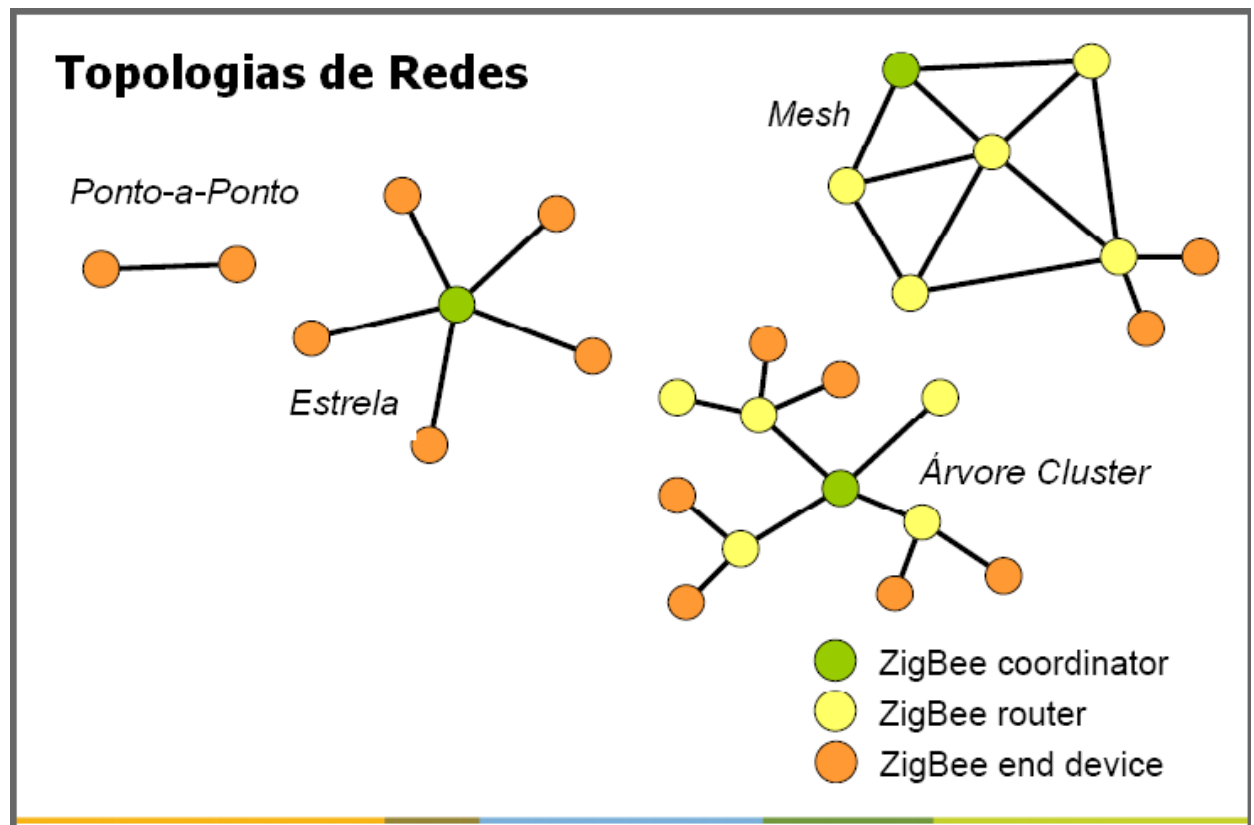

FIGURA 2.6- Topologias de redes suportados pelo padrão ZigBee (Adaptado VRIES - 2008).

De acordo com a FIG.2.6 pode-se notar que uma rede tem um nó coordenador. Os nós end device (dispositivos finais) fazem a atuação ou coleta direta dos dispositivos apropriados. Um nó router (roteador) poderá ter a sua configuração para comunicar com uma rede IP. Nesse caso o nó IP serve de gateway (nó porta de comunicação) com outras topologias de rede.

\subsubsection{Softwares e Aplicativos}

Para o desenvolvimento e a operação do sistema, são utilizadas, preferencialmente, ferramentas (softwares) livres de licença (freeware). A vantagem dessa escolha reside no fato que não há custo para utilização dos softwares. Outra vantagem é o fato do software evoluir com a contribuição de usuários e ou desenvolvedores comprometidos na construção e divulgação de 
softwares livres ao redor do mundo. Como desvantagem, pode-se citar a dificuldade para resolver problemas pontuais. Sempre se depende de fóruns de discussão para obter tais informações.

A adoção de softwares livres para o desenvolvimento do sistema resultou na seguinte escolha:

- JUDE para modelagem sob o paradigma de orientação a objetos. Permite elaborar os diagramas: Classes, Caso de Uso, Gráfico de Estado, Atividade, Sequência, Colaboração, Componente e Distribuição;

- BONITA para construção e operação do fluxo do processo. Permite que o usuário veja a lista de atividade Todo List ("a fazer") tarefas disponíveis que o usuário pode de executar; Done List ("feito") tarefas que já terminaram. Já o operador (gerente) pode verificar detalhes dos processos (Processes); as instâncias (processo iniciado para uma atividade) e as atividades (Activities) na qual são mostradas informações de todas as atividades do processo e suas propriedades;

- JOnAS (Java Open Application Server) como o servidor de aplicação. É uma plataforma J2EE (Java2 Platform Enterprise Edition) é uma tecnologia que torna possível projetar, desenvolver, empacotar e implantar aplicações empresariais baseadas em componentes. A plataforma oferece um modelo multicamada distribuída com a possibilidade de reutilização de componentes, transferência de dados feita em XML, com modelo de segurança unificado e um flexível controle transacional. Também pode ser utilizado o Servidor JBOSS;

- JAVA (J2EE) no desenvolvimento de rotinas programadas. A plataforma de desenvolvimento JAVA integrada é o Eclipse ${ }^{9}$ com plug-ins para o Bonita e Jonas. O Bonita utiliza a interface gráfica do editor ProEd também integrada ao Eclipse;

- Sistema Operacional LINUX para suportar o aplicativo, embora possa ser utilizado o sistema Windows XP também;

\footnotetext{
${ }^{9}$ http://www.eclipse.org/downloads/packages/release/galileo/sr2
} 
- Servidor de banco de dados: ORACLE, MYSQL, POSTGRESQL, H2, HSQLDB entre outros. Tanto o Bonita quanto o Jonas são capazes de incorporar diversos gerenciadores de banco de dados.

- IDE - ECLIPSE: plataforma de desenvolvimento e testes para desenvolvimento dos fluxos de processos através de plug-ins Proed e Bonita e a linguagem JAVA para desenvolver as interfaces com a aplicação de dados (hooks).

- A página de testes do sistema é disponibilizada no sitio www.cobalto60.net.br especialmente criado para este fim.

\subsubsection{Software de WorkFlow - BONITA}

O sistema de workflow escolhido é o Bonita. Pertence à categoria de softwares de código aberto. Sua arquitetura é fundamentada nos padrões preconizados pelo Workflow Patterns Initiative, dos quais é aderente a 20 padrões dos 21 padrões inicialmente definidos (LORIDAN \& ROSELL, 2006).

Esses padrões foram definidos pelo professor Wil van der Aalst, da Eindhoven University of Tecnnology, que em conjunto com o professor Arthur ter Hofstede, da Queensland University of Technology, criaram a Workflow Patterns Initiative.

Além do Bonita, fazem parte da Workflow Patterns Initiative a IBM, TIBCO, BPMN, ORACLEBPEL, entre outros. Os desenvolvedores do Bonita, liderados por Miguel Valdez Faura ${ }^{10}$, sempre se preocuparam em garantir a continuidade do produto e para isso se associaram à várias iniciativas. Entre elas estão importante contribuição da Bull e da France Telecom. Essas associações garantiram uma excelente documentação dos softwares bem como a possibilidade de treinamentos. Essa é uma grande vantagem em se tratando de código aberto no qual, normalmente, as dúvidas são esclarecidas em fóruns nem sempre amigáveis. $\mathrm{O}$ Bonita e $\mathrm{O}$ Jonas estão disponíveis para download no sitio Object WEB ${ }^{11}$.

\footnotetext{
${ }^{10}$ HTTP://bonitasoft.com

${ }^{11}$ WWW.ow2.org
} 
A equipe de desenvolvimento do Bonita criou uma plataforma denominada Process Virtual Machine (PVM) representado na FIG.2.7 (LACY, 2008)

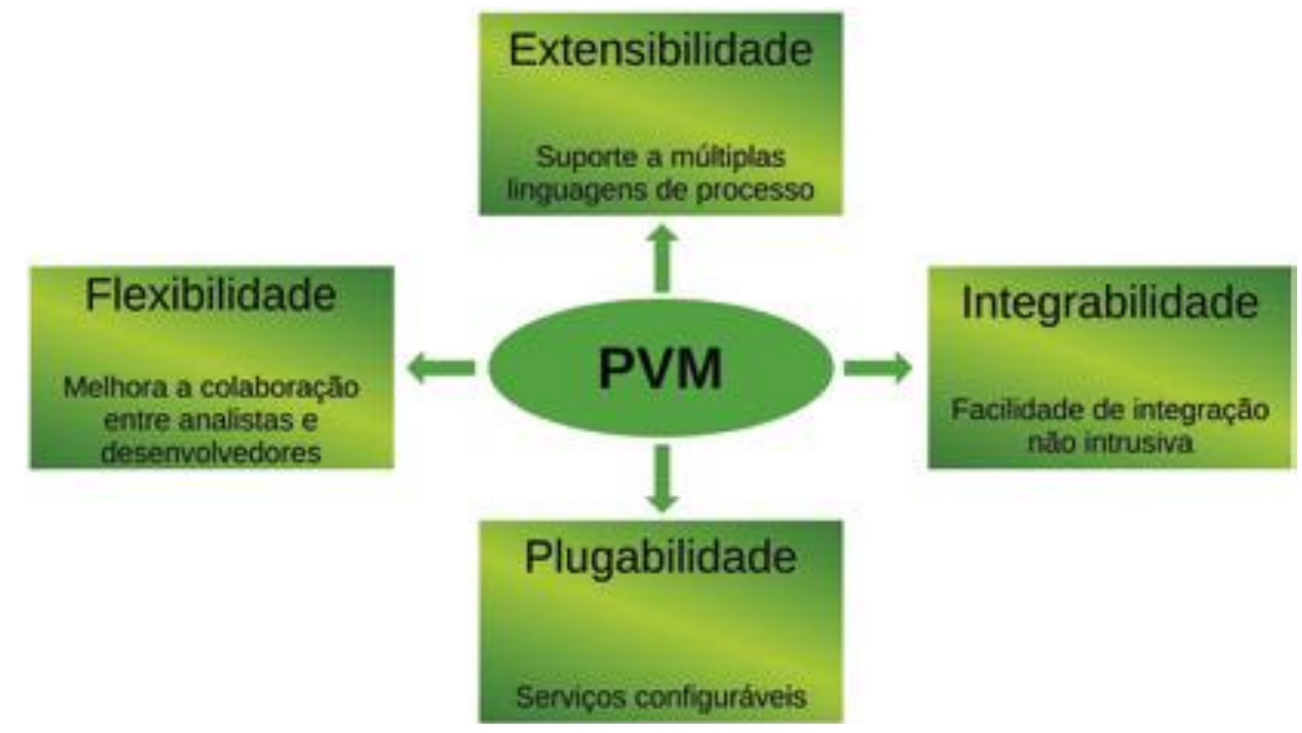

FIGURA 2.7- Process Virtual Machine como núcleo do Bonita(LACY, 2008).

A definição da arquitetura PVM se deu em associação com a Had Hat que também desenvolve o sistema jBPM.

A arquitetura do Bonita está representada na FIG.2.8. O Bonita é uma ferramenta desenvolvida na linguagem JAVA. $O$ acesso ao motor (engine) se faz por intermédio de API (Application Programming Interface ou Interface de Programação de Aplicações) desenvolvidas para essa finalidade. Pode ser executado como uma aplicação JSE ou JEE (ambiente corporativo).

Existem várias versões do Bonita. Para este projeto foi escolhida a versão estável 4.1.1 que pode ser executada tanto no Windows quanto no Linux ou Unix.

A arquitetura do Bonita está baseada em conceitos de interação entre componentes através da máquina do PVM. A FIG.2.8 mostra esta arquitetura. 


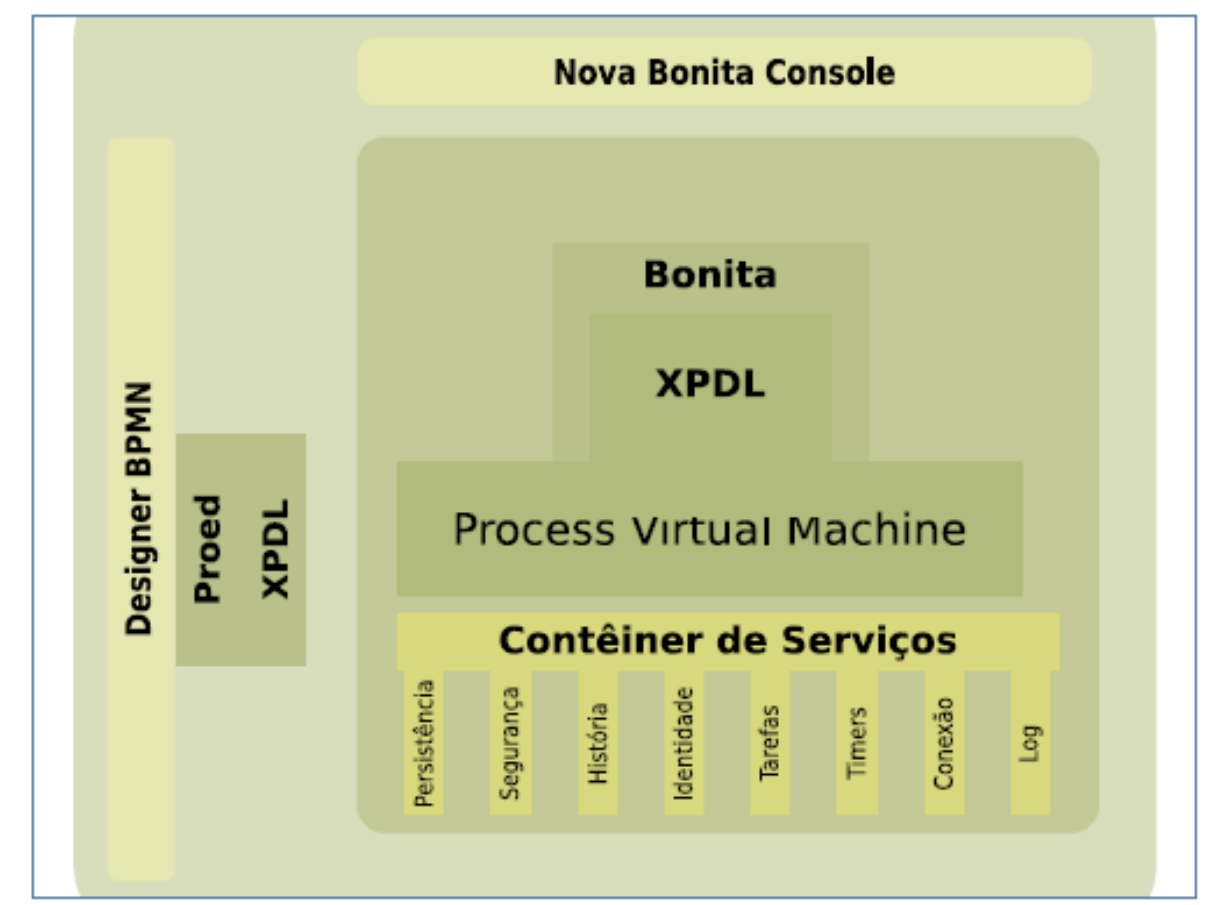

FIGURA 2.8- Diagrama Funcional do Bonita (LACY, 2008).

Na FIG.2.8 está presente o editor gráfico do workflow o Proed que traduz os comandos gráficos na linguagem XPDL.

Em tempo de execução a máquina do PVM faz a interação dos processos descritos em XPDL com os diversos componentes do sistema.

A interface de console de operação do sistema é construída e exibida no Portal Exo Plataform. Esse portal trás a facilidade do usuário selecionar widgest (objetos de tela) para iniciar atividades. A URL local http://localhost:8080/portal ou WWW.cobalto60.net.br (página de teste criada para este sistema) dá acesso à tela de console do Bonita. A FIG.2.9 mostra esta tela inicial de login do sistema para qualquer usuário.

As FIG.2.9 e 2.10 mostram as telas iniciais nas quais o usuário root fez seu login. Por ser o administrador do sistema, o root recebe uma maior gama de widgest com as respectivas funcionalidades agregadas. 


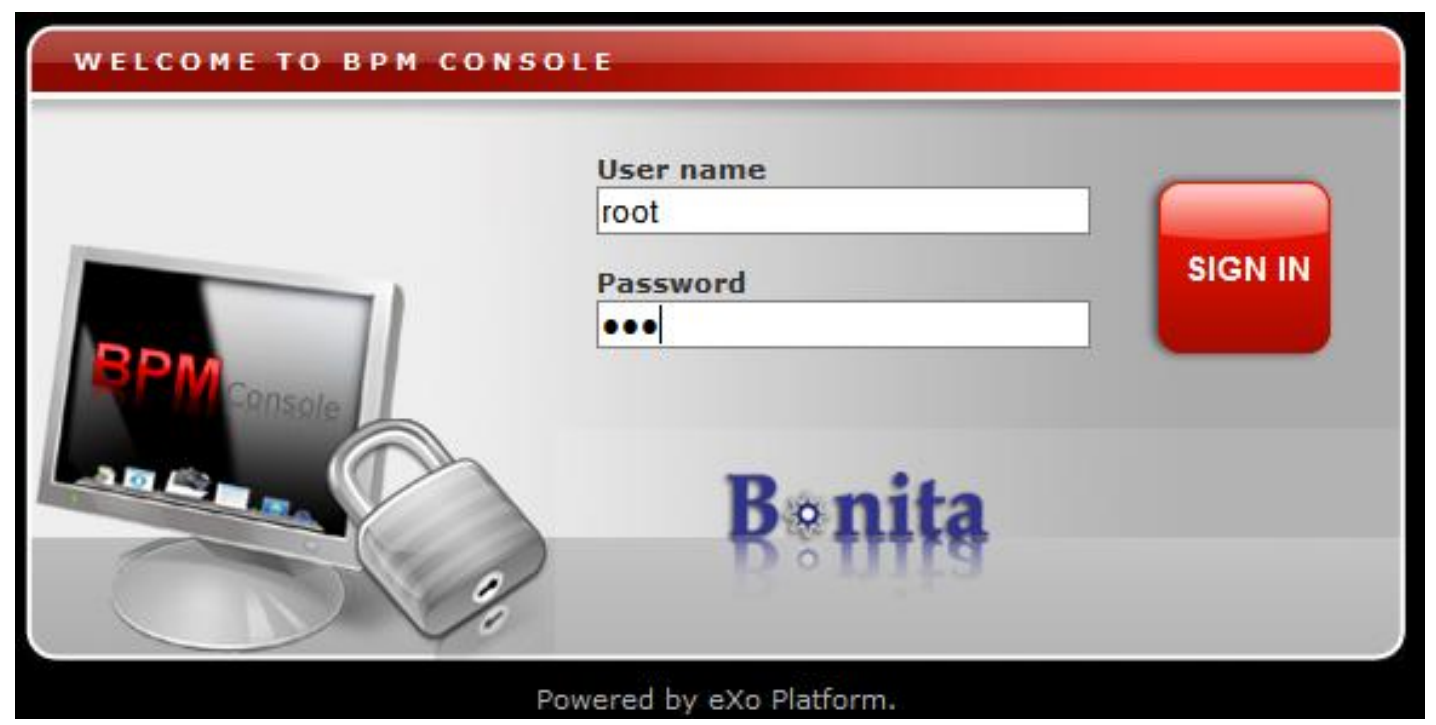

FIGURA 2.9 - Tela de Login da Console do Bonita: o administrador do sistema (root) faz o seu login para acessar o sistema.

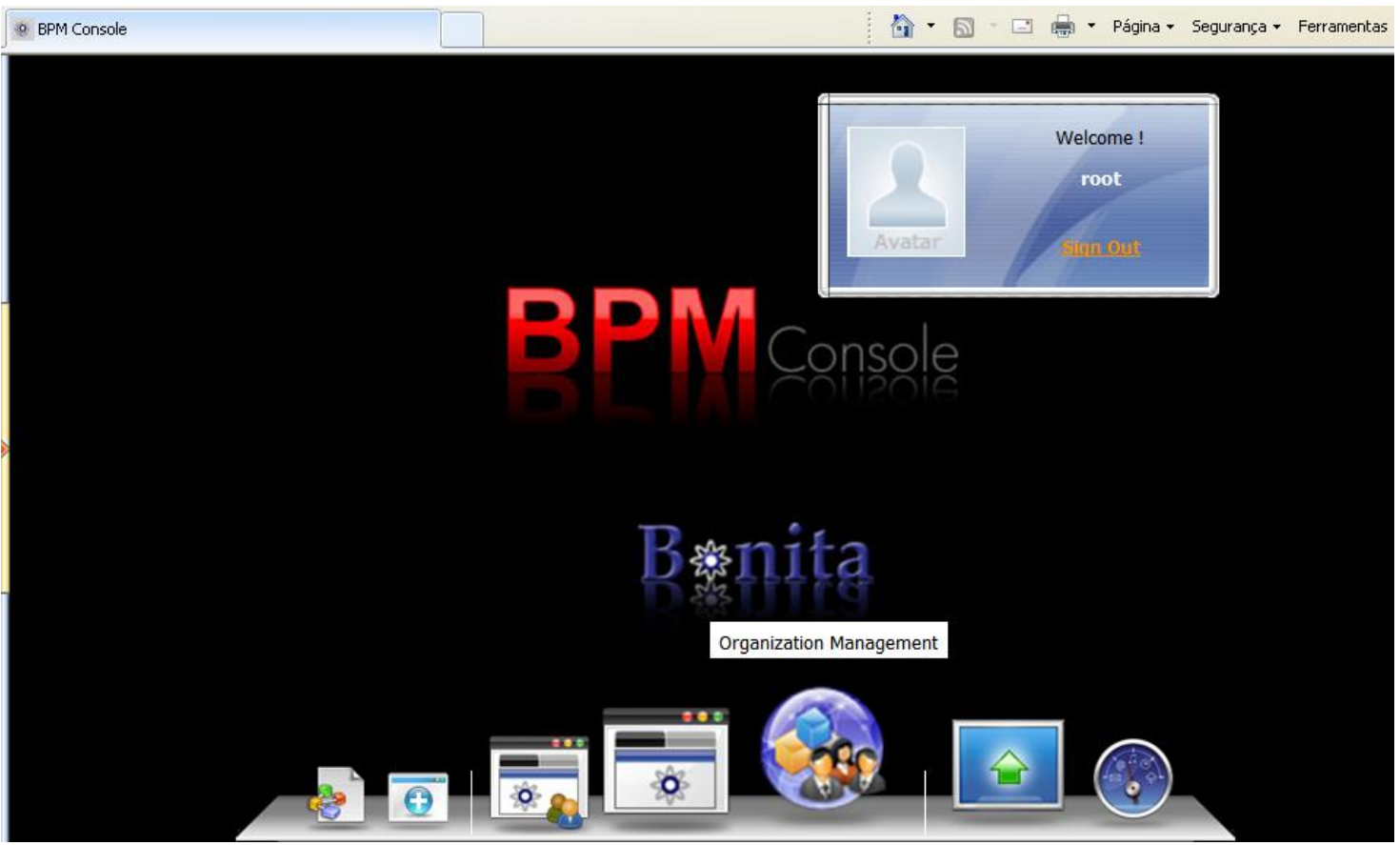

FIGURA 2.10 - Tela de Console do Bonita com diversos widgets (objetos de tela). O widget selecionado é para fazer a manutenção dos usuários ou grupos de usuários. 
Para fazer a manutenção dos usuários, grupos ou relacionamentos, o root acessa o widget Organization Management (Gerenciamento da Organização conforme se observa na FIG.2.11.

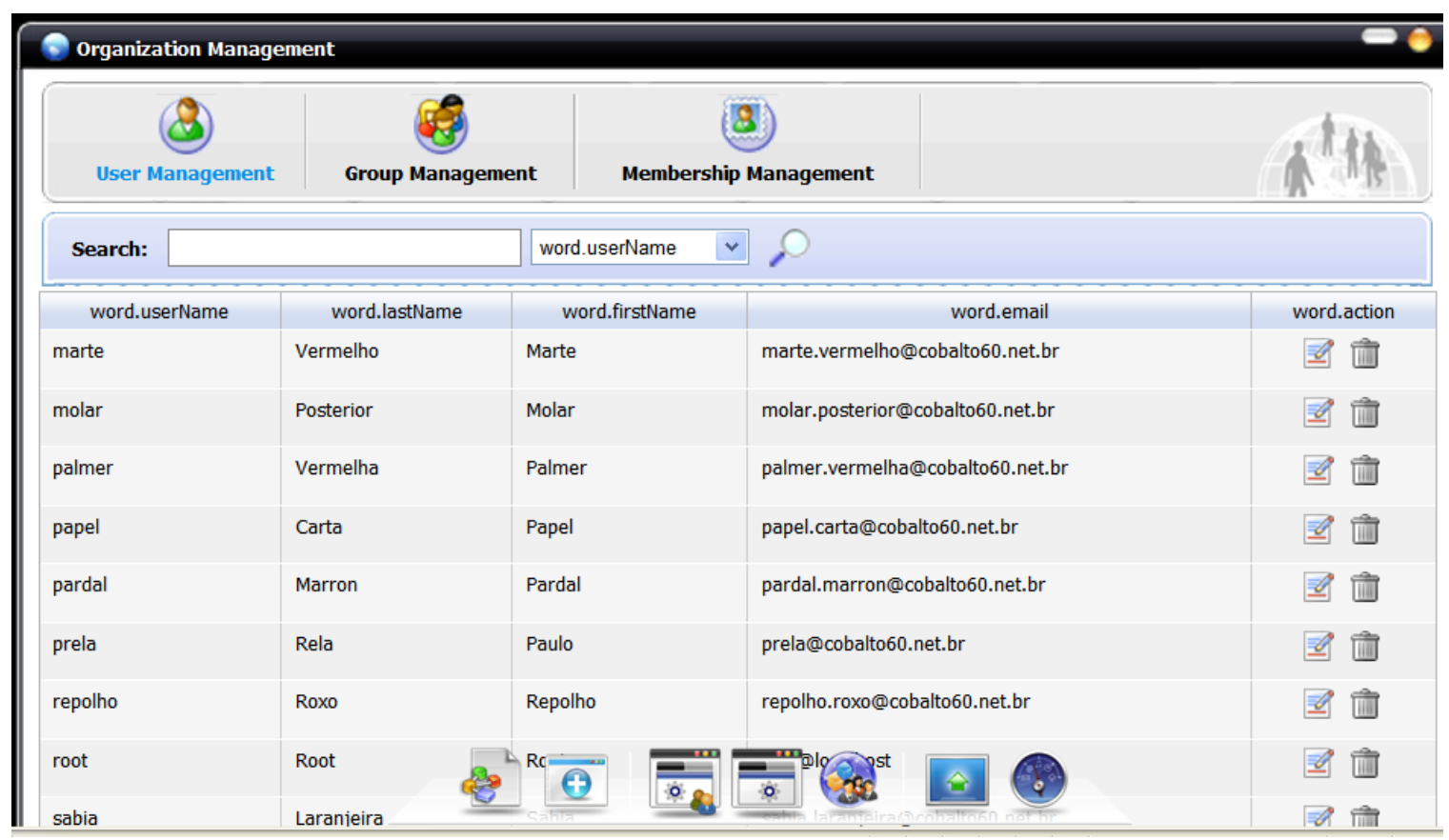

FIGURA 2.11 - Página do Bonita que o usuário root poder escolher entre cadastrar um novo usuário ou incluir um novo relacionamento.

A manutenção dos usuários é de vital importância para o correto funcionamento do sistema. Ao criar grupos e relacionar quais usuários pertencem ao grupo, o administrador estará fazendo o filtro de privacidade dos dados do grupo de cada usuário.

Quando o usuário se "logar" no sistema, se aceito, ele terá disponível o nome de todos os processos. Entretanto, ele terá acesso somente àqueles processos ao qual o grupo dele foi permitido iniciarem. Uma vez iniciado o processo qualquer membro do seu grupo poderá dar sequência ao mesmo.

Se a opção for por fazer a "subida" (deploy) de uma versão de processo, o root faz uso do widget BPM Managment (Gerenciamento do BPM). As FIG.2.12 e 2.13 mostram a opção do Administrador em fazer a manutenção dos processos do sistema. 


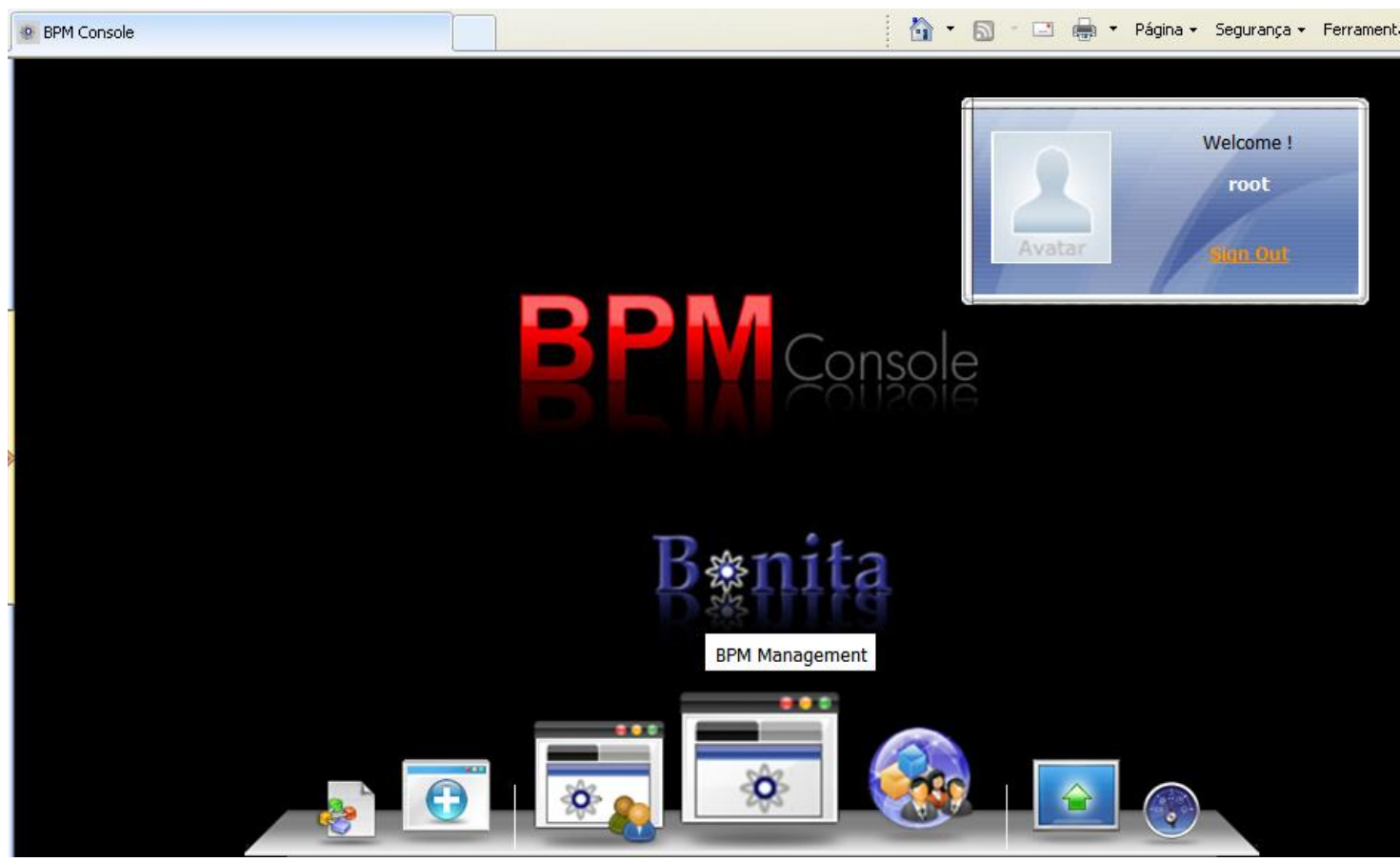

FIGURA 2.12 - Página do Bonita para o Administrador faz acesso ao sistema para fazer a manutenção de funcionalidades.

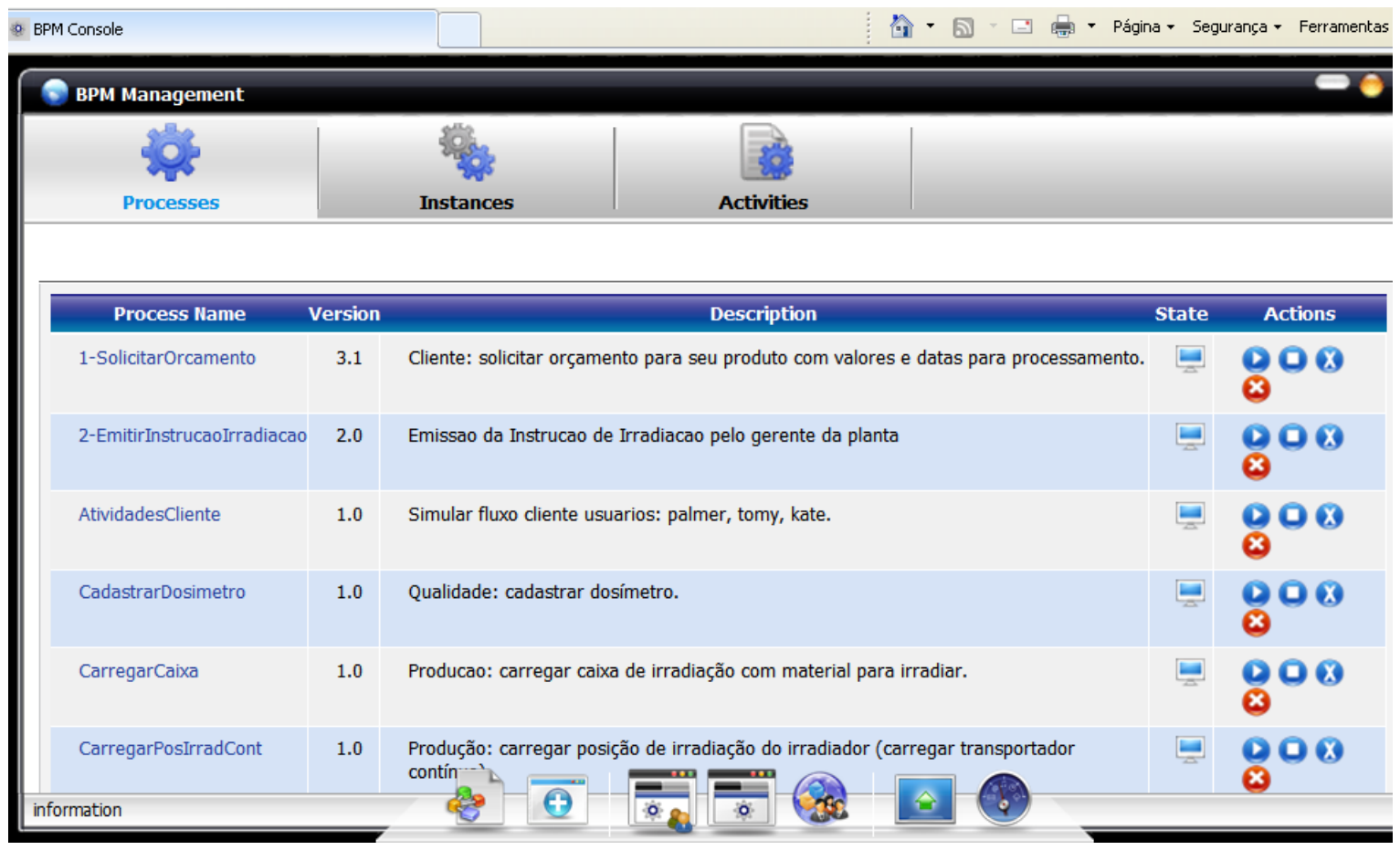

FIGURA 2.13 - Página do Bonita para o Administrador do sistema fazer a manutenção dos processos do sistema - aba Processes. 
Com base na FIG.2.13 a aba Processes tem como atributos:

- Process name: Nome do processo designado pelo Analista de Processos;

- Version: Versão do processo. O processo pode ter mais de uma versão em operação. Isto facilita a necessidade de alterações nos processos enquanto outros estão em andamento;

- Description: Descrição do processo

- STATE: Verificar o respectivo estado: DEPLOYED ("levantado") ou UNDEPLOYED ("baixado");

- ACTIONS: Ações

- START: instanciar (iniciar) um processo;

- DELETE ALL INSTANCES: deletar (apagar) todas as instâncias do processo;

- UNDEPLOY: baixar o processo do sistema;

- DELETE PROCESS AND ALL INSTANCES: deletar o processo e todas as suas instâncias

Na FIG.2.14 é visto a aba Instances que tem como atributos:

- Instances Name: nome da instância do processo. É composto pelo Nome do Processo, versão do processo e um número de sequência do processo;

- Process Name: Nome do processo;

- Started by: iniciado por (usuário responsável pela início do processo);

- Started Date: data de início do processo;

- End Date: data final do processo. Se a data estiver em branco indica que o processo está em andamento;

- State: estado do processo: STARTED (iniciado) ou FINISHED (finalizado);

- Actions: Delete Instances (possibilidade do Administrador deletar a instância do processo) 


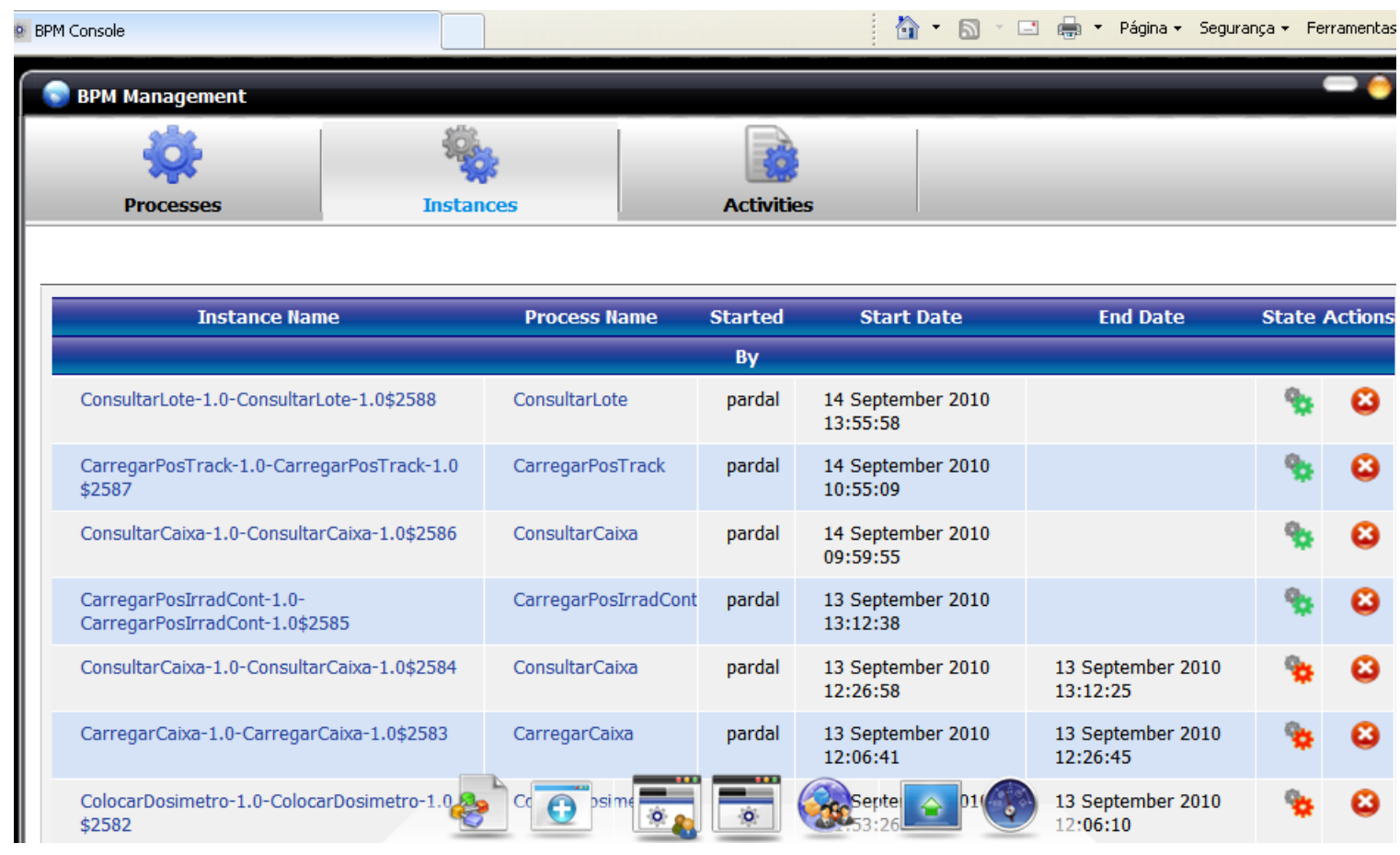

FIGURA 2.14 - Página do Bonita para o Administrador do sistema fazer a manutenção dos processos do sistema - aba Instances.

Na FIG.2.15 é visto a aba Activities (Atividades) que tem como atributos:

- Name: nome da atividade;

- Type: tipo da atividade

- TASK: tarefa iniciado por usuário;

- AUTOMATIC: iniciada automaticamente pelo sistema;

- Instance Name: nome da instância de processo;

- Started by: iniciado por

- usuário que iniciou a atividade TASK;

- SYSTEM quando o tipo de atividade é AUTOMATIC;

- Start date: data de início da atividade;

- End date: data final da atividade;

- State: estado da atividade

- READY: pronta para ser iniciada;

- FINISHED: encerrada;

- Actions: ações a serem tomadas quando no estado READY 
- PERFORM: iniciar a atividade;

- SUSPEND: suspender a atividade.

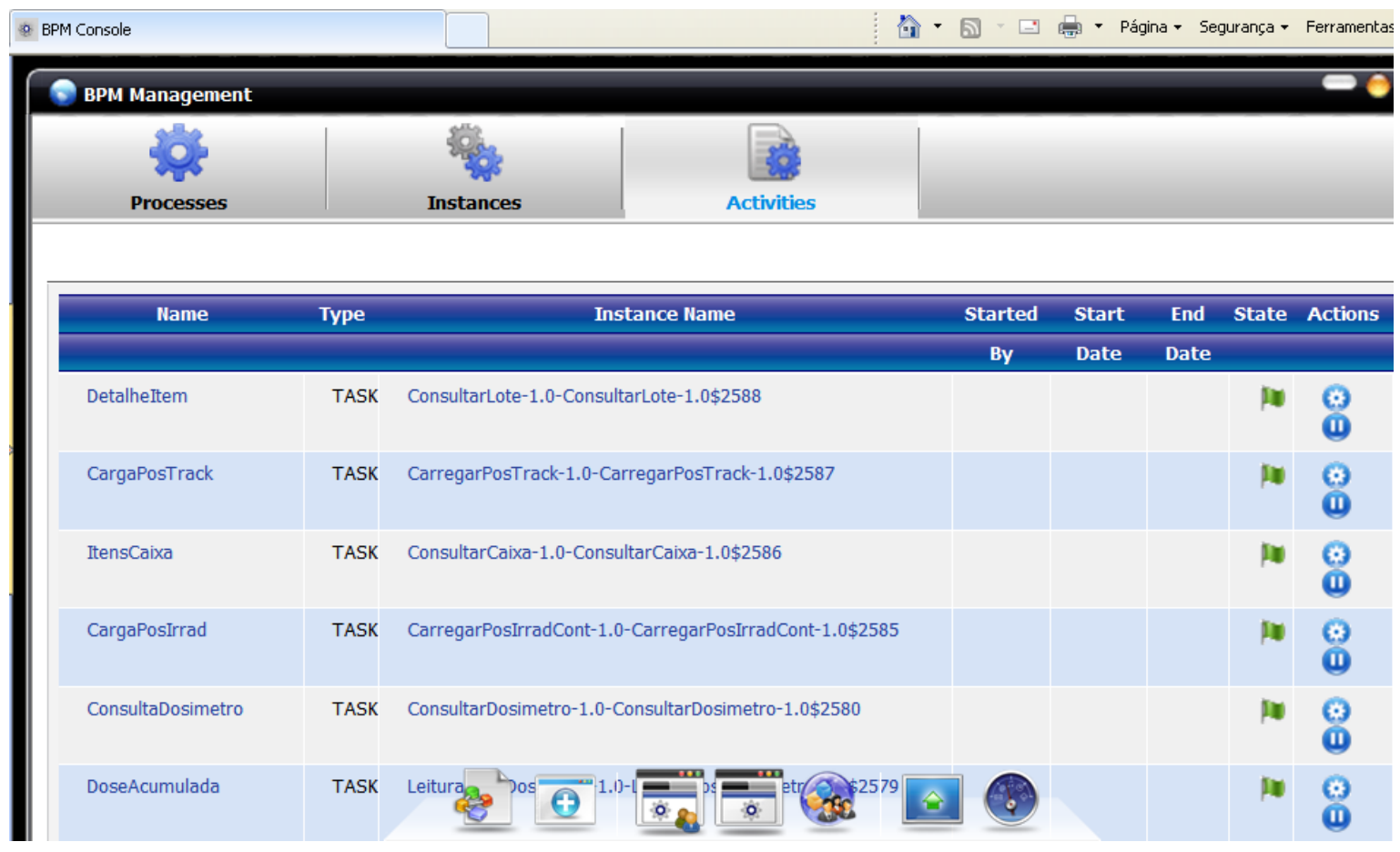

FIGURA 2.15 - Página do Bonita para o Administrador do sistema fazer a manutenção dos processos do sistema - aba Activities.

O Bonita faz interações com outras aplicações ou base de dados através de hooks ("ganchos"). Estes são classes Java pré-inicializadas quando é feita a declaração da classe no Eclipse.

Através dos hooks são realizadas atualizações da base de dados, consistência lógica e física dos dados de entrada; gerar relatórios, etiquetas; verificar posicionamento de fontes; leitura de código de barras; envio de emails; criar subprocessos; etc.

A plataforma de desenvolvimentos de hooks é a IDE Eclipse com plugins do Bonita e Proed. A FIG.2.16 mostra uma imagem da plataforma com uma tarefa sendo configurada para executar um hook quando a tarefa terminar. 


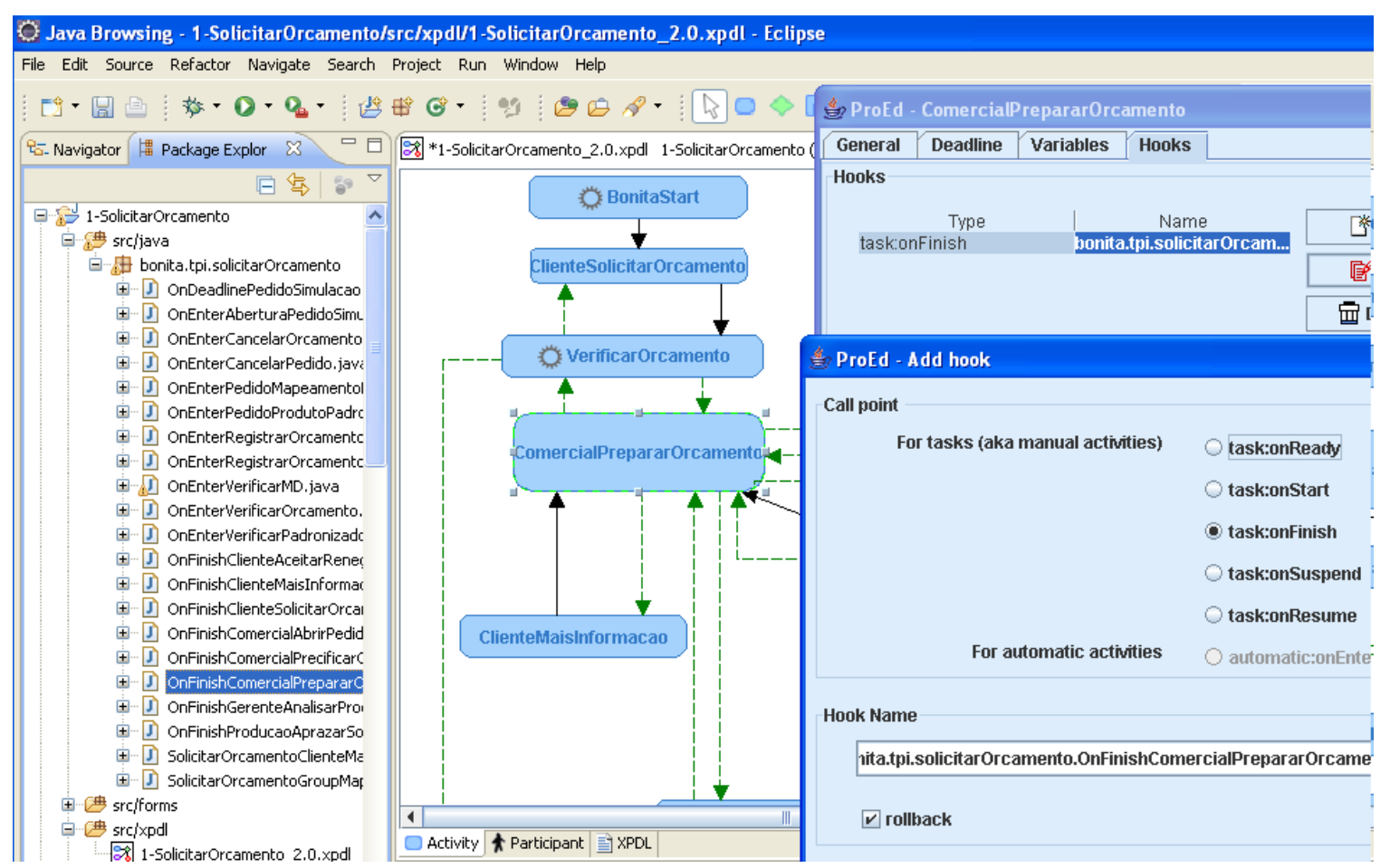

FIGURA 2.16 - IDE Eclipse com as classes JAVA de um processo no qual é configurado uma tarefa "chamar" um método (hook) quando a tarefa terminar.

A FIG.2.16 contém o desenho de fluxo de atividades (Activity) e as telas para configurá-lo. Ainda está disponível a visão dos participantes (Participant) relacionados com as atividades. Também é possível verificar a codificação do fluxo na linguagem XPDL.

Ao se criar um novo processo (fluxo) a plataforma Eclipse disponibiliza o ambiente gráfico Proed visto na FIG.2.17.

No destaque em vermelho no cabeçalho da figura vê-se as ferramentas disponíveis para desenho:

- SEARCH: seta que faz com que seja selecionada a parte do desenho que se deseja alterar: uma atividade, ou uma transição entre tarefas, ou mudar o foco de seleção;

- $\quad A D D$ ACTIVITY: retângulo azul que faz a inclusão de uma nova atividade no processo;

- ADD ROUTE ACTIVITY: losângulo verde que serve para escolha de opções (é o if da programação); 
- $A D D$ SUBPROCESS: adiciona um subprocesso ao processo principal. Este subprocesso já deve estar pronto para ser chamado no processo principal;

- ADD TRANSACTION: faz as transições entre as tarefas

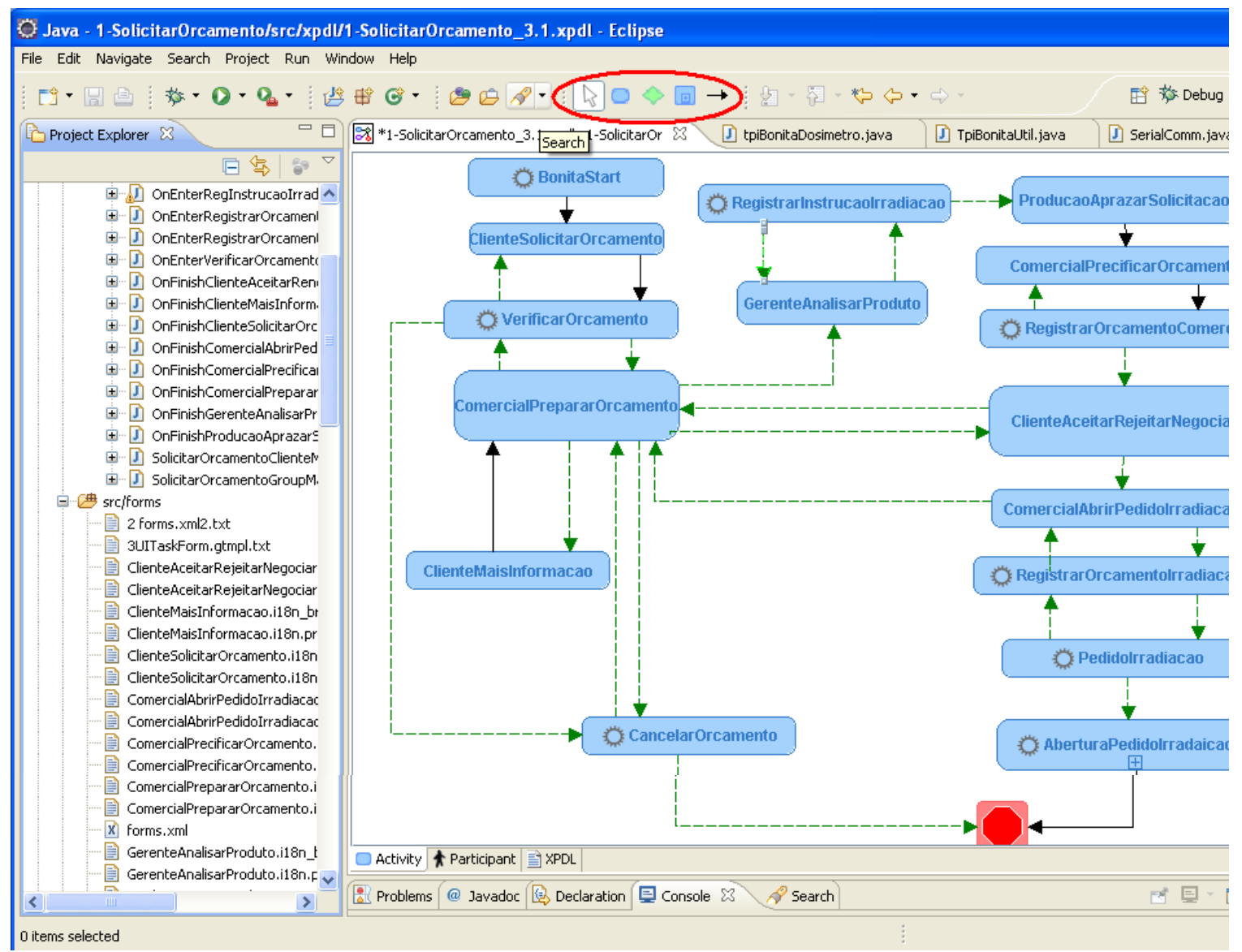

FIGURA 2.17 - IDE Eclipse-Proed mostrando um processo, atividades e transições.

Todo fluxo tem início na atividade BonitaStart e término na atividade mostrada em vermelho no final do fluxo. As atividades com um pequeno círculo indicam que são atividades automáticas disparadas pelo sistema. As demais atividades têm um usuário ou grupo de usuários responsável.

Com o mouse posicionado no centro da tela, o botão direito da acesso às propriedades do fluxo. 


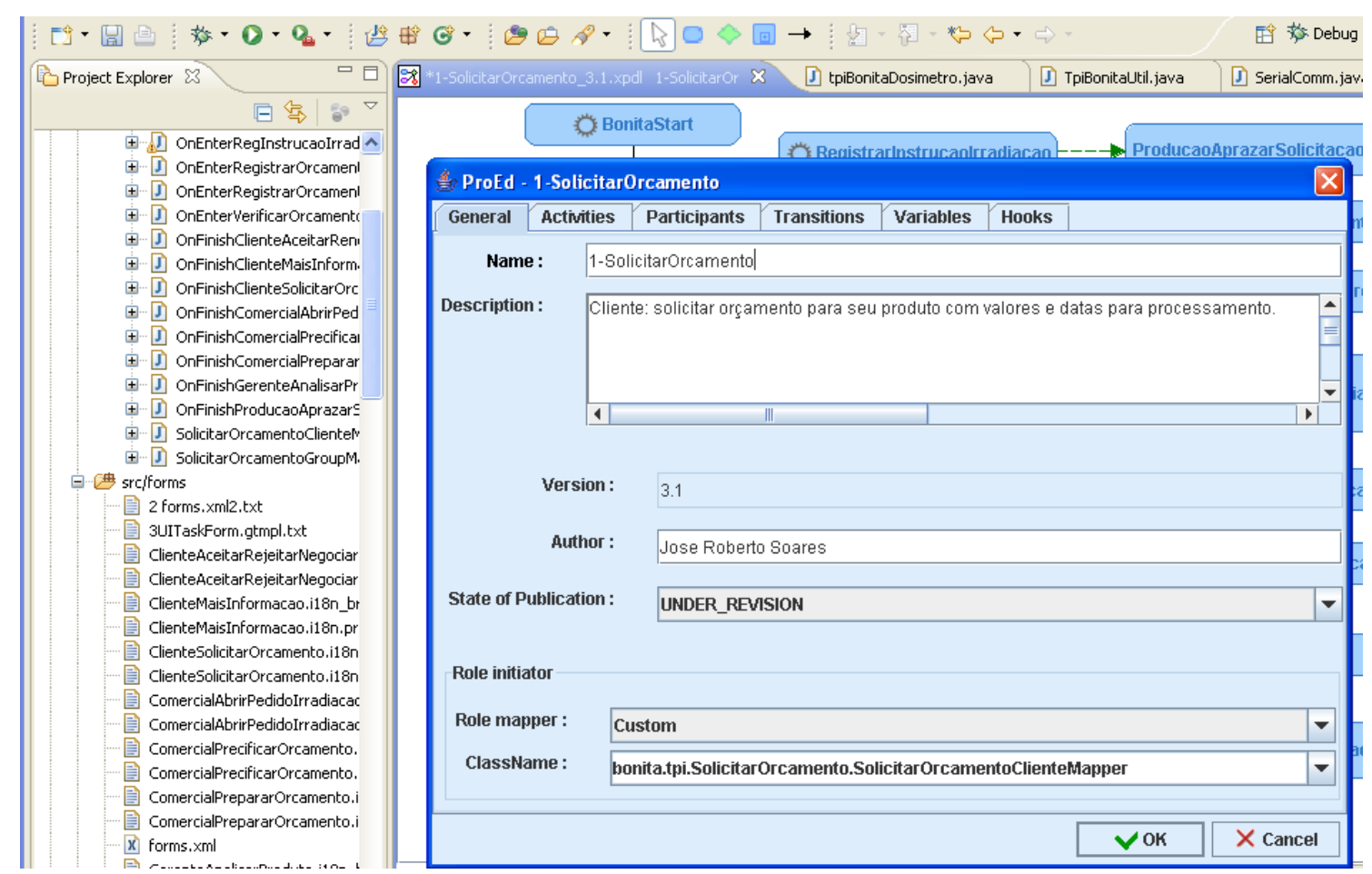

FIGURA 2.18 - IDE Eclipse-Proed mostrando as propriedades de um processo.

Na FIG.2.18 estão presentes as propriedades do processo: Nome, descrição, versão, autor, estado da publicação: under_revision, released e under_test. A propriedade Roler mapper tem duas opções: Custom e LDAP. LDAP se refere à autenticação de usuários numa rede corporativa.

Custom indica que a autenticação é feita a partir de uma classe escrita em Java. Essa classe é escrita de tal forma que são selecionados os usuários que pertencem ao mesmo Grupo de usuários que pertence o usuário que iniciou o processo. Exemplo: se o usuário palmer, pertencente ao Grupo do cliente MangasJanjão do qual também fazem parte os usuários tomy e kate, iniciou uma instância de processo que é assinalada ao Participant Cliente do qual MangasJanjão é membro, os usuário kate e tomy também são assinalados para o processo que o usuário palmer iniciou. Se algum usuário de algum outro grupo tentar iniciar um processo que o usuário palmer iniciou não vai ter sucesso.

Outra propriedade, Variables, é mostrada na FIG.2.19. Essas variáveis são globais ao processo, ou seja, todas as atividades do processo têm acesso às 
variáveis globais. Uma atividade em particular pode ter suas próprias variáveis locais que são visíveis somente a essa atividade e às transições que partem dela.

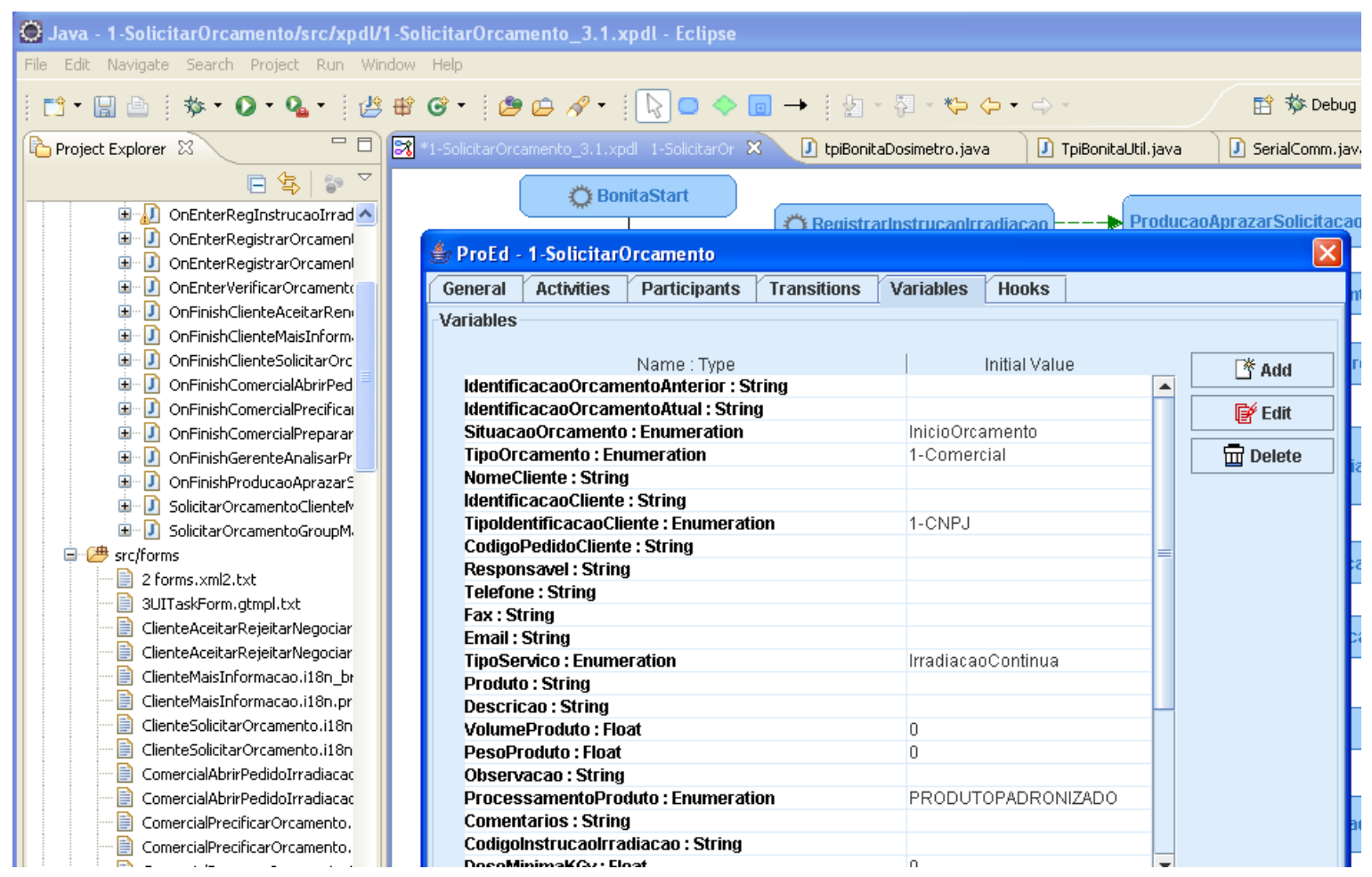

FIGURA 2.19 - IDE Eclipse-Proed mostrando as variáveis globais de um processo.

As variáveis são dos tipos: String, Integer, Float e Enumeration (várias possibilidades) e Date. Podem conter um valor inicial quando carregada pela primeira vez.

Ao ser selecionada uma atividade do processo esta exibe as suas propriedades. A FIG.2.20 mostra uma atividade do tipo Manual, ou seja, pertence a um agente do processo. Neste caso, o agente é o CLIENTE. Como já dito anteriormente, a atividade ao ser iniciada por um usuário que pertence a um grupo que pertence ao grupo Cliente (ver funções do ROOT - Gerenciamento de Usuários), somente poderá ser acessada por usuários que pertençam ao grupo do usuário que iniciou a atividade. 


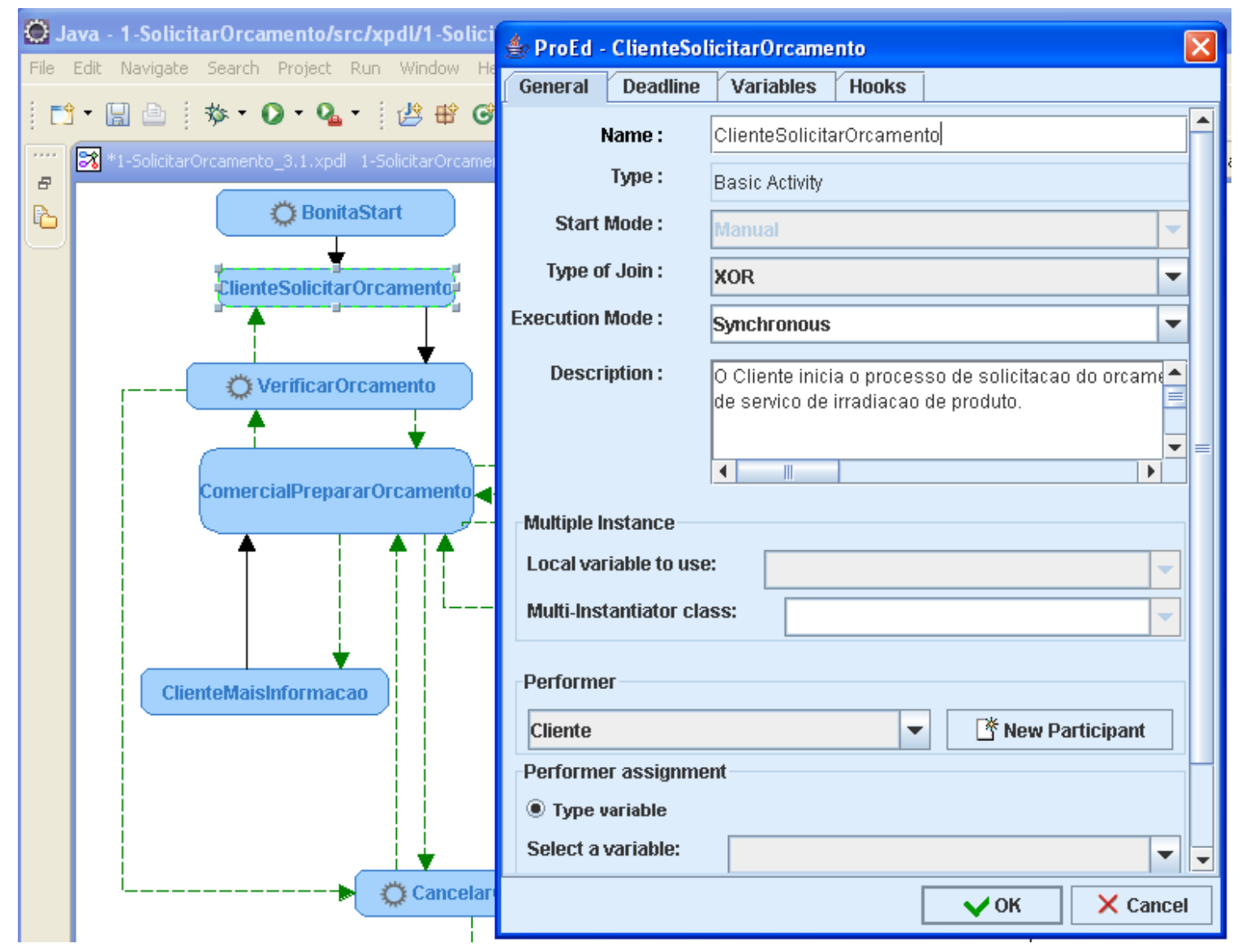

FIGURA 2.20 - IDE Eclipse-Proed exibe as propriedades de uma atividade do processo iniciada por um usuário.

Outro modo de iniciar uma atividade é pelo sistema. São atividades intermediárias com o propósito de fazer consistências dos dados e atualizações de bando de dados.

Um elemento importante na construção do fluxo são os formulários, ou seja, as telas de entrada dos dados no sistema. Na FIG.2.21 está exposto a customização de uma tela na qual é possível editar os nomes dos campos no idioma português. Na FIG.2.21 também está explicitado o modo de como é construído os campos no qual há várias opções de escolha pelo usuário. 


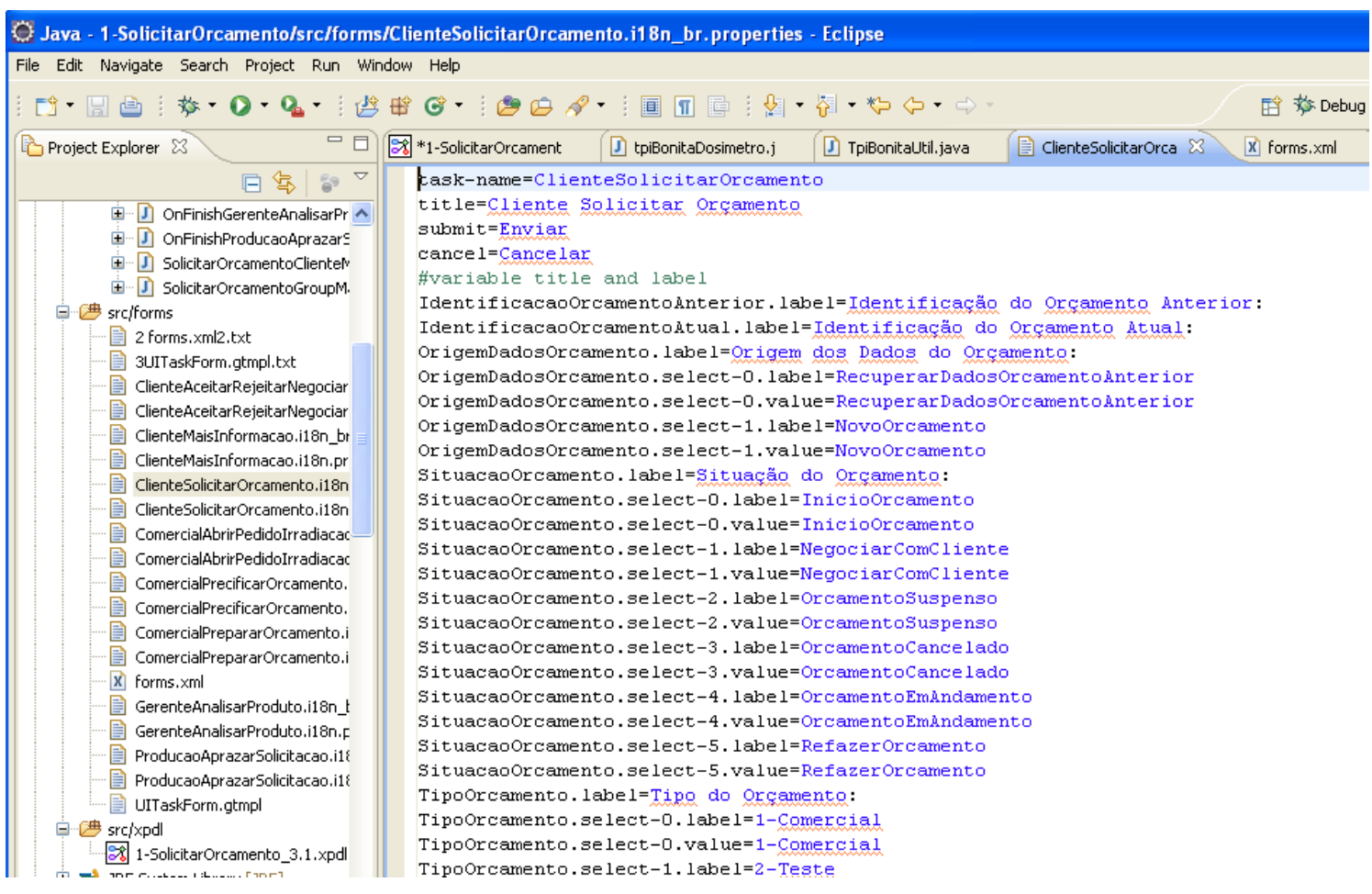

FIGURA 2.21 - IDE Eclipse-Proed exibe a lista de formulários utilizados pelas atividades no processo.

No formulário, o atributo task-name, se refere ao nome da atividade manual que consta do fluxo. Também é possível traduzir o nome dos botões para Enviar ou Cancelar o formulário da atividade. Se o usuário escolher ENVIAR, o fluxo transita para a próxima atividade em condições no fluxo. Se escolher CANCELAR, a atividade volta para a lista do usuário e fica aguardando ser reiniciada. 


\section{MATERIAIS E MÉTODOS}

Neste capítulo são descritos os materiais e métodos utilizados para a concretização do plano de trabalho ou projeto.

\subsection{Sistema TPI}

O sistema computacional foi desenvolvido com o propósito de atender às necessidades de realizar o seguimento (acompanhamento, tracking) do produto enquanto submetido ao ciclo do processo de irradiação. Tem como base operacional o Irradiador Multipropósito de Cobalto-60 Tipo Compacto do IPEN/CNEN/USP construído por Rela e descrito por Calvo (2004). Os requisitos de acompanhamento do produto são baseados na emissão de uma Ordem de Serviço de irradiação e esta monitorada por todos os participantes do processo. No final do processo o sistema emite um Certificado de Irradiação contendo todos os passos que o produto percorreu no ambiente do irradiador, bem como, os passos cumpridos pelo Cliente do processo: entrega e retirada do produto.

O sistema visa atender aos seguintes requisitos $e$ funcionalidades:

- Função de Login

- Efetuar Login;

- Identificação de Perfil;

- Alteração de Senha;

- Disponibilizar Acesso.

- Função de Cadastros Básicos

- Manutenção de Login;

- Manutenção de Clientes;

- Manutenção de Produtos;

- Manutenção de Perfil de Usuários.

- Função Cliente

- Solicitar Orçamento de Serviço de Irradiação de Produto;

- Solicitar abertura de pedido de irradiação ao Setor Comercial;

- Enviar produto para irradiação de acordo com programação;

- Acompanhamento de Irradiação do Produto;

- Consulta do Status de Irradiação realizada;

- Verificação do Certificado de Irradiação de Produto (CI);

- Retirada do produto irradiado. 
- Função Setor Comercial

- Manutenção do cadastro de Clientes;

- Manutenção de Pedidos;

- Manutenção de Ordem de Serviço (OS);

- Emitir Ordem de Serviço associado ao pedido do cliente;

- Solicitar ao cliente troca de material por modificação de embalagem ou outra não conformidade.

- Função Gerência da Planta

- Manutenção de dados do Irradiador;

- Verificação da Interface do leitor de código de barras;

- Verificação da interface de Status do Irradiador;

- Analisar OS;

- Emitir e disponibilizar a Instrução de Irradiação (II) para produtos novos.

- Função de Produção/Operação

- Agrupar OS à correspondente Programação de Irradiação $(\mathrm{PI})$;

- Programar a irradiação e o local de armazenagem dos produtos antes e após a irradiação;

- Emitir Folha de Programação de Irradiação e armazenamento (FP);

- Recepção do material do cliente na área de produtos não irradiados;

- Conferência do material com a OS;

- Carimbar NF e anotar número da OS e codificar o produto:

- Identificar cada unidade de produto com etiqueta de Código de Barras;

- Agrupar os produtos em Lote;

- Preparar material e embalar para irradiação,

- Aguardar inspeção da Garantia da Qualidade (GQ);

- Processar material, preencher a Programação e Registro de Carregamento do Irradiador (RC);

- Após o processamento, armazenar os produtos irradiados na área de produtos já irradiados;

- Aguardar inspeção da GQ;

- Preparar material para expedição e armazenar o produto na área destinada na I.I.;

- Aguardar NF o $\mathrm{Cl}$ e a retirada do produto pelo Cliente.

- Funções auxiliares:

- Disponibilizar Permissão de Envio de E-mail;

- Recuperação de Dados de Irradiação;

- Seleção de Irradiação Padronizada;

- Envio de e-mail através de processo automatizado;

- Função de Garantida da Qualidade

- Inspeção de produto preparado para irradiação, colocação de indicadores de doses e dosímetros;

- Inspeção do produto irradiado e dosímetros; 
- Emissão de certificado de irradiação;

- Liberar material para expedição e emissão de nota fiscal;

- Solicitação de reparo e Emissão de Relatório de Não Conformidade $(\mathrm{RN})$;

- Função Interfaces de Leitura/Gravação Código de Barras e Posição das Fontes

- Importação de estados das fontes;

- Importação de leitura dos leitores de código de barras;

O sistema foi desenvolvido para estar de acordo com as Boas Práticas de Fabricação e Radiação preconizadas pelas normas detalhadas ao longo do texto.

É costume batizar o sistema com um nome. Este foi batizado por TPI Tracking de Produtos Irradiados. O termo tracking tem o significado de seguimento, acompanhamento. Para este sistema, o seguimento ou acompanhamento de produtos irradiados tem o propósito de atender aos requisitos de GMP. Para tanto, a irradiação de produtos é feita a partir da geração de Ordem de Serviço para o acompanhamento (tracking) do produto e a sua finalização com a emissão do Certificado de Irradiação o respectivo faturamento dos serviços de irradiação ao cliente. $O$ processo se encerra com o envio do material por meio da emissão de nota fiscal de remessa ou uma carta de remessa quando for o caso.

O objetivo do sistema TPI é fazer o gerenciamento do fluxo do processo (workflow) de forma a acompanhar todas as etapas do processo de irradiação dos produtos. Registrar todos os eventos importantes do processo, de maneira que se possam emitir relatórios de acompanhamento, estatísticas de processos, certificado de irradiação, entre outras possibilidades.

\subsection{Desenvolvimento do Projeto}

O sistema TPI é uma ferramenta publicada na WEB, ou seja, pode ser operado por pessoas remotamente. É uma peça de software complexa tanto na sua concepção quanto no seu desenvolvimento e teste. A metodologia adotada no desenvolvimento do sistema TPI é composta das seguintes fases: 
- Manuais do Sistema: todo sistema tem um mínimo documentos que garanta a uniformidade de definições de campos, colunas, termos, nomes, etc.;

- Requisitos do Sistema: requisitos mínimos que o sistema deve atender para conseguir o objetivo requerido pelo cliente. Essa fase é descrita pelo cliente (Patrocinador). No nosso caso é a figura do orientador. $O$ foco principal é a rastreabilidade das informações (tracking). O resultado final do processo de irradiação é a emissão do Certificado de Irradiação no qual constam as evidências de que o produto foi irradiado segundo a Instrução de Irradiação e atingiu os requisitos mínimos e máximos de dose de irradiação requeridos pelo cliente. Esta certificação é necessária para garantir que o serviço foi executado segundo às Boas Práticas de Fabricação (GMP);

- Formatação: esta fase é composta por documentos que descrevem, de maneira geral, como atingir os objetivos descritos na Fase de Requisitos. Nesta fase são elaborados documentos que consolidam o escopo do projeto confrontado com os Requisitos do sistema. Também Incluem desenho dos fluxos dos processos, descrição detalhada dos casos de uso, descrição dos dados, descrição das telas, interfaces dos operadores, interfaces de comunicação, interfaces de aquisição de dados;

- Desenvolvimento: esta fase compreende a implementação do sistema. São elaborados documentos para que sejam desenvolvidas as interfaces, os fluxos de dados, a base de dados, as interfaces elétricas, as interfaces de WEB. São envolvidos diversos profissionais nesta fase consultor de sistemas, analista de negócio, analista de dados, analista de banco de dados, programadores WEB e java, analistas de redes, técnicos de eletrônica. Os consultores de sistema e de negócios detalham os negócios envolvidos na forma que os outros profissionais irão seguir para desenvolver o sistema. Nesta fase também são elaborados os documentos de teste e treinamento dos usuários no uso do sistema; 
- Testes: esta fase compreende a especificação dos testes de aceitação que o sistema deve comportar. É escrita por um profissional ligado ao negócio. É detalhado aquilo que cada interface deve executar e os retornos que a mesma deve acusar em caso de erro lógico, falha ou dados incorretos. O conjunto dos documentos de teste é que atestam a veracidade do sistema e o cumprimento dos objetivos definidos na Especificação de Requisitos. Também nesta fase são realizados treinamentos com os usuários para que esses possam realizar os testes do sistema.;

- Encerramento: esta fase compreende a aceitação formal do sistema e as garantias do mesmo. Nesta fase ocorre a operação assistida por um período no qual são corrigidos erros de desenvolvimento e programação. Se houver necessidade de corrigir algum erro de concepção, que não estava no escopo inicial, ela é vista como um acréscimo de escopo e demanda um pequeno projeto de desenvolvimento.

\subsubsection{Fase de Manuais do projeto}

O uso de padrões visa facilitar o trabalho de atribuir nome aos dados e aos objetos de dados, permitindo assim maior facilidade na sua identificação e manutenção, maior agilidade na construção de novos sistemas e na alteração de sistemas existentes.

\subsubsection{Manual de Padronização}

Este documento apresenta as regras para a elaboração da documentação dos modelos de dados e padrão de nomenclatura.

Abrangência:

- A formação do Glossário de Termos, siglas consagradas e abreviaturas;

- Regras de nomenclatura do modelo Lógico e Físico; 
- Nível de documentação dos elementos do modelo de dados;

- Padrão de layout dos modelos.

\subsubsection{Metodologia de Desenvolvimento de Sistemas}

Este documento reúne as fases de desenvolvimento de um projeto. Essas fases formam um todo que podemos chamar de Boas Práticas para 0 Desenvolvimento de Projeto e Sistemas. São métodos consagrados pelo uso ao longo dos anos e adotados pela maioria dos desenvolvedores e empresas de desenvolvimento.

A metodologia cobre todas as fases do projeto. São agrupados em módulos, tais como:

- Módulo 0 - Design Conceitual, o módulo é caracterizado pela visão de negócio em contraposição às necessidades de Sistemas de Informação;

- Módulo 1 - Especificação Funcional, este módulo é caracterizado pela especificação dos processos que compõem o negócio/domínio objetivando a proposição de soluções de melhoria;

- Módulo 2 - Especificação Técnica onde se faz o detalhamento físico dos modelos lógicos aprovados no módulo anterior, disponibilizando uma visão clara e compreensiva aos técnicos responsáveis pelo desenvolvimento;

- Módulo 3 - Desenvolvimento, é a materialização das especificações funcionais de um sistema de informação, produzindo um sistema físico e testando-o.

- Módulo 4 - Implantação, consiste na operacionalização da solução e sua disponibilização para o Cliente. Neste módulo os usuários e operadores do sistema desenvolvido deverão ser treinados, finalizada a infraestrutura do ambiente de produção e dada a carga inicial do sistema. O cliente deverá testar o sistema em produção, e obtido o aceite, este deverá ser formalizado para o início da garantia, suporte e manutenção; 
- Módulo 5 - Manutenção, é a operacionalização do plano global de manutenção elaborado na especificação técnica, de acordo com as condições contratuais estabelecidas junto ao Cliente.

O documento serve como orientação para elaboração dos documentados citados no início do tópico. Nesse projeto são utilizados apenas um conjunto mínimo de documento.

Importante salientar que, embora o objetivo principal seja a descrição e a definição de utilização de uma fase e seus documentos, serviu-se dos documentos originais do projeto e o preenchimento destes já contemplando o que foi definido para o projeto.

Portanto, a título de exemplo, se esta de fato, explicitando o desenvolvimento do projeto.

\subsubsection{Fase de Gestão de Requisitos do projeto}

Esta fase reúne documentos que definem o escopo e objetivos do projeto. É contemplada a necessidade do cliente num documento chamado de Requisitos do Projeto. A visão do projetista sobre as necessidades do cliente é concretizada ao elaborar o documento Solicitação do Cliente, e a partir destes, elabora-se a Especificação Funcional - UML. O termo UML se refere à modelagem das especificações utilizando a metodologia conhecida como Unified Modeling Language.

Nesta fase são descritos os requisitos do cliente para o projeto também designado como o Patrocinador do projeto. A figura do cliente, o patrocinador do projeto, é central. Cabe a ele a descrição das premissas do projeto. Os entregáveis, a qualidade dos dados, os documentos que acompanharam as fases de desenvolvimento, teste e aceitação. Usa-se de linguagem formal, mas não padronizada, para essa descrição. Entre elas, a exemplo, pode-se citar:

- Apresentação: o cliente faz uma explanação da empresa, do serviço que ele quer sistematizar e da visão geral do projeto;

- Objetivos: são declarados os objetivos gerais e específicos do projeto para que não haja dúvidas sobre o desenvolvimento do projeto; 
- Descrição dos requisitos: procedimentos gerais do processo de irradiação. São descritos de forma geral as necessidades do projeto. Para esse projeto tem-se:

- Solicitação de orçamento pelo cliente;

- Análise da Ordem de Serviço;

- Programação de processamento;

- Recebimento de material (produto) para irradiação;

- Inspeção do produto antes da irradiação;

- Processamento do produto no irradiador;

- Controle da irradiação após a irradiação;

- Emissão de nota fiscal e faturamento;

- Expedição do produto.

- Características e funcionalidades: são descritas as funcionalidades do projeto:

- Função de login;

- Função de Cadastros Básicos;

- Função de Irradiação do Produto;

- Função do Setor Comercial;

- Função Gerência de Planta;

- Função de Produção/Operação;

- Função de Garantia de Qualidade;

- Função interface de leitura/gravação de código de barras e posição das fontes de irradiação;

\subsubsection{Especificação Funcional - UML}

Faz parte da documentação da Especificação dos Requisitos a visão do projetista.

O projetista elabora a Especificação Funcional utilizando a notação UML para expressar os relacionamentos entre os diversos atores (agentes) e o trâmite das informações entre eles.

Nele o projetista faz a sua interpretação das necessidades do cliente já com a orientação de desenvolvimento. 
Na FIG.3.1 é mostrado o workflow (fluxo) no qual o Cliente (solicitante do serviço de irradiação) inicia o pedido de orçamento para irradiar um produto. Numa seqüência natural do processo, o Setor Comercial prepara o formulário do Orçamento, envia-o (através do trâmite da aplicação) à Gerência para analisá-lo. A Gerência decide se o produto já foi processado anteriormente ou se é um produto novo. O Setor Comercial faz o preenchimento das informações pertinentes e libera o formulário para que o mesmo seja enviado ao Cliente para a apreciação. O Cliente tem duas opções: aprová-lo iniciando o processo do pedido interno de irradiação, ou reenviá-lo ao Setor Comercial para nova negociação.

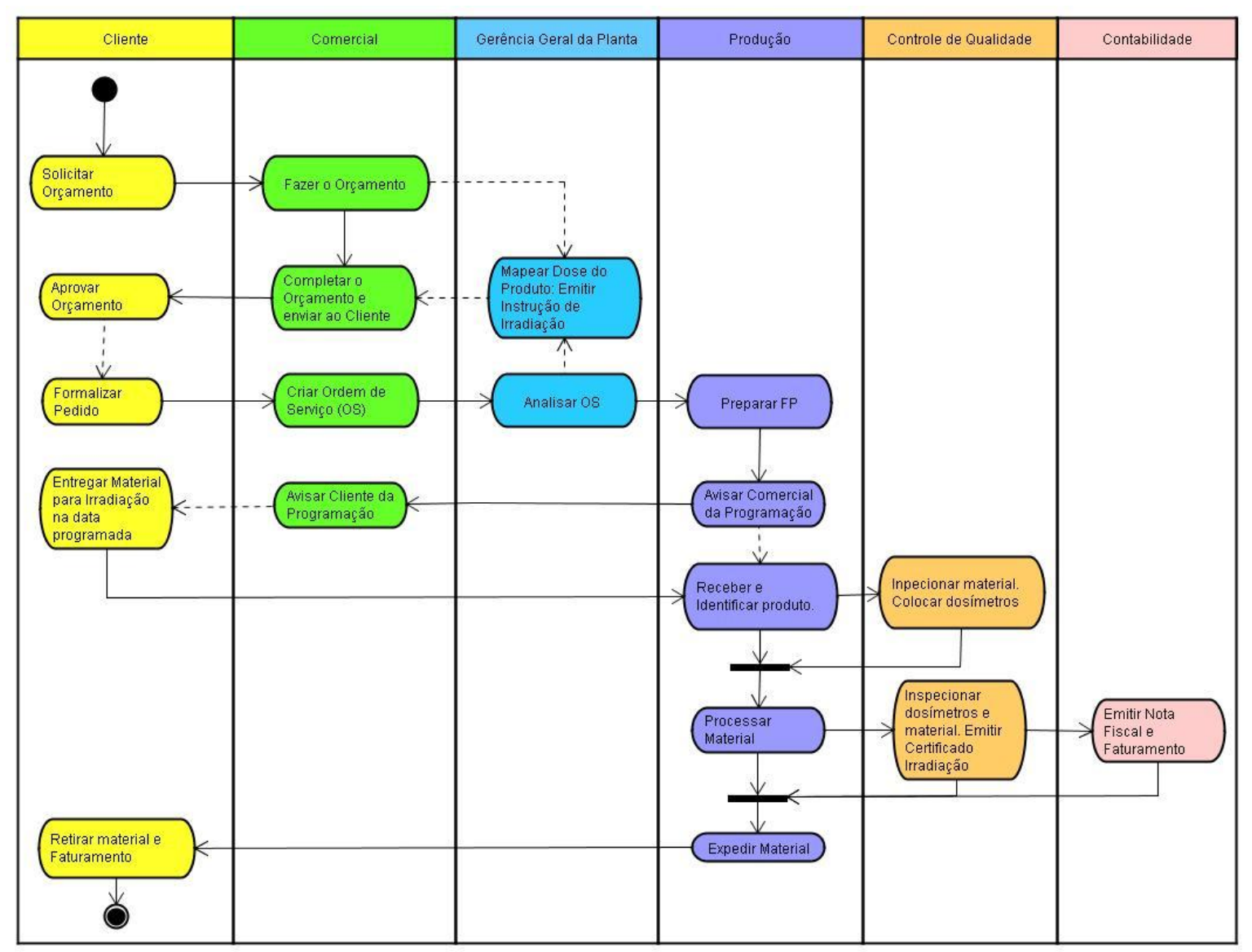

FIGURA 3.1 - Modelagem UML do fluxo do processo de Solicitação de Serviço.

O projetista faz uma descrição geral do projeto e uma seção no qual ele apresenta as premissas que nortearão o desenvolvimento do projeto, também, são incluídas as restrições do projeto. A descrição das restrições é um item importante na elaboração de um projeto para poder situá-lo no que será 
contemplado e, principalmente, o quê não será contemplado. Também são avaliados os riscos potenciais que poderão influir na conclusão do projeto.

A partir dessa introdução o projetista inicia a Descrição dos Processos. Nessa fase é utilizado um misto de descrição narrativa com elementos visuais denominados Diagramas de Caso de Uso. A FIG.3.2 apresenta o diagrama de caso de uso geral dos processos e dos agentes envolvidos 


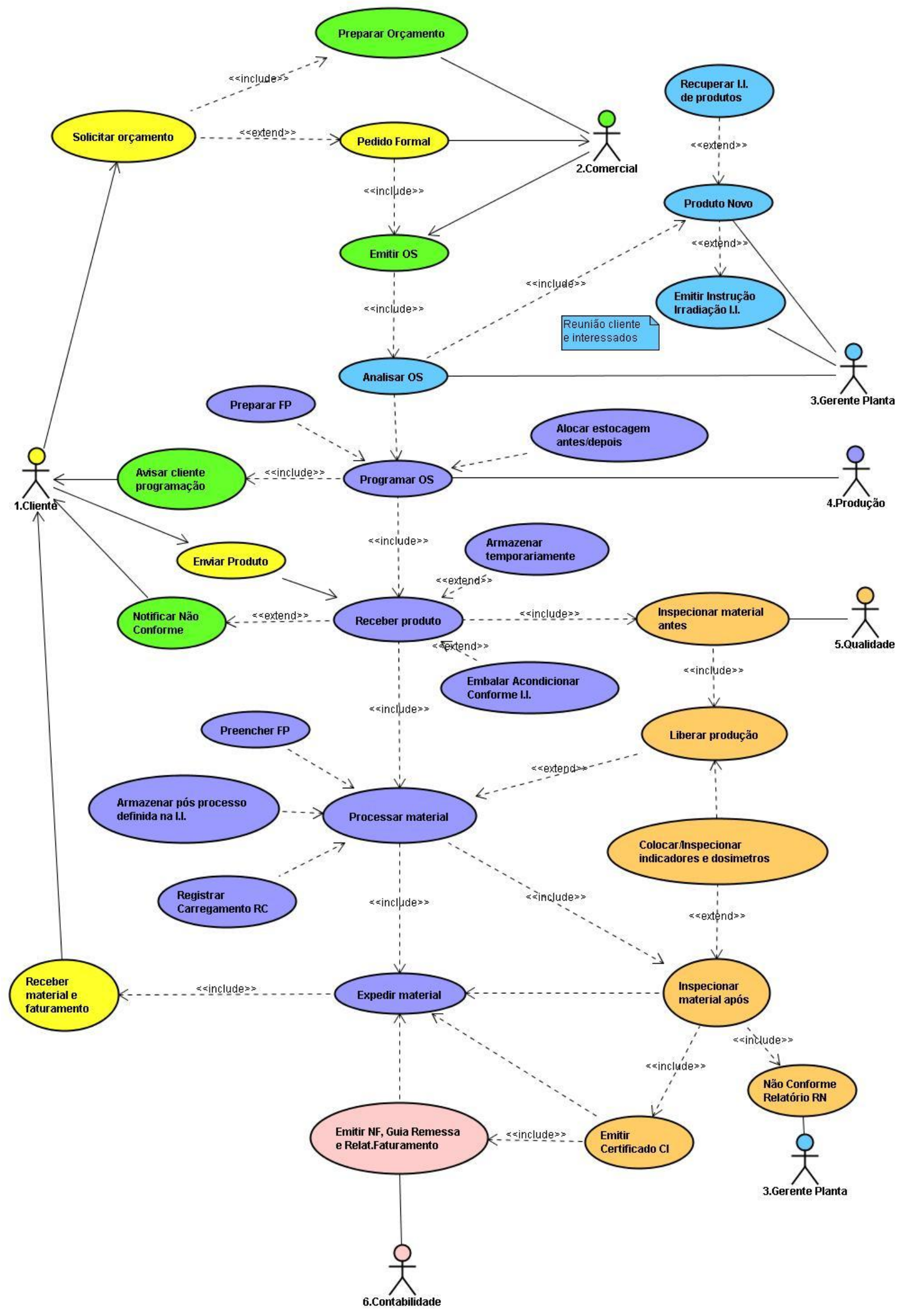

FIGURA 3.2 - Diagramas de Casos de Uso de Serviço de Irradiação de Produto. 
No diagrama estão representados os agentes diferenciados por cores. O cliente é cor amarela, o comercial verde, o gerente azul claro, a produção azul escuro, a qualidade marrom e a contabilidade, magenta. Essas cores são escolhas do projetista. Nada tem a ver com a metodologia.

O processo de descrição do projeto é repetitivo e sempre acrescenta alguma informação ou definição ao processo à medida que o projeto evolui e é amadurecido.

Esse recurso acontece devido aos documentos serem elaborados em datas diferentes por pessoas diferentes. $O$ importante é a linha mestra de o projeto ser mantida coesa e aderente aos Requisitos do Projeto elaborado pelo cliente.

\subsubsection{Descrição do atores}

Os atores do sistema são apresentados bem como suas respectivas responsabilidades. O Quadro 3.1 mostra a descrição dos atores de forma tabular:

QUADRO 3.1 - Descrição do Atores do Sistema TPI

\begin{tabular}{|l|l|}
\hline \multicolumn{1}{|c|}{ Nome } & \multicolumn{1}{|c|}{ Descrição } \\
\hline Cliente & Interessado em processar produto no irradiador. \\
\hline Setor Comercial & $\begin{array}{l}\text { Responsável pela pré-venda e pós-venda e } \\
\text { atendimento ao cliente. }\end{array}$ \\
\hline Gerente da Planta & $\begin{array}{l}\text { Responsável pela análise da Ordem de Serviço e } \\
\text { emitir a Instrução de Irradiação para produtos novos. }\end{array}$ \\
\hline Setor de Produção & $\begin{array}{l}\text { Responsável pelo processamento dos produtos no } \\
\text { irradiador, recebimento, armazenagem antes e após } \\
\text { a irradiação e expedição do produto }\end{array}$ \\
\hline $\begin{array}{l}\text { Garantia da } \\
\text { Qualidade }\end{array}$ & $\begin{array}{l}\text { Responsável pela inspeção do produto e emissão do } \\
\text { Certificado de Irradiação }\end{array}$ \\
\hline $\begin{array}{l}\text { Setor de } \\
\text { Contabilidade }\end{array}$ & $\begin{array}{l}\text { Setor responsável pela atividade fiscal e faturamento } \\
\text { do serviço de irradiação }\end{array}$ \\
\hline
\end{tabular}

O descritivo é bem sucinto e claro. Deve estar de acordo com a definição de requisitos.

\subsubsection{Descrição geral das atividades dos atores}

As atividades do projeto que aparecem na FIG.3.2 são descritas de forma tabular no Quadro 3.2. Nele são relacionados as atividades a serem 
executadas com os agentes ou atores responsável pela atividade e o descritivo da atividade.

QUADRO 3.2 - Descrição das responsabilidades dos agentes ou atores do sistema.

\begin{tabular}{|c|c|c|}
\hline Atividades & $\begin{array}{l}\text { Agente } \\
\text { Responsável }\end{array}$ & Descrição \\
\hline Cliente solicita orçamento & Cliente & $\begin{array}{l}\text { Cliente solicita, ao Setor Comercial, orçamento } \\
\text { de produto a ser irradiado. }\end{array}$ \\
\hline Gerar orçamento & Comercial & $\begin{array}{l}\text { Comercial recupera informações do produto } \\
\text { solicitado e da l.I. e prepara orçamento. }\end{array}$ \\
\hline Aprovar orçamento & Cliente & Cliente valida orçamento de irradiação. \\
\hline Formalizar pedido & Cliente & $\begin{array}{l}\text { Cliente formaliza pedido com base no } \\
\text { orçamento. }\end{array}$ \\
\hline Gerar Ordem de Serviço & Comercial & $\begin{array}{l}\text { Recebe pedido formal. Gera Ordem de Serviço } \\
\text { OS para irradiar produto. }\end{array}$ \\
\hline $\begin{array}{l}\text { Analisar Ordem de } \\
\text { Serviço de irradiação: } \\
\text { Produto Novo }\end{array}$ & $\begin{array}{l}\text { Gerente de } \\
\text { Planta }\end{array}$ & $\begin{array}{l}\text { Verifica se produto da OS é Produto Novo. Se } \\
\text { for, faz reunião com interessados para definir } \\
\text { plano de irradiação de protótipo. Emitir nova } \\
\text { Instrução de Irradiação (I.I.). }\end{array}$ \\
\hline Preparar FP & Produção & $\begin{array}{l}\text { Preparar Folha de Programação e avisar } \\
\text { Comercial sobre a programação que avisará o } \\
\text { Cliente }\end{array}$ \\
\hline $\begin{array}{l}\text { Avisar Cliente da data } \\
\text { para irradiação do } \\
\text { material }\end{array}$ & Comercial & $\begin{array}{l}\text { Setor Comercial avise ao Cliente da data } \\
\text { programada para envio do material para } \\
\text { irradiação }\end{array}$ \\
\hline $\begin{array}{l}\text { Envio do material para } \\
\text { irradiação }\end{array}$ & Cliente & $\begin{array}{l}\text { Na data acertada, o cliente envia o material } \\
\text { para irradiação com a Nota Fiscal de Remessa }\end{array}$ \\
\hline $\begin{array}{l}\text { Preparar produto para } \\
\text { irradiação. }\end{array}$ & Produção & $\begin{array}{l}\text { Prepara o material para irradiação. Acondiciona } \\
\text { em paletes e identifica-os com código de barra } \\
\text { ou RFID }\end{array}$ \\
\hline $\begin{array}{l}\text { Inspecionar e colocar } \\
\text { dosímetros }\end{array}$ & $\begin{array}{l}\text { Garantia da } \\
\text { Qualidade }\end{array}$ & $\begin{array}{l}\text { Inspecionar caixas, paletes e embalados. } \\
\text { Colocar dosímetros. }\end{array}$ \\
\hline $\begin{array}{l}\text { Processar material no } \\
\text { irradiador }\end{array}$ & Produção & $\begin{array}{l}\text { Submeter os materiais ao irradiador de acordo } \\
\text { com a FP. }\end{array}$ \\
\hline $\begin{array}{l}\text { Separar os materiais no } \\
\text { setor irradiados. }\end{array}$ & Produção & Preparar material para inspeção e expedição. \\
\hline $\begin{array}{l}\text { Inspecionar e retirar } \\
\text { dosímetros }\end{array}$ & $\begin{array}{l}\text { Garantia da } \\
\text { Qualidade }\end{array}$ & $\begin{array}{l}\text { Inspecionar os materiais irradiados. Examinar } \\
\text { os dosímetros. Emitir o Certificado de } \\
\text { Irradiação. Enviar liberação para Contabilidade } \\
\text { emitir a Nota Fiscal de Devolução e o } \\
\text { Faturamento. }\end{array}$ \\
\hline $\begin{array}{l}\text { Expedir material ao } \\
\text { Cliente }\end{array}$ & Produção & Preparar \\
\hline $\begin{array}{l}\text { Retirar material e o } \\
\text { faturamento }\end{array}$ & Cliente & $\begin{array}{l}\text { Retirar o material com a correspondente Nota } \\
\text { Fiscal de Devolução e o respectivo faturamento. }\end{array}$ \\
\hline
\end{tabular}




\subsubsection{Especificação Funcional UML}

A especificação funcional UML é um descritivo de processos segundo modelagem da UML. Como exemplo é descrito o processo de abertura de pedido de irradiação.

\subsubsection{Pedido de Serviço de Irradiação}

Na representação gráfica UML as descrições são reduzidas, precisas e claras para evitar erros. Na FIG.3.3 é mostrado o caso de uso do processo de irradiação quando o cliente inicia um orçamento do serviço de irradiação. Se aprovado o sistema abre um pedido de serviço de irradiação.

O processo envolve todos os atores. No diagrama estão representados os macros processos com os respectivos atores. O fluxo inicia a partir da aprovação do orçamento e a posterior abertura do pedido. Desse é aberta uma Ordem de Serviço e o produto é processado em lotes. No final o lote de produto é enviado ao cliente com o respectivo faturamento. Quando a ordem for completada essa é encerrada. Para cada lote expedido é emitido um Certificado de Irradiação 


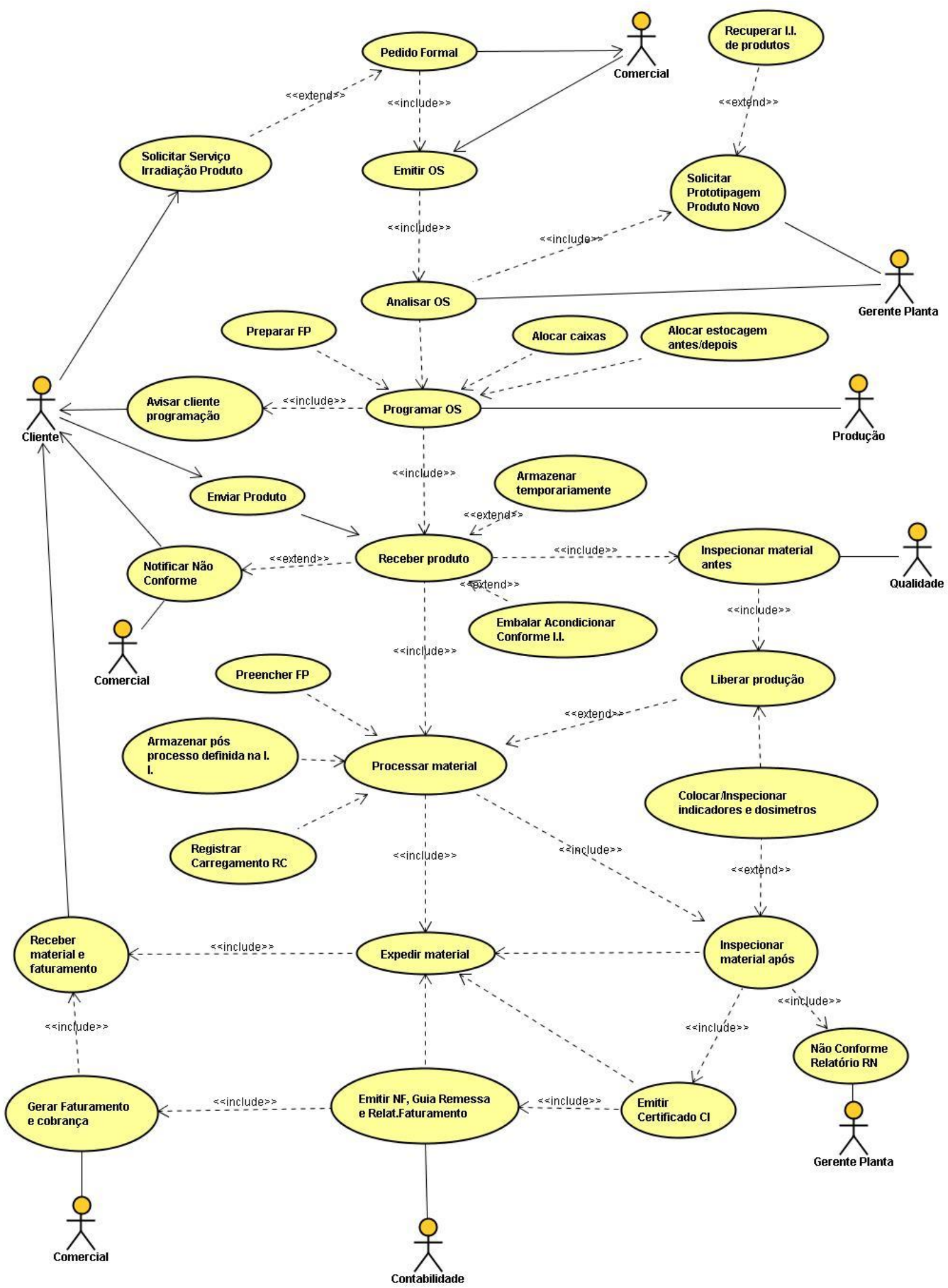

FIGURA 3.3 - Casos de Uso de Pedido de Serviço de Irradiação de Produto. 


\subsubsection{Caso de Uso: Pedido de Irradiação de Produto}

No Quadro 3.3, são descritos de forma tabular o fluxo do processo que o pedido percorre desde o início até a sua conclusão. Estão descritos também os fluxos alternativos.

QUADRO 3.3 - Descrição das atividades dos atores na geração do pedido de irradiação.

\begin{tabular}{|c|c|}
\hline \multicolumn{2}{|l|}{ Código } \\
\hline Título & Gerar Pedido Formal de Irradiação \\
\hline Descrição & $\begin{array}{l}\text { Este caso de uso descreve o processo de geração do pedido } \\
\text { formal de irradiação de produto referente à uma solicitação de } \\
\text { geração de Ordem de Serviço }\end{array}$ \\
\hline Pré-condições & $\begin{array}{l}\text { Receber solicitação de geração de Ordem de Serviço que pode } \\
\text { ser para atender um orçamento de cliente ou pedido de testes de } \\
\text { produto novo ou produto de pesquisa. }\end{array}$ \\
\hline Pós-condições & $\begin{array}{l}\text { Ordem de Serviço armazenada no sistema aguardando o } \\
\text { prazo da FP para iniciar serviço }\end{array}$ \\
\hline Prioridade & Alta \\
\hline Freqüência de Uso & Alta \\
\hline \multicolumn{2}{|r|}{ Fluxo Básico de Eventos } \\
\hline Ação do Ator & Resposta do Sistema \\
\hline $\begin{array}{l}1 \text { - Cliente acessa tela WEB com } \\
\text { login/senha de usuário }\end{array}$ & 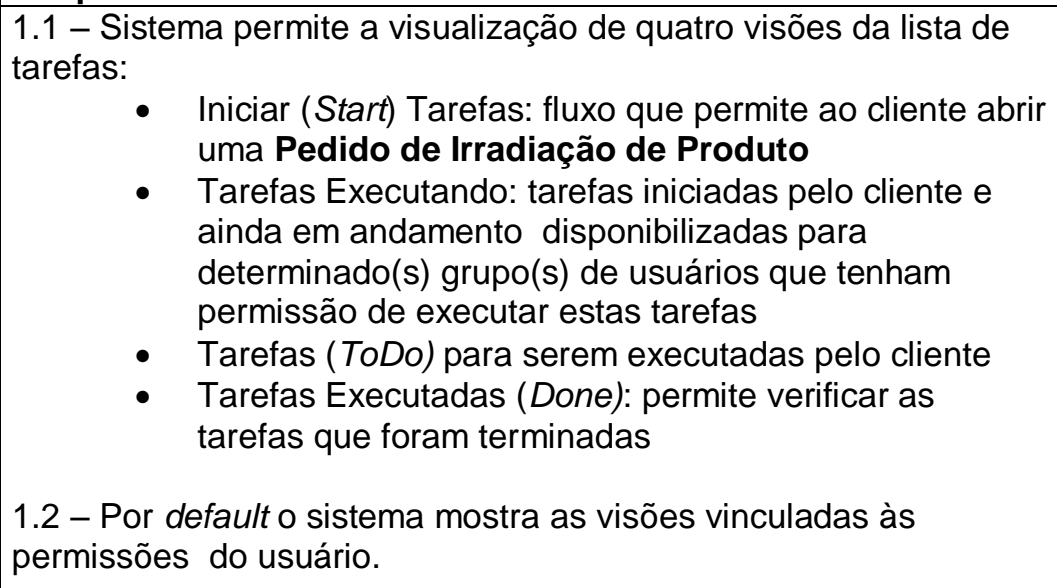 \\
\hline $\begin{array}{l}2 \text { - Cliente formaliza o Pedido de } \\
\text { Irradiação de Produto }\end{array}$ & \begin{tabular}{|l} 
2.1 - O sistema exibe um formulário para Registrar o Pedido de \\
Irradiação de Produto: \\
1. Dados do cliente \\
Nome \\
Responsável \\
Identificação do Cliente \\
Telefone \\
Fax \\
E-mail \\
Número do Pedido do Cliente \\
Número do Nosso Orçamento \\
2. Descrição do Produto \\
Produto Novo \\
Produto já Processado
\end{tabular} \\
\hline
\end{tabular}




\begin{tabular}{|c|c|}
\hline & $\begin{array}{l}\text { Características ou aplicação } \\
\text { Material } \\
\text { Volume/Peso } \\
\text { Número de Embalados } \\
\text { Identificação do(s) lote(s) de fabricação do cliente } \\
\text { Observação } \\
\text { 3. Dose Requerida pelo Cliente } \\
\text { Dose Mínima kGy } \\
\text { Dose Máxima kGy }\end{array}$ \\
\hline $\begin{array}{l}3 \text { - Comercial visualiza o } \\
\text { formulário de Pedido de Irradiação } \\
\text { e registra a Ordem de Serviço, } \\
\text { realiza a conferência junto ao } \\
\text { Cliente, identifica alguma } \\
\text { pendência e clica em "Registrar } \\
\text { OS" }\end{array}$ & $\begin{array}{l}\text { 3.1 - O sistema exibe um formulário para Cadastrar a Ordem de } \\
\text { Serviço (OS): } \\
\text { - } \text { Número da OS } \\
\text { 1. Dados do cliente } \\
\text { Nome } \\
\text { Responsável } \\
\text { Identificação do Cliente } \\
\text { Telefone } \\
\text { Fax } \\
\text { E-mail } \\
\text { Número do Pedido do Cliente } \\
\text { Número do Nosso Orçamento } \\
\text { 2. Descrição do Produto } \\
\text { Produto Novo } \\
\text { Produto já Processado } \\
\text { Características ou aplicação } \\
\text { Material } \\
\text { Volume/Peso } \\
\text { Número de Embalados } \\
\text { Identificação do(s) lote(s) de fabricação do cliente } \\
\text { Observação } \\
\text { 3. Dose Requerida pelo Cliente } \\
\text { Dose Mínima kGy } \\
\text { Dose Máxima kGy }\end{array}$ \\
\hline $\begin{array}{l}4 \text { - Gerente da Planta recupera } \\
\text { Instrução de Irradiação e examina } \\
\text { se correspondente ao produto a } \\
\text { ser irradiado }\end{array}$ & 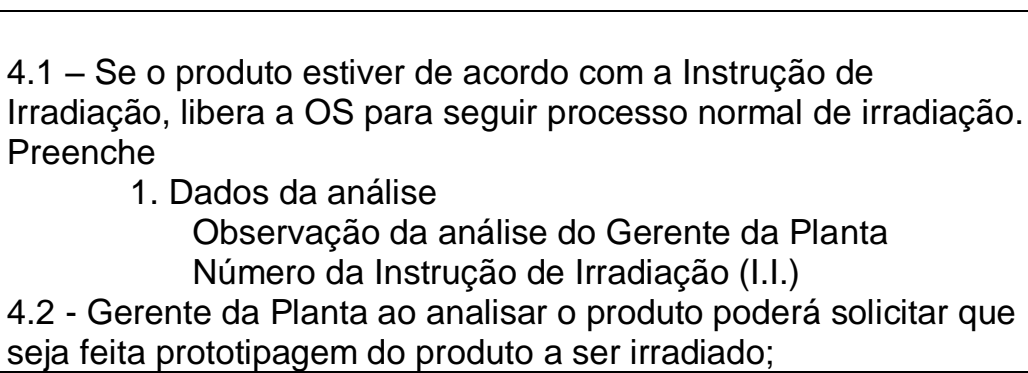 \\
\hline $\begin{array}{l}5 \text { - Setor de Produção recebe a } \\
\text { OS e prepara a irradiação }\end{array}$ & $\begin{array}{l}\text { 5.1 - Setor de Produção emite a Folha de Programação(FP) } \\
\text { 1. Dados da programação } \\
\text { Número da Folha de Programação } \\
\text { Semana } \\
\text { Data do processamento } \\
\text { Número da OS } \\
\text { Número de paletes/caixa de irradiação } \\
\text { Número de carriers } \\
\text { Local de armazenagem inicial } \\
\text { Local de armazenagem final } \\
\text { Data/Hora início } \\
\text { Data/Hora Término } \\
\text { Dose Média } \\
\text { Números de passagens } \\
\text { Troca de fase }\end{array}$ \\
\hline
\end{tabular}




\begin{tabular}{|c|c|}
\hline & \begin{tabular}{|l} 
Racks de fontes expostos \\
Time Set \\
Número Instrução de Irradiação \\
5.2 - Informa Setor Comercial e o Cliente sobre a programação de \\
irradiação
\end{tabular} \\
\hline $\begin{array}{l}\text { 6. Setor Comercial fica ciente da } \\
\text { programação de irradiação }\end{array}$ & $\begin{array}{l}6.1 \text { - Fluxo fica parado até a chegada da data programada para a } \\
\text { irradiação do produto. }\end{array}$ \\
\hline $\begin{array}{l}\text { 7. Cliente na data programada } \\
\text { envia o produto para ser irradiado }\end{array}$ & $\begin{array}{l}\text { 7. - Cliente preenche a expedição do material irradiação com a } \\
\text { respectiva Nota Fiscal de Remessa: } \\
\text { Dados da remessas } \\
\text { Número da Nota Fiscal } \\
\text { Data da NF } \\
\text { Quantidade material (embalados) } \\
\text { Peso } \\
\text { Volume do material } \\
\text { Número de Lote do material } \\
\text { Número de paletes }\end{array}$ \\
\hline $\begin{array}{l}\text { 8. Setor de produção recebe } 0 \\
\text { material }\end{array}$ & $\begin{array}{l}\text { 8.1 - Setor de Produção recebe o material para irradiação com a } \\
\text { respectiva Nota Fiscal de Remessa } \\
8.2 \text { - Se não estiver conforme a OS, o Setor Comercial é } \\
\text { informado. }\end{array}$ \\
\hline $\begin{array}{l}\text { 9. Setor de Produção prepara o } \\
\text { material para irradiação }\end{array}$ & $\begin{array}{l}\text { 9.1 - Preparar o material embalando-o de acordo com a I.I. } \\
\text { 9.2 - Armazenar temporariamente no local de acordo com a } \\
\text { programação da FP } \\
\text { 9.3 - Identificar o material com código de barras ou RFID } \\
\text { relacionando-os com a OS e os paletes; } \\
\text { 9.4 - Preencher a OS com os dados referentes ao processamento: } \\
\text { 1. Dados do processamento } \\
\text { Número da Folha de Programação } \\
\text { Local Inicial de armazenamento } \\
\text { Local Final de armazenamento } \\
\text { 2. Recebimento de Produto e Identificação } \\
\text { Número da Nota Fiscal } \\
\text { Número de Embalados } \\
\text { Data do Recebimento } \\
\text { 3. Identificação dos produtos, paletes } \\
\text { Número do RFID do palete } \\
\text { Código de barras de cada produto no palete } \\
\text { 9.5 - Cada lote de processamento dará origem a um subprocesso } \\
\text { de controle }\end{array}$ \\
\hline $\begin{array}{l}\text { 10. Setor de Garantia da } \\
\text { Qualidade Faz a inspeção do } \\
\text { material, embalados e paletes }\end{array}$ & $\begin{array}{l}\text { 10.1 - Após inspeção dos produtos, embalados e identificação, } \\
\text { são colocados dosímetros e indicadores de doses } \\
10.2 \text { - Liberar material para o processo de irradiação }\end{array}$ \\
\hline 11. Processamento do Produto & $\begin{array}{l}\text { 11.1 - Processar material no irradiador. } \\
11.2 \text { - Preenche a Programação e Registro de Carregamento do } \\
\text { Irradiador (RC): } \\
\text { Número do Registro de Carregamento } \\
\text { Configuração de Fontes } \\
\text { Número do Carrier Inicial } \\
\text { Número do Carrier Final } \\
\text { Quantidade de Caixas/Carrier } \\
\text { Data e Hora Carregamento Inicial } \\
\text { Data e Hora Carregamento Finalização } \\
\text { Data e Hora Descarga Inicial } \\
\text { Data e Hora Descarga Final } \\
\text { Rack expostos } \\
\text { Número do Registro de Carregamento } \\
\text { Data e Hora do Processamento }\end{array}$ \\
\hline
\end{tabular}




\begin{tabular}{|c|c|}
\hline & $\begin{array}{l}11.4 \text { - Acompanha o processamento de cada lote } \\
\text { (subprocesso)para fechar a OS. } \\
\text { 11.6 - Armazena os produtos no local irradiados definida no I.I. } \\
\text { Aguardando a liberação da Garantia da Qualidade }\end{array}$ \\
\hline $\begin{array}{l}\text { 12. Setor Garantia da Qualidade } \\
\text { inspeciona os produtos após a } \\
\text { irradiação }\end{array}$ & $\begin{array}{l}\text { 12.1 - Inspecionar os produtos após a irradiação } \\
\text { 12.2 - Inspeciona indicadores de doses e dosímetros } \\
\text { 12.3 - Não estando aprovado, emitir o Relatório de Não } \\
\text { Conformidade (RN) } \\
\text { 12.4 - Estando tudo conforme, emitir o Certificado de Irradiação } \\
\text { 12.5 - Registrar o número do Cl na OS } \\
\text { 12.6 - Enviar OS para setor Contabilidade para emitir a Nota } \\
\text { Fiscal de Remessa e o documento de Faturamento }\end{array}$ \\
\hline $\begin{array}{l}\text { 13. Setor de Contabilidade emitir } \\
\text { documento fiscal }\end{array}$ & $\begin{array}{l}\text { 13.1 - Emitir a Nota Fiscal de Remessa e documento de } \\
\text { faturamento; } \\
\text { 13.2 - Registrar o número da Nota fiscal na OS } \\
\text { 13.3 - Enviar documentos para o Setor de Produção expedir o } \\
\text { material }\end{array}$ \\
\hline $\begin{array}{l}\text { 14. Setor de Produção prepara o } \\
\text { material para expedição }\end{array}$ & $\begin{array}{l}\text { 14.1 - Setor de Produção recebe documentos para expedição do } \\
\text { material; } \\
\text { 14.2 - Enviar OS para Setor de Garantia de Qualidade }\end{array}$ \\
\hline $\begin{array}{l}\text { 15. Setor de Garantia de } \\
\text { Qualidade examina processo de } \\
\text { expedição }\end{array}$ & $\begin{array}{l}15.1 \text { - Setor de Garantia da Qualidade examina procedimentos de } \\
\text { expedição e encerra OS. }\end{array}$ \\
\hline \multicolumn{2}{|c|}{ Fluxo Alternativo de Eventos: Trocar material para prototipagem } \\
\hline Ação do Ator & Resposta do Sistema \\
\hline $\begin{array}{l}1 \text { - Ao final do passo } 6 \text {, o Setor de } \\
\text { Produção poderá solicitar ao } \\
\text { Cliente trocar o material ou } \\
\text { prototipar o material }\end{array}$ & $\begin{array}{l}\text { 1-Solicitar do Cliente a troca de material para irradiação } \\
\text { 2- Se for o caso, encerrar a OS e abrir nova OS para prototipagem }\end{array}$ \\
\hline $\begin{array}{l}\text { 2. Ao final do passo } 11, \text { o Setor de } \\
\text { Produção poderá encerrar lotes } \\
\text { parciais de processamento }\end{array}$ & $\begin{array}{l}\text { 2.1 - Setor de Garantia de Qualidade poderá solicitar a emissão de } \\
\text { Nota Fiscal de Remessa para o lote. } \\
\text { 2.2 - Emitir o Certificado de Irradiação parcial para o produto } \\
\text { 2.3 - Faz a expedição parcial do produto } \\
\text { 2.4 - A OS somente é encerrada quando todos os lotes forem } \\
\text { encerrados }\end{array}$ \\
\hline
\end{tabular}

\subsubsection{Modelos de formulários, etiquetas e relatórios}

Faz parte da documentação do projeto a proposição de modelos de formulários, etiquetas ou relatórios com finalidade de dimensionar impressoras e leitores de código de barras.

\subsubsection{Fase de Formatação e Desenvolvimento}

Esta fase da metodologia detalha as informações coletas na fase anterior. O projetista define todos os processos que foram identificados tanto para seguimento dos produtos no irradiador, quanto dos processos necessários em manter o sistema, principalmente, cadastros.

A preocupação do projetista é detalhar ("estressar") ao máximo cada etapa do processo. O principal documento dessa fase é a Especificação Técnica. 
Com essa documentação os desenvolvedores conseguem construir e desenvolver o sistemas.

Uma fase importante nesse processo é a elaboração da base de dados que reflete as ações dos processos. Além da base de dados dos softwares Bonita e Jonas, a aplicação TPI tem a sua própria para a persistência dos dados dos processos.

Os assuntos tratados na Especificação Técnica são agrupados da seguinte maneira:

\subsubsection{Descrição da Solução em Vigor}

São descritos de que maneira o serviço era conduzido, ou seja:

1. O serviço de irradiação de produtos no irradiador gama objeto desse projeto era feito manualmente;

2. Todos os documentos eram informais e não possuíam controle efetivo de prazos para o processamento nem priorização de serviços.

3. Os produtos não eram agrupados em lotes ou submetidos à irradiação sob uma ordem de serviço formal.

\subsubsection{Requisitos da Solução Proposta}

A fase de requisitos da solução proposta contempla vários aspectos da vida do sistema ora construído, tais como:

- Requisitos Funcionais: contempla todas as funcionalidades que 0 sistema deverá ter;

- Requisitos de Interface de Sistema: são tratadas as interfaces que o sistema fará com outros sistemas. O TPI por ora não irá interfacear (trocar informação) com outros sistemas;

- Requisitos de Interface de Usuário: são apresentadas as telas que o usuário irá receber quando estiver frente ao sistema;

- Requisitos Operacionais: são consideradas as características de operação do sistema, tais como: modo de operação, rotinas de backups, etc. 
- Requisitos de Desempenho e Confiabilidade: são definidos parâmetros de confiabilidade do sistema, arquivamentos históricos;

- Requisitos de Infra-estrutura: são descritas as instalações do ambiente no qual o sistema será operado;

- Requisitos de Segurança: são descritos os requisitos de confidencialidade, disponibilidade de informações, integridade, condições de proteção contra intrusos, alteração de dados ou de instalação

\subsubsection{Requisitos de Interface do Usuário}

O sistema foi desenvolvido com filosofia de fluxo de processos. A ferramenta escolhida foi o software Bonita por ser livre de licença.

O aplicativo é acessado como página WEB através da URL HTTP://localhost:8080/portal, quando executado no servidor, ou, WWW.cobalto60.net.br quando acessado remotamente. Os sistemas operacionais que suportam a aplicação são Windows, Linux ou Unix. Requer um servidor de aplicação. O Bonita foi desenhado para ser executado nos servidores aplicação Jonas (como nativo) ou JBoss.

Todo usuário receberá a mesma página para se "logar" no sistema. O próprio sistema Bonita gerencia os usuários e senhas.

Para esse projeto os relacionamentos possíveis são: o usuário pertencer a um Cliente específico (Empresa) ou pertencer a algum grupo interno do IPEN: Comercial, Produção, Gerente de Planta, Qualidade ou Contabilidade

O administrador também tem outras tarefas. Os fluxos ou processos quer sejam novos ou modificação destes, o administrador através da funcionalidade BPM Management faz a instalação (deploy) dos fluxos de processos.

\subsubsection{Arquitetura Tecnológica do Projeto}

Os aspectos tecnológicos desenvolvidos para esse projeto são bem simples, porém, fundamentais para o bom desempenho do sistema. Baseia-se no apontamento do local no qual está localizado certo material e qual fase o mesmo 
se encontra. Quer esteja armazenado em determinada área, ou, esteja acomodado em alguma caixa de irradiação, palete ou posição do irradiador.

\subsection{Irradiador Multipropósito do IPEN}

O desenvolvimento do sistema para controle e aquisição de dados de processo de irradiação em irradiadores de grande porte, foi realizado utilizando-se como modelo o Irradiador Compacto Multipropósito do IPEN. Este tem as seguintes características descritas por CALVO (2005):

- Capacidade total licenciada pela CNEN é de $37 \mathrm{PBq}(1 \mathrm{MCi})$, categoria IV; atividade inicial de operação 3.407,7 TBq $(92.099$ Ci, em 16/11/04);

- Piscina com 7,0 m de profundidade e 2,7 m de diâmetro;

- Portas de concreto, sendo uma deslizante, para montagem e manutenção da instalação, com 4,0 m (comprimento) por 4,0 m (altura) e 2,45 m (largura), e uma porta giratória, para entrada e saída dos produtos na câmara de irradiação, com 2,65m (diâmetro) por 4,0 m (altura); possui paredes de concreto $1,80 \mathrm{~m}$ de espessura (densidade 2,35 $\mathrm{g} / \mathrm{cm}^{3}$ );

- As fontes são condicionadas em dois racks de fontes retangulares com capacidade para oito magazines por rack, num total de 504 lápis de ${ }^{60} \mathrm{Co}$; a geometria de irradiação é do tipo product overlap source;

- O sistema de transporte é do tipo tote box, contínuo, duplo empilhamento de caixas, sendo que cada nível de caixa com os produtos movimenta-se na mesma direção (horizontal), mas em sentido contrário; a câmara de irradiação tem capacidade para irradiar quatorze caixas, aproximadamente $6,47 \mathrm{~m}^{3}$;

- Produtos: materiais médicos, cirúrgicos e biológicos; alimentos e matérias-primas para as indústrias de alimentos, produtos farmacêuticos e cosméticos, entre outros. 


\subsection{Interface de aquisição de dados}

A aquisição dos dados do processo de irradiação é realizada obtendose informações referentes aos dados do irradiador, seu estado e dos produtos. A interface de aquisição dos dados do irradiador foi desenvolvida utilizando-se a própria infra-estrutura eletrônica do CTR. Esta última se caracteriza por informar se as fontes se encontram expostas durante todo ciclo no qual o produto foi submetido à irradiação e que o produto ocupou todas as posições de irradiação estabelecidas pelo sistema de transporte. Se ocorrer a queda da fonte durante a irradiação o tempo de irradiação será interrompido. O somatório de todos os tempos de "fonte em cima" dará o tempo total de irradiação.

A FIG.3.4 ilustra o irradiador Compacto Multipropósito do IPEN. O desenho esquemático do irradiador (superior à direita da figura) mostra as caixas no transportador; a porta giratória que a cada passo introduz, pela parte superior, uma caixa na câmara de irradiação, retirando outra pela parte inferior. Também no mesmo desenho, observa-se a posição das fontes quando expostas e as caixas passando ao seu redor. $\mathrm{Na}$ foto superior esquerda, observa-se o operador posicionando uma caixa na esteira superior com o auxílio de uma paleteira.

Ainda na FIG.3.4, nas duas fotos inferiores, observa-se o momento em que é introduzida uma caixa de irradiação pela parte superior do transportador (foto inferior à esquerda) e no momento seguinte, uma caixa é extraída do irradiador na parte inferior (foto inferior à direita).

Na FIG.3.4 estão representados os pontos de coleta dos leitores fixos de código de barras das caixas de irradiação entrando no irradiador e saindo do irradiador. 


\section{Irradiador Compacto Multipropósito do IPEN}

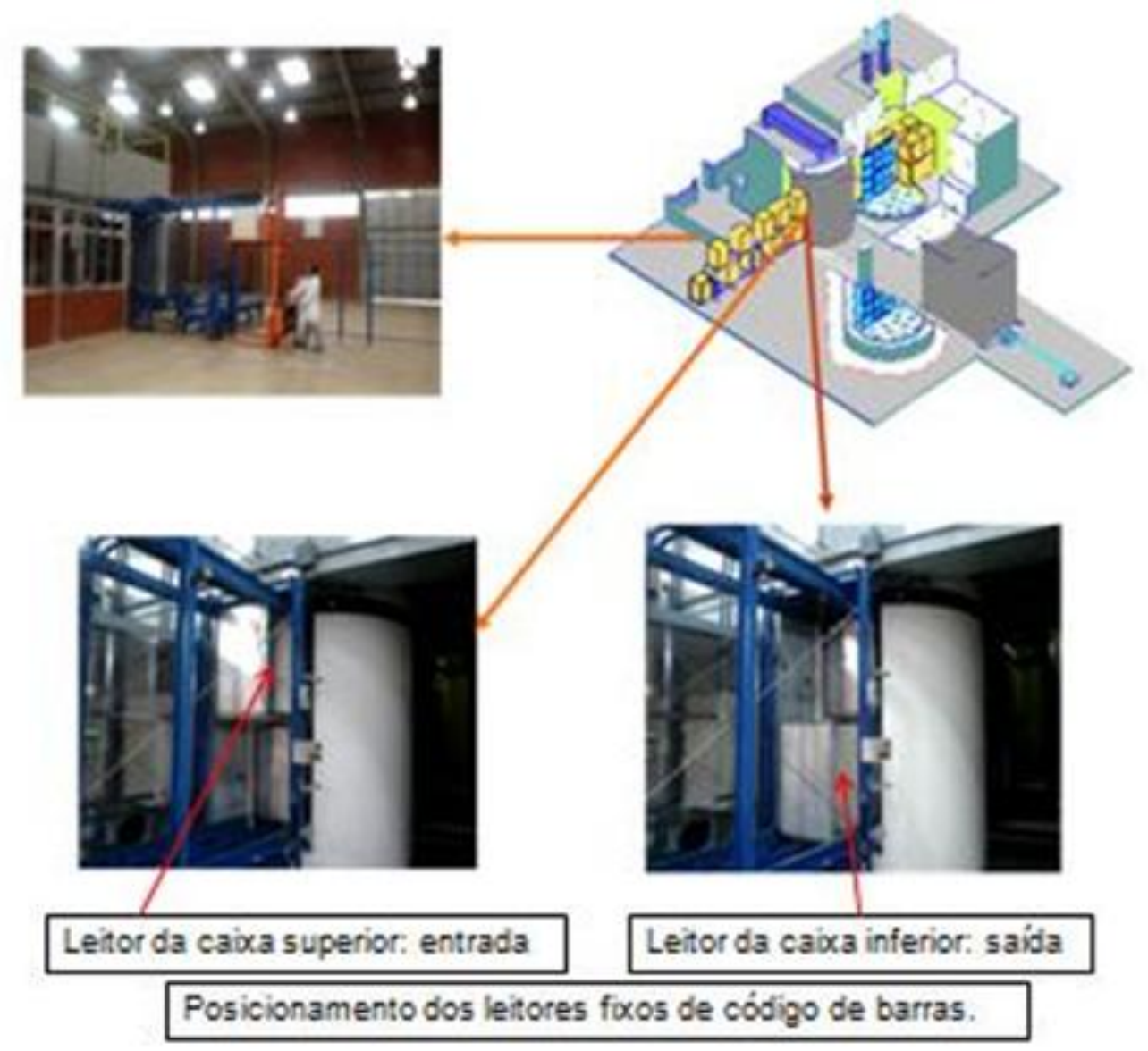

FIGURA 3.4 - Irradiador Compacto Multipropósito do IPEN. (Fotos: Paulo Roberto Rela).

Pela FIG.3.4 a posição dos dois leitores fixos de código de barras, um para entrada e o outro para saída da caixa garante que, quando a caixa foi identificada entrando no irradiador, com as fontes expostas, e esta percorreu todas as posições internas ao redor das fontes, quando esta caixa for identificada na porta de saída, os produtos no interior da caixa foram irradiados.

A leitura do posicionamento das fontes: "em cima" ou "embaixo" são realizadas nos contatos (NF normalmente fechado) do sistema de controle de posicionamento das fontes que ficam dentro da sala de controle do irradiador. A sala de controle esta à esquerda na figura superior da FIG.3.4. 


\section{RESULTADOS E DISCUSSÃO}

Um dos objetivos do sistema é a emissão do Certificado de Irradiação no final do processo como requisito de GMP.

Esse certificado contém as principais informações sobre o cliente e o produto. Também contém as evidências de irradiação, ou seja, são listados os itens de produto nos quais foram agregados dosímetros quer seja diretamente ou indiretamente através colocação nas caixas de irradiação.

A FIG.4.1 mostra a imagem de um Certificado de Irradiação. O Certificado de Irradiação é o documento que oficializa o processamento do produto no irradiador gama. Este certificado é elaborado segundo a necessidade de cada cliente, podendo ter mais ou menos informações. Nele estão presentes as informações do Cliente, do Pedido do Cliente, as Doses Máximas e Mínimas que os produtos receberam. No final o responsável pelo irradiador assina o mesmo.

De forma concentradas estão as informações sobre:

- Ordem de Serviço e o Lote de processamento;

- Quantidade de itens do lote;

- O número de ordem do lote na ordem de serviço;

- O tempo total de irradiação dos produtos. Esse tempo é contado somente para o tempo das fontes expostas ("em cima");

- Doses mínima e máxima em kGy que os produtos do lote receberam.

- Dosímetro utilizado (tipo e lote)

Como evidências das medidas das doses absorvidas pelos produtos estão listados os itens de lotes que diretamente receberam dosímetros ou também, estavam dentro de caixas que receberam dosímetros para medição da dose absorvida.. Para os itens de lote estão mostrados:

- O código de barras gerado para o item no momento que o produto foi recebido para a irradiação. Esse código de barras é composto de:

○ 8 - identifica que o código é de item de lote; 
- NNNNNN - número da ordem de serviço;

- NNNNNN - número do lote

- NNN - numero de ordem do item dentro do lote

- Ordem: número de ordem do item no lote. É o mesmo número dos três últimos dígitos do código de barras do item de lote;

- Passagens: número de passagens que o item de lote foi submetido ao irradiador até atingir a dosagem estabelecida na Instrução de Irradiação;

- CodBarCliente: código de barras do item de lote do cliente. Normalmente esse código é único para código de barras EAN. Ou seja, para produtos iguais o código de comercialização registrado para o mesmo é único. 


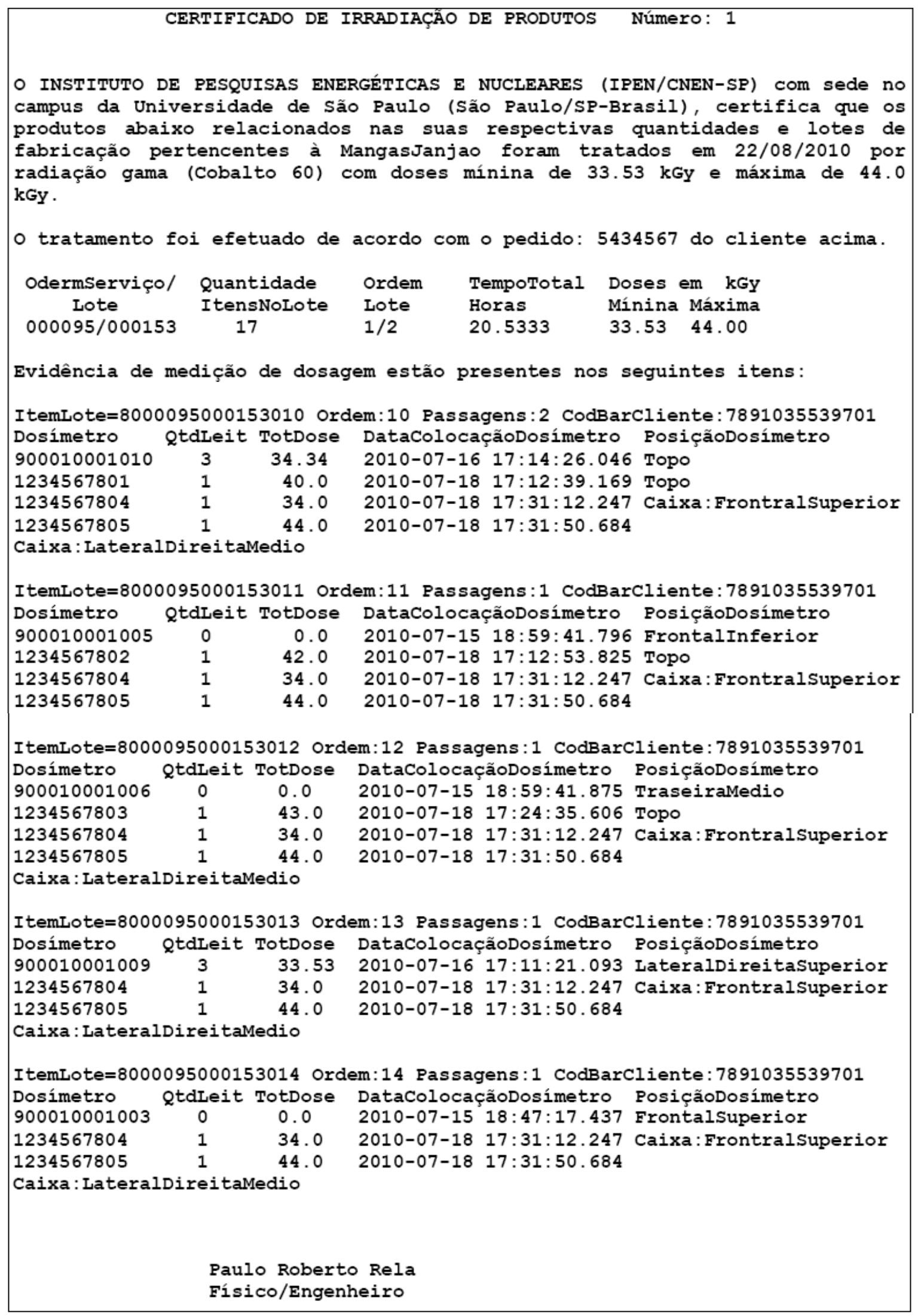

FIGURA 4.1 - Imagem do Certificado de Irradiação de produtos. 
Quanto aos dosímetros que foram utilizados para medir as doses recebidas pelos produtos são listadas:

- Dosímetro: código de barras do dosímetro que pode ser gerado no momento do cadastramento do dosímetro ou o dosímetro já possuir o seu próprio código gerado pelo fabricante;

- QtdLeit: quantidade de leitura que foram efetuadas para o dosímetro;

- TotDose: total de dose absorvida pelo dosímetro. As doses são cumulativas, portanto, o operador faz as medições das doses recebidas e certifica que a mesma está dentro dos parâmetros de doses contratados pelo cliente e presentes na Instrução de Irradiação. Esse valor é verificado pelo sistema TPI toda vez que um produto é enviado ao irradiador. Se o valor está prestes a superar a dose máxima o sistema alerta o operador do fato para não submeter o produto a uma "over dose". Esse valor também é verificado se no momento de liberação do produto o sistema verificar que ainda não foi atingida a dose mínima;

- DataColocaçãoDosímetro: data e hora em que o dosímetro foi colocado no tracking;

- PosiçãoDosímetro: posição de colocação do dosímetro no item de produto quanto na caixa de irradiação de acordo com a prescrição da Instrução de Irradiação.

Os dados contidos no Certificado de Irradiação são ilustrativos. O mesmo pode conter outros dados que estão armazenados na base de dados do sistema. Pode-se emitir relatório extremamente detalhado no qual conste cada atividade executada e os passos internos do sistema. Bem como, cada atividade que os participantes executaram.

\subsubsection{Fluxo Geral das Atividades do TPI}

O fluxo geral das atividades do Sistema TPI reúne todos os participantes (atores). A FIG.4.2 mostra o fluxo geral do TPI com suas 25 etapas 


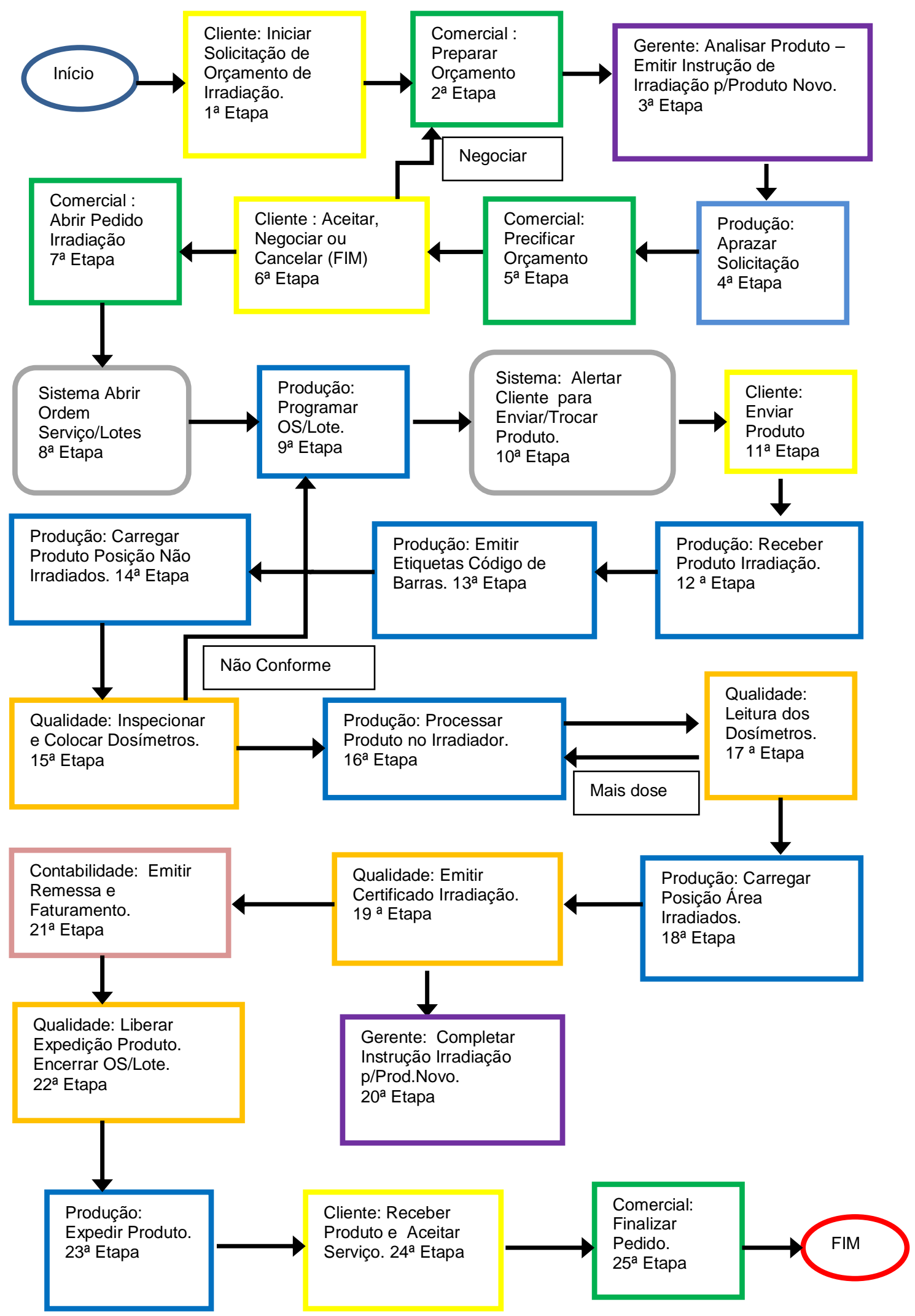

FIGURA 4.2 - Fluxo Geral das Atividades do TPI. 
As cores dos blocos presentes na FIG.4.2 têm a seguinte associação:

- Amarela: atividades do Cliente;

- Verde: atividades do Comercial;

- Lilás: atividades do Gerente a Planta;

- Azul: atividades da Produção;

- Ocre: atividades da Qualidade;

- Salmão: atividades da Contabilidade;

- Cinza: atividades automáticas do Sistema.

A FIG.4.2 mostra o fluxo geral do TPI. O processo mapeado é "SolicitarOrcamento" iniciado pelo Cliente (cliente é qualquer empresa, departamento, aluno, etc. que foi cadastrado como tendo o perfil Cliente). Cabe explicar a transição alternativa que ocorre em algumas etapas:

- $3^{a}$ Etapa: O Gerente da Planta ao analisar o Orçamento verifica se o produto já foi irradiado anteriormente ou se é Produto Novo. Um Produto Novo é aquele que tem características diferentes de um Produto já Processado. Ele informa o código da Instrução de Irradiação para o produto conhecido. Se for Produto Novo ele emite uma nova Instrução de Irradiação para o produto utilizando o processo EmitirInstruçãolrradiacao;

- 6a Etapa: O Cliente recebe o Orçamento e pode optar por aprová-lo, rejeitá-lo ou renegociá-lo. Se a opção for por renegociar, o Comercial reinicia o ciclo de consultas aos outros atores do processo. Se a decisão for pela aceitação é aberto pedido de irradiação;

- 7a Etapa: O Comercial faz abertura de Pedido de Irradiação. Essa etapa faz com que o fluxo do Orçamento inicie o subprocesso Pedido de Irradiação. Os fluxos escritos na linguagem XPDL estão nos Apêndices A1 e A2;

- 15a Etapa: na recepção do material, a Qualidade poderá reprovar algum produto. Neste caso, é solicitado ao Cliente a troca do produto. Por conseqüência, o lote deverá ser reprogramado pela Produção; 


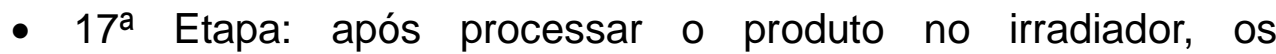
dosímetros são medidos pela Qualidade. Se a dose absorvida não estiver dentro dos limites mínimos e máximos contratados é feita nova passagem pelo irradiador;

- 19 Etapa: a Qualidade certifica que todas as etapas foram cumpridas e as doses foram atingidas. É emitido o Certificado de Irradiação, e se for Produto Novo, o Gerente da Planta completa a Instrução de Irradiação. 


\subsubsection{Fluxos do SIstema TPI}

O sistema TPI é composto de vários fluxos. O principal é SolicitarOrçamento (FIG.4.2) e outros são fluxos acessórios

- SolicitarOrcamento: Cliente: solicitar orçamento para seu produto com valores e datas para processamento. Detalhes deste fluxo podem ser vistos no Apêndice A1;

- Pedidolrradiacao: subprocesso que abre o Pedido de Irradiação (Apêndice A2);

- Emitirlnstrucaolrradiacao: Emissão da Instrução de Irradiação pelo Gerente da Planta (Apêndice B1);

- CadastrarDosimetro: Qualidade - cadastrar dosímetro (Apêndice C1);

- LeituraDosimetro: Qualidade - registrar leitura de dose do dosímetro (Apêndice C2);

- ConsultarDosimetro: Qualidade - consultar informações dos dosímetros (Apêndice C3);

- ColocarDosimetro: Qualidade - colocar dosímetro no material ou na caixa de irradiação (Apêndice C4);

- CarregarCaixa: Produção - carregar caixa de irradiação com material para irradiar (Apêndice D1);

- ConsultarCaixa: Produção - consultar itens da caixa de irradiação (Apêndice D2);

- CarregarPosIrradCont: Produção - carregar posição de irradiação do irradiador (carregar transportador contínuo) (Apêndice D3);

- CarregarPosTrack: Produção - carregar posição do track, que são: preparação, pátio não irradiados, câmara não irradiados, pátio irradiados, câmara irradiados, posição estática do irradiador (Apêndice D4);

- ConsultarLote: consulta dos dados gerais do lote de irradiação: posição, dosagens, quantidades, etc. (Apêndice D5) 
- EmitirEtiquetasCodBar: Produção - emissão de etiquetas de código de barras dos produtos tanto na recepção quanto na expedição dos produtos;

- EmitirCertificadoIrradiacao: Qualidade - emissão do Certificado de Irradiação que acompanha o produto após o serviço de irradiação;

- AtividadesCliente - Fluxo que documenta as etapas que o cliente percorre durante o ciclo de processo do produto.

\subsubsection{Processos do SIstema TPI}

A FIG.4.3 mostra a tela que o usuário recebe ao se "logar". O sistema divide a apresentação dos processos em duas páginas. Os processos são ordenados em ordem alfabética de nomes.

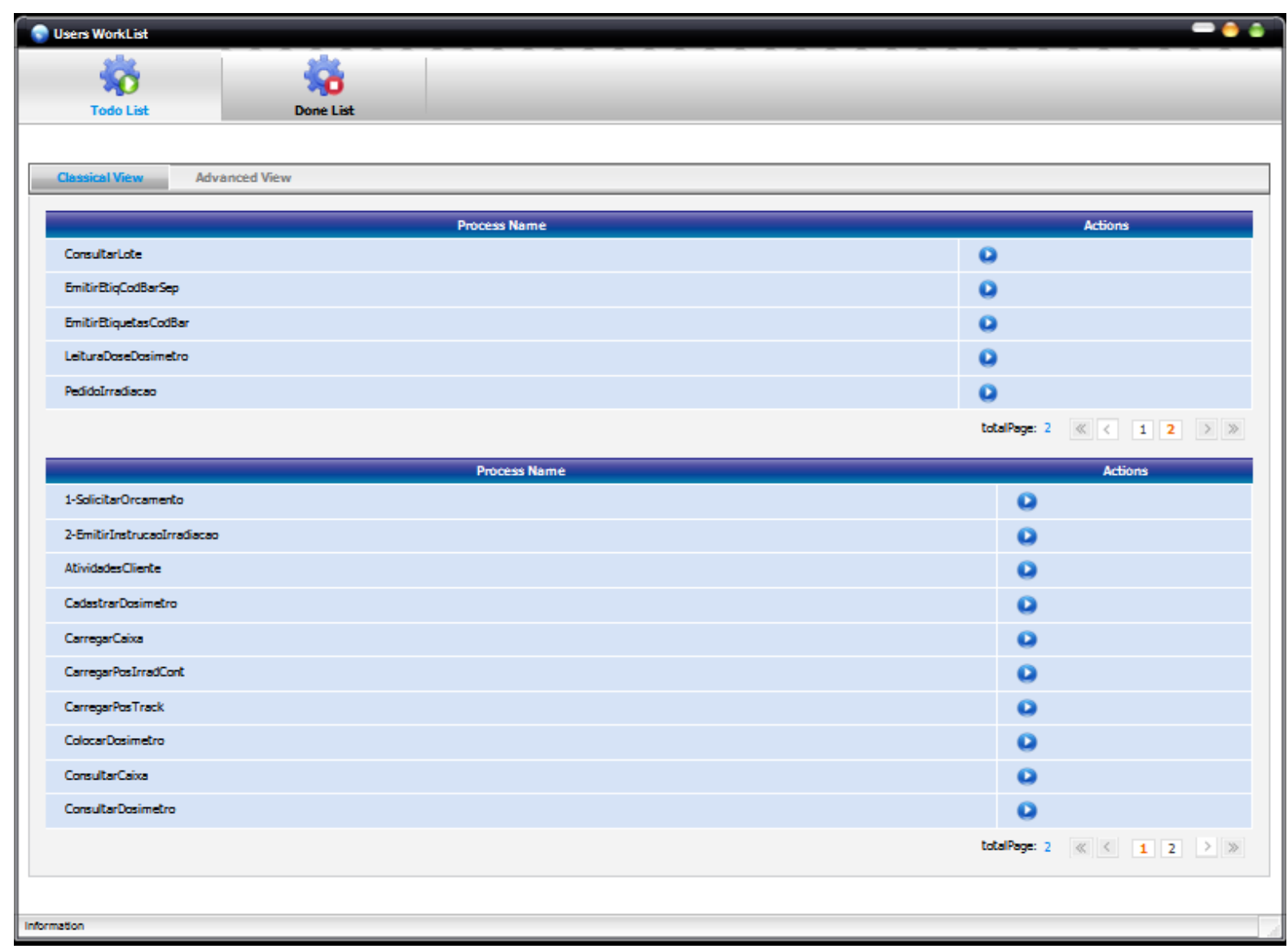

FIGURA 4.3 - Tela do Bonita com os processos do TPI disponíveis aos usuários (Apêndice E1 mostra a tela aumentada). 
Foi utilizado o artifício de inserir o dígito um "1-" no início do nome do processo "1-SolicitacaoOrcamento" para que o mesmo fosse o primeiro da lista. Caso contrário, o processo seria o último da página 2 , o que dificultaria sua localização.

Os processos são iniciados quando o usuário clicar no botão (seta) à direita da tela. Se o usuário pertencer ao grupo para o qual o processo foi designado este será iniciado.

No Apêndice A1 está mostrado a tela que o usuário do Cliente recebe ao iniciar o processo 1-SolicitarOrcamento. Ao todo o processo deve cumprir 25 etapas até que seja finalizado.

Uma das principais características do sistema de workflow Bonita está em controlar e manter processos de longa duração. Mesmo que o processo receba novas versões, os processos iniciados nas versões anteriores continuarão sendo mantidos e atualizados até seu final.

O processo Pedidolrradiação (Apêndice A2) não é iniciado diretamente pelo usuário. $O$ processo é inicializado como conseqüência da tramitação do processo 1-SolicitarOrcamento. O subprocesso Pedidolrradiação é iniciado por decisão do Comercial em escolher a opção de Pedido Firme. Opcionalmente o Comercial poderá RefazerOrçamento. Nesse caso o orçamento pode refazer o fluxo (FIG.4.3) a partir da segunda etapa.

\subsubsection{Rastreabilidade dos dados do SIstema TPI}

Uma característica essencial do sistema TPI é a rastreabilidade dos dados dos processos. Esse requisito é básico quando se trata das Boas Práticas de Fabricação. As normas e regulamentos exigem que todas as atividades dos processos com os produtos sejam documentadas e de fácil acesso e recuperação. Ou seja, os processos e seus dados sejam auditáveis.

\subsubsection{Modelos de dados do TPI}

O sistema TPI tem o propósito de fazer o seguimento (track) dos produtos submetidos ao serviço de irradiação. Faz parte da documentação do projeto a proposição de modelos de dados do processo. O objetivo é tanto 
armazenar as informações durante o processo quanto, posteriormente, a qualquer momento, a recuperação desses dados numa auditoria ou um estudo.

O modelo de dados apresentado na FIG.4.4 foi elaborado com apoio de ferramenta de UML. Estão representados as principais classes, atributos e seus relacionamentos. Não estão contemplados os métodos que são utilizados para acessar essas classes. Esses métodos fazem parte da construção dos processos. São métodos escritos na linguagem Java, e na definição do software Bonita, são denominados HOOK ("gancho").

A FIG.4.4 espelha o andamento dos processos. A classe principal é denominada ItemTrack. Nela estão relacionadas as informações do item de lote que está em processo, do item de dosímetro que por ventura o acompanha e. o local onde cada item está localizado.

O principal motivo de manter o modelo de dados apartado do sistema Bonita é a sua independência de plataforma. As interações com a base de dados está centrada na biblioteca tpiUtil. Esta biblioteca reúne os acessos à base de dados com as querys, inserts, updates e cancels no jargão de sistemas de denomina embeded, ou seja, os acessos estão construídos nos próprios métodos de acessos. Isso tem vantagens e desvantagens: vantagem pode-se migrar de plataforma de dados relacional sem se preocupar em recompilar store procedure (querys residentes na base de dados); desvantagem ser mais lenta a execução. 


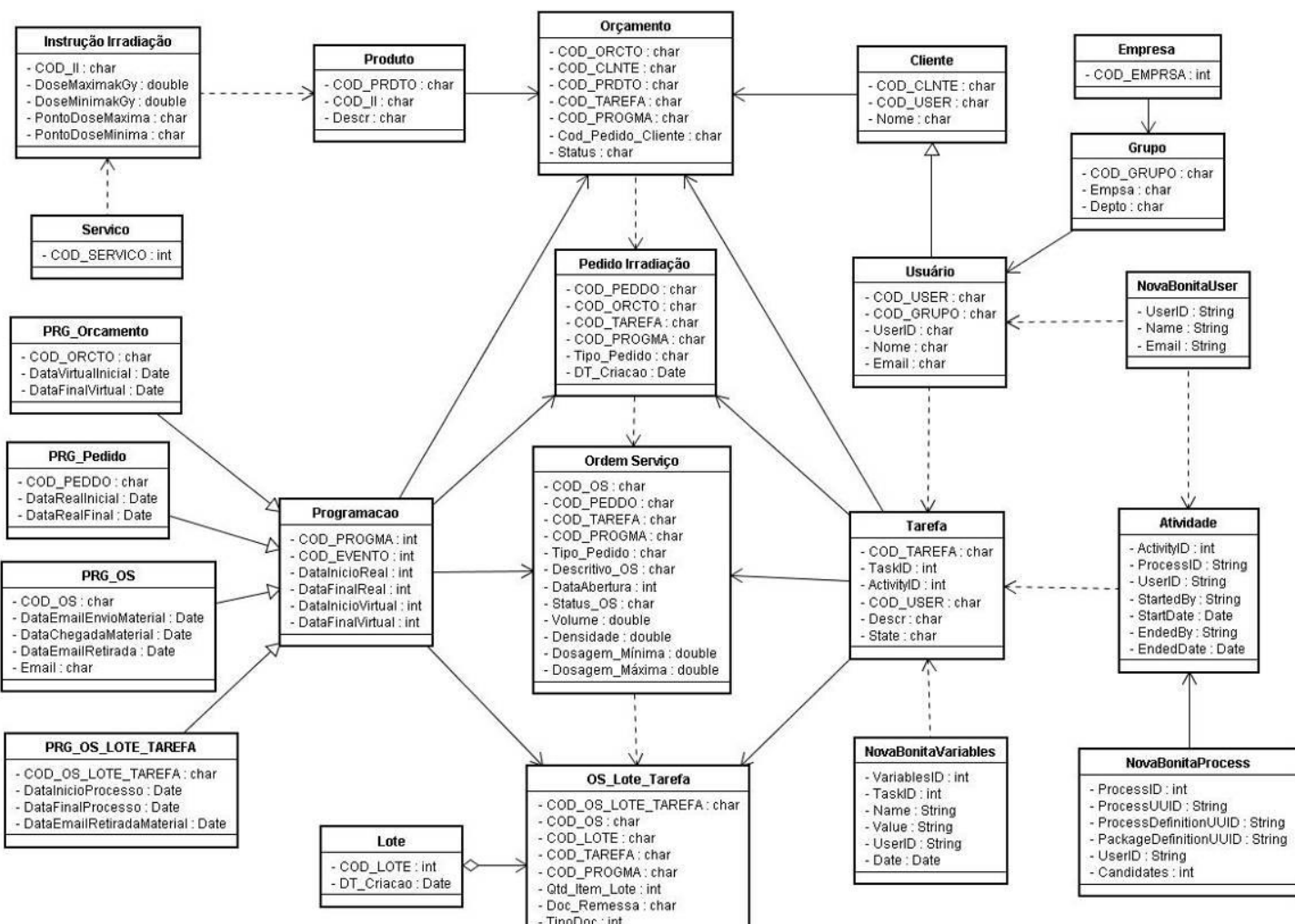

Status_lote : char
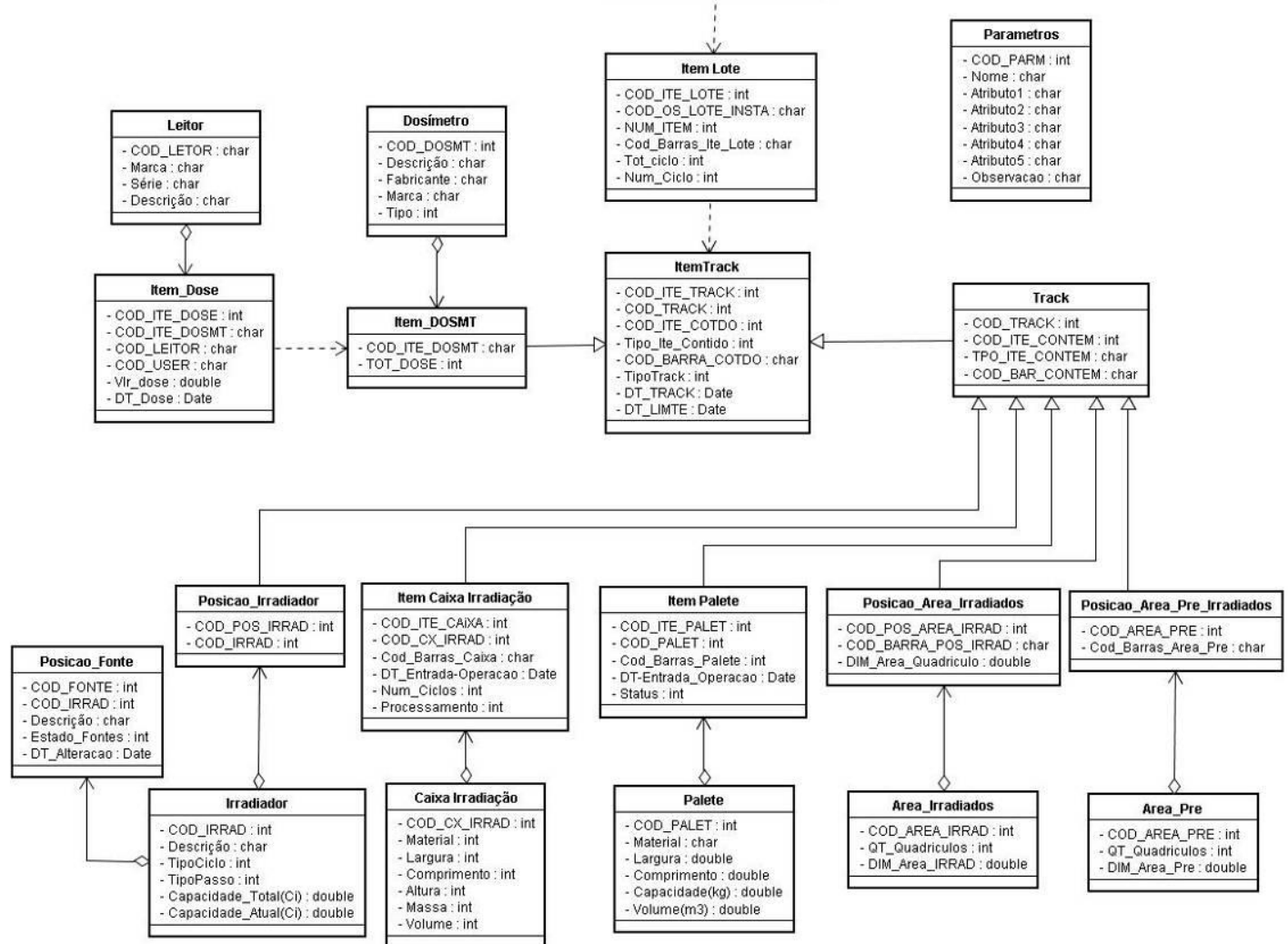

FIGURA 4.4 - Modelo de Dados do Projeto TPI (APÊNDICE F1- Modelo de Dados do Sistema TPI ampliado) . 


\subsection{A Classe Tarefa}

A classe Tarefa é fundamental no modelo e é definida para fazer o registro das tarefas iniciados no processo. Registra as informações passo-apasso quando vão acontecendo. Essa classe é essencial para uma auditoria mais apurada do processo.

Nela estão registrados:

- O usuário que iniciou e terminou a tarefa;

- Os valores de cada variável de tela e suas alterações;

- A sequência de execução: se o usuário alterou algum dado informado anteriormente; se ele reiniciou algum processo; etc.

- As datas em que cada atualização ocorreu.

\subsection{A Classe Item de Track}

A classe Track é definida para fazer o seguimento (tracking) de cada item de lote, caixa de irradiação, dosímetro, palete, áreas de armazenamento no ambiente do irradiador.

As diversas localizações ou situações de cada conjunto de locais ou armazenamentos estão relacionadas por essa classe Track.

A lógica de seguimento reside na associação "contém-contido". A qualquer tempo deve-se saber o que cada local contém:

- área de armazenamento;

- caixa de irradiação;

- palete;

- posição do irradiador e

- item de lote.

E onde cada item está contido:

- item de caixa de irradiação;

- item de palete;

- item de lote

- item de dosímetro.

Devem-se levar em conta que caixa de irradiação, palete e posição do irradiador são itens de transporte em constante atualização de status, local e 
conteúdo. Os relacionamentos dos itens ocorrem como se estivesse compondo os subconjuntos de um produto.

\subsection{Relacionamento do que contem o quê}

Os relacionamentos dos elementos que transitam pelo ambiente do irradiador com os componentes fixos ou de transportes seguem uma hierarquia lógica. Na FIG.4.5 estão presentes os relacionamentos possíveis de cada elemento. A saber:

- Áreas de armazenamento de Material Não Irradiado e Material Irradiado contêm item de lote, palete ou caixa de irradiação;

- Palete contém item de lote;

- Caixa de Irradiação contém item de lote e item de dosímetro.

- Posição de irradiação contém item de lote (processo manual de irradiação) ou caixa de irradiação (processo contínuo) com seus itens de lote e dosímetros;

- Item de lote contém item de dosímetro
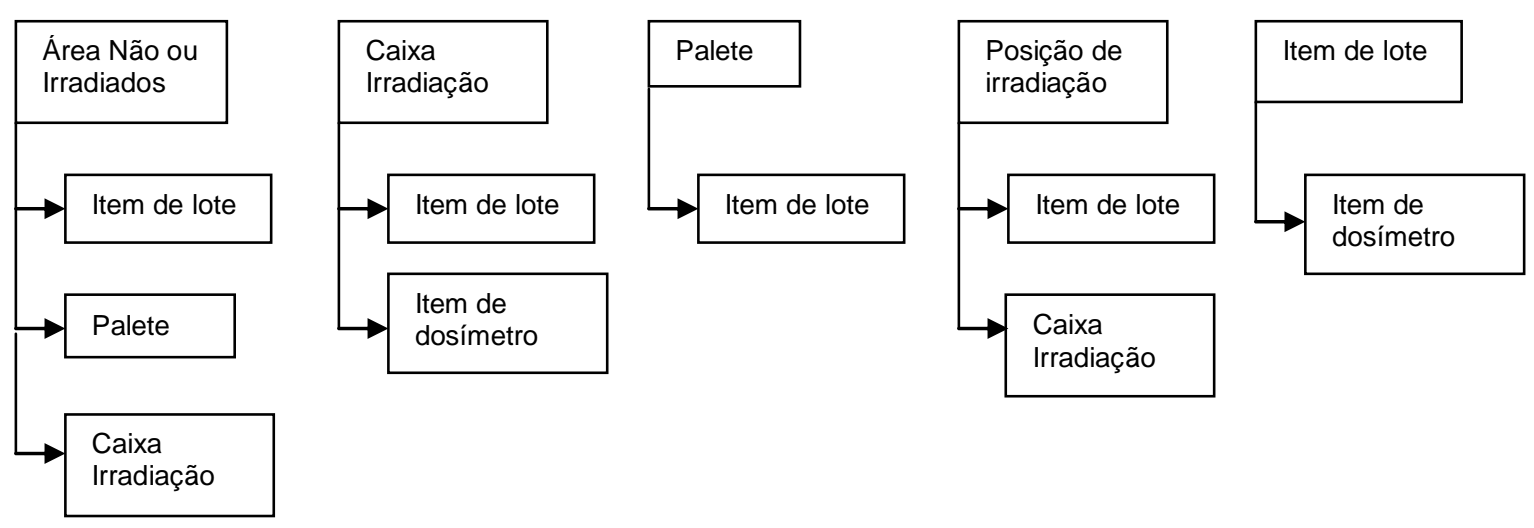

FIGURA 4.5 - Hierarquia de tracking ou relacionamento contém-contido.

A FIG.4.5 mostra um esquema no qual estão presentes os possíveis relacionamentos. 


\subsubsection{Plataforma de Desenvolvimento do Sistema TPI}

O Sistema TPI é desenvolvido seguindo o paradigma de orientação a objetos e open source (software de código aberto e livre de licença). Os softwares envolvidos nesse sistema também seguem essa orientação.

A plataforma nativa de desenvolvimento utilizado é a linguagem Java (jdk1.5.0_11) e a execução dos processos são realizados na máquina Java. Ou mais precisamente, Java ${ }^{\mathrm{TM}}$ Standard Edition Runtime Environment (versão jre6), própria para processos executados em browsers na WEB (internet).

O sistema de workflow adotado é o Bonita (versão 4.1.1) que tem como servidor de aplicação o JOnAS (Java on Aplication Server, versão 4.8.6) e Tomcat (versão 5.5.17) ou o servidor JBoss.

A base de dados adotada é H2 Database Engine (versão h2-1.2.134). Podem ser adotados os sistemas de base de dados Oracle, Postgresql, Mysql e outros.

A plataforma de programação dos processos é utilizado a IDE Eclipse (versão eclipse-jee-galileo3.5-win32) com plug-ins do Bonita e Proed.

Por ser o Java independente de plataforma o sistema TPI pode ser executado no Windows, Linux ou Unix (no Apple não foi testado). Também não foi testado como sistema embarcado em celulares ou palmtops. Ainda que esses dispositivos executem páginas da internet.

\subsubsection{Biblioteca TPIUTIL}

O sistema TPI para cumprir seu objetivo de proporcionar GMP ou GRP aos serviços de irradiação é desenvolvido tendo como compromisso independência de plataforma.

A concepção do TPI segue o paradigma de desenvolvimento em camadas de interface:

- Primeira camada de interfaceamento com o sistema de workflow utilizando as APIs definidas para esse fim;

- Segunda camada de interfaceamento com o sistema de armazenamento. 
A camada de interface com os processos do workflow são definidas pelo próprio sistema. O processo em si com as definições de variáveis, formulários e interfaces com ambiente do usuário (hooks). Os hooks são classes escritas em Java. São métodos que executam APIs do sistema para produzir efeitos nas informações que transitam nas tarefas e atividades dos processos.

A camada de acesso aos dados do sistema está agrupada na biblioteca TPIUTIL. Essa biblioteca agrupada métodos e classes acessórias às outras classes. A principal função é manter o acesso aos dados isolados da camada de interface com o workflow. Também contém as querys de acesso aos dados na forma de embeded ("embutida") nos métodos e classes. Essa providência dá certa liberdade de mudar a plataforma de dados sem grandes retrabalhos.

\subsubsection{Processos desenvolvidos para o TPI}

Os principais processos desenvolvidos para o sistema TPI estão agrupados no Quadro 4.1. Os dados coletados são simples contagem realizada nos códigos gerados na plataforma Eclipse.

A finalidade dos números expostas é para se ter idéia do volume de código gerado para a aplicação. Também há estimativas de horas trabalhadas e uma coluna com os custos estimados.

Foram considerados que cada tarefa de cada processo consumiu dez horas de trabalho para desenvolvimento e teste. As telas consumiram 20 horas de trabalho cada uma. Por variável estima-se um trabalho de duas horas. O código gerado nos hooks estima-se dois minutos por linha de código para processos simples e cinco minutos para atividades mais complexas (Solicitação de Orçamento, Pedido de Irradiação e Consultar Lotes).

QUADRO 4.1 - Estimativa de horas de desenvolvimento dos processos do TPI.

\begin{tabular}{|l|c|c|c|c|c|c|}
\hline Processo & Tarefas & Telas & Variáveis & hooks & $\begin{array}{c}\text { Linhas de } \\
\text { Código }\end{array}$ & $\begin{array}{c}\text { Desenvolvimento } \\
\text { e teste (horas) }\end{array}$ \\
\hline Solicitar Orçamento & 15 & 8 & 26 & 20 & 2.728 & 589 \\
\hline Pedido Irradiação & 28 & 7 & 39 & 30 & 4.130 & 842 \\
\hline $\begin{array}{l}\text { Emitir Instrução de } \\
\text { Irradiação }\end{array}$ & 5 & 1 & 41 & 6 & 1.040 & 187 \\
\hline $\begin{array}{l}\text { Cadastrar } \\
\text { Dosimetro }\end{array}$ & 5 & 3 & 7 & 6 & 645 & 146 \\
\hline Leitura Dosimetro & 3 & 2 & 7 & 5 & 819 & 111 \\
\hline
\end{tabular}




\begin{tabular}{|l|c|c|c|c|c|c|}
\hline $\begin{array}{l}\text { Consultar } \\
\text { Dosimetro }\end{array}$ & 3 & 2 & 7 & 5 & 621 & 105 \\
\hline Colocar Dosimetro & 2 & 1 & 6 & 3 & 495 & 69 \\
\hline Carregar Caixa & 2 & 1 & 6 & 3 & 496 & 69 \\
\hline Consultar Caixa & 3 & 2 & 5 & 5 & 626 & 101 \\
\hline $\begin{array}{l}\text { Carregar } \\
\text { PoslrradCont }\end{array}$ & 2 & 1 & 6 & 3 & 496 & 69 \\
\hline Carregar Pos Track & 2 & 1 & 7 & 4 & 722 & 78 \\
\hline Consultar Lote & 4 & 3 & 49 & 7 & 1.311 & 308 \\
\hline $\begin{array}{l}\text { Emitir Etiquetas } \\
\text { CodBar }\end{array}$ & 3 & 1 & 9 & 4 & 744 & 93 \\
\hline $\begin{array}{l}\text { Emitir Certificado de } \\
\text { Irradiação }\end{array}$ & 2 & 1 & 8 & 3 & 435 & 71 \\
\hline & 79 & 34 & 223 & 104 & 15.308 & 2.838 \\
\hline Total & & & & & \\
\hline
\end{tabular}

As informações contidas no Quadro 4.1 foram coletadas no ambiente de desenvolvimento. Os valores de horas são estimados uma vez que os controles foram informais. Entretanto, eles refletem tempos de desenvolvimento praticados no mercado em ambiente de desenvolvimento de sistemas.

O Quadro 4.2 reúne informações do desenvolvimento da Biblioteca TPIUTIL. As quantidades de métodos e linhas foram coletadas no ambiente de desenvolvimento. As horas de desenvolvimento foram estimadas como dois minutos por linha de código para desenvolvimento e testes.

QUADRO 4.2 - Estimativa de horas de desenvolvimento da biblioteca TPIUTIL.

\begin{tabular}{|l|c|c|c|}
\hline $\begin{array}{l}\text { Biblioteca } \\
\text { TPIUTIL } \\
\text { (Classes) }\end{array}$ & Métodos & $\begin{array}{c}\text { Linhas de } \\
\text { código }\end{array}$ & $\begin{array}{c}\text { Desenvolvimento e } \\
\text { teste } \\
\text { (horas) }\end{array}$ \\
\hline tpiDosimetro & 9 & 2.255 & 75 \\
\hline tpill & 10 & 2.294 & 76 \\
\hline tpiOnFinished & 3 & 1.102 & 37 \\
\hline tpiOrcamento & 6 & 2.628 & 88 \\
\hline tpiPedido & 3 & 1.120 & 37 \\
\hline tpiOS & 8 & 2.118 & 71 \\
\hline tpiOSLote & 14 & 4.391 & 146 \\
\hline tpiTrack & 12 & 6.493 & 216 \\
\hline tpiUtil & 241 & 16.957 & 565 \\
\hline & & & \\
\hline Total & 306 & 39.958 & 1.311 \\
\hline
\end{tabular}




\subsubsection{Estimativas de custos de desenvolvimento do sistema TPI}

O sistema TPI desenvolvimento como objeto de tese é uma experiência inovadora do ponto de vista de custos. Depende somente da disponibilidade do candidato. Entretanto, fazer uma estimativa de custos para o projeto se mostra bastante útil.

Um projeto do porte e complexidade do TPI normalmente é feito por empresas de softwares. Essas empresas têm no seu portfólio de profissionais pessoas para cumprir determinadas fases do projeto:

- Consultor de Sistema: fase inicial para definir o escopo e abrangência do projeto;

- Gerente do Projeto: profissional que tem a responsabilidade pelos prazos e pelos objetos entregáveis. Determina quando cada tipo de profissional entra e sai do projeto. Os marcos importantes: início, entregas parciais, testes de aceitação, instalação no ambiente do cliente, operação assistida, manutenção;

- Analistas de Dados: profissional que desenha a base de dados e suas relações;

- Analista de Bando de Dados: constrói as querys, procedures e mantém a integridades dos dados;

- Analista de Negócios e Processos: faz a especificação dos processos, agentes e o desenho dos processos;

- Analista de Sistema: faz a especificação funcional e técnica do projeto para atender as interfaces requeridas pelos processos.

- Desenvolvedores: programadores de web, programadores de objetos em Java;

- Analista de Documentos: responsável por manter os documentos atualizados e testes com o cliente;

- Analistas de Redes: responsável pelo servidor de aplicação e segurança de comunicação.

O Quadro 4.3 faz uma estimativa dos custos de desenvolvimentos tendo como premissa que o valor de $R \$ 150,00$ por hora de trabalho é um misto 
das horas dos profissionais citados acima pelo tempo que cada um deles participa do projeto (reflete o custo atual de mercado).

QUADRO 4.3 - Estimativa de custos de desenvolvimento do TPI.

\begin{tabular}{|l|l|l|}
\hline Processo e classes & $\begin{array}{l}\text { Desenvolvime } \\
\text { nto e teste } \\
\text { (horas) }\end{array}$ & $\begin{array}{l}\text { Custo de Consultor } \\
\text { R } \$ 150 \text { por hora } \\
\text { (vários perfis) }\end{array}$ \\
\hline Solicitar Orçamento & 589 & 88.350 \\
\hline Pedido Irradiação & 842 & 126.300 \\
\hline $\begin{array}{l}\text { Emitir Instrução de } \\
\text { Irradiação }\end{array}$ & 187 & 28.050 \\
\hline Cadastrar Dosimetro & 146 & 21.900 \\
\hline Leitura Dosimetro & 111 & 16.650 \\
\hline Consultar Dosimetro & 105 & 15.750 \\
\hline Colocar Dosimetro & 69 & 10.350 \\
\hline Carregar Caixa & 69 & 10.350 \\
\hline Consultar Caixa & 101 & 15.150 \\
\hline Carregar PosIrradCont & 69 & 10.340 \\
\hline Carregar Pos Track & 78 & 11.700 \\
\hline Consultar Lote & 308 & 46.200 \\
\hline Emitir Etiquetas CodBar & 93 & 13.950 \\
\hline Emitir Certificado de & 71 & 10.650 \\
\hline Irradiação & & \\
\hline & 2.838 & $\mathrm{R} \$ 425.700$ \\
\hline & & \\
\hline Biblioteca TPIUTIL & 75 & 11.250 \\
\hline tpiDosimetro & 76 & 11.400 \\
\hline tpill & 37 & 5.550 \\
\hline tpiOnFinished & 88 & 13.200 \\
\hline tpiOrcamento & 37 & 5.550 \\
\hline tpiPedido & 71 & 10.650 \\
\hline tpiOS & 146 & 21.900 \\
\hline tpiOSLote & 216 & 32.400 \\
\hline tpiTrack & 565 & 84.750 \\
\hline tpiUtil & 1.311 & $\mathrm{R} \$ 196.650$ \\
\hline & 4.149 & $\mathrm{R} \$ 622.350$ \\
\hline & & \\
\hline & Sotal & \\
\hline
\end{tabular}

No volume de horas deve ser considerada a fase de elaboração dos documentos de requisitos, funcional e desenvolvimento.

Podem-se estimar mais 1.000 horas para toda documentação o que acrescentaria mais $R \$ 150.000,00$ dando um total de $R \$ 772.350,00$. 
Ainda, nos custos, no caso de empresa, deve se considerar impostos e margem de lucro. Isso acrescenta de $40 \%$ a $60 \%$ no valor de custo total.

Considerando $40 \%$ de impostos e margem de lucro ficaria $\mathrm{R} \$$ $1.081 .290,00$ no melhor caso. No pior caso com $60 \%$ para impostos e margem de lucro $\mathrm{R} \$ 1.235 .760,00$.

Devem-se considerar também os custos de aquisição dos equipamentos para a operação do TPI. Procurou-se nas várias soluções àquela que apresentou o melhor custo-benefício. Ou seja, estruturar a rede com comunicações wireless de baixo custo (ZigBee), leitores de códigos de barras e impressora de baixo custo.

Os itens de comunicação e código de barras envolveram custos inferiores a $\mathrm{R} \$ 5.000,00$.

\subsubsection{Rede de coleta/escrita Wireless ZigBee/WiFi}

Na FIG.4.6 está representada esquematicamente a infra-estrutura de posicionamento dos equipamentos para a realização do controle do fluxo dos produtos no pátio de irradiação. Estão incluídos as áreas de produtos não irradiados, produtos irradiados, a câmara fria, o irradiador e a sala dos operadores. Também, estão representados: o servidor da aplicação, os equipamentos de coleta e escrita de códigos de barras que ocorrerá em diversos momentos do ciclo de irradiação.

A FIG.4.6 evidencia que as comunicações entre o servidor e os diversos equipamentos é feita via comunicação wireless (sem fio) utilizando-se do padrão e IEEE.802.15.4 (ZigBee). Também há a comunicação por WiFi (IEEE.802.11.g) com notebook ou outro equipamento móvel.

A principal razão da comunicação não ser "cabeada" é a necessidade de mobilidade do operador na identificação dos produtos e caixas de irradiação. Outra razão, também importante, é assegurar 0 isolamento elétrico entre os equipamentos de controle do irradiador e os equipamentos de processo do sistema de tracking de produtos.

A rede de coleta e escrita de informações é baseada na tecnologia ZigBee. A configuração é centralizada num elemento denominado Coordenador. 
É uma placa de comunicação que comporta comunicação com outras quatro placas denominadas End Point.

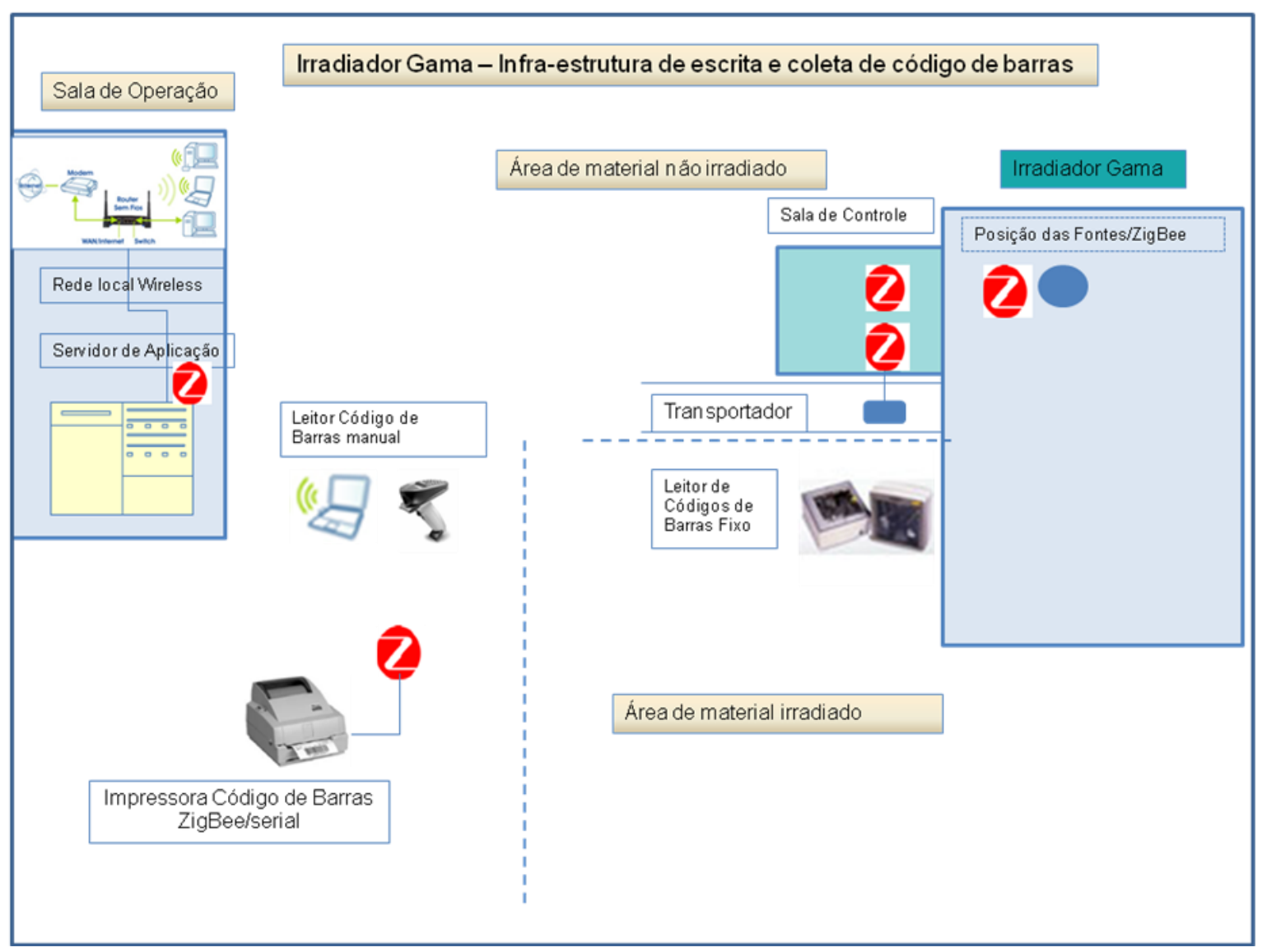

FIGURA 4.6 - Infra-estrutura de escrita e coleta de código de barras e posicionamento das fontes de irradiação.

A configuração típica é mostrada na FIG.4.7 na qual estão representados alguns equipamentos e as correspondentes interfaces.

O dispositivo ZigBee-Pro tem capacidade de transmissão indoor com alcance de $100 \mathrm{~m}$, e externo com visada direta, até $1.600 \mathrm{~m}$.

A montagem das placas do ZigBee é feita em encapsulamento próprio de rádios com antena externa e alimentação por fonte de alimentação. Essa fonte de alimentação é do tipo 80-240VAC com saída de 12 DC bastando uma tomada comum com aterramento. 


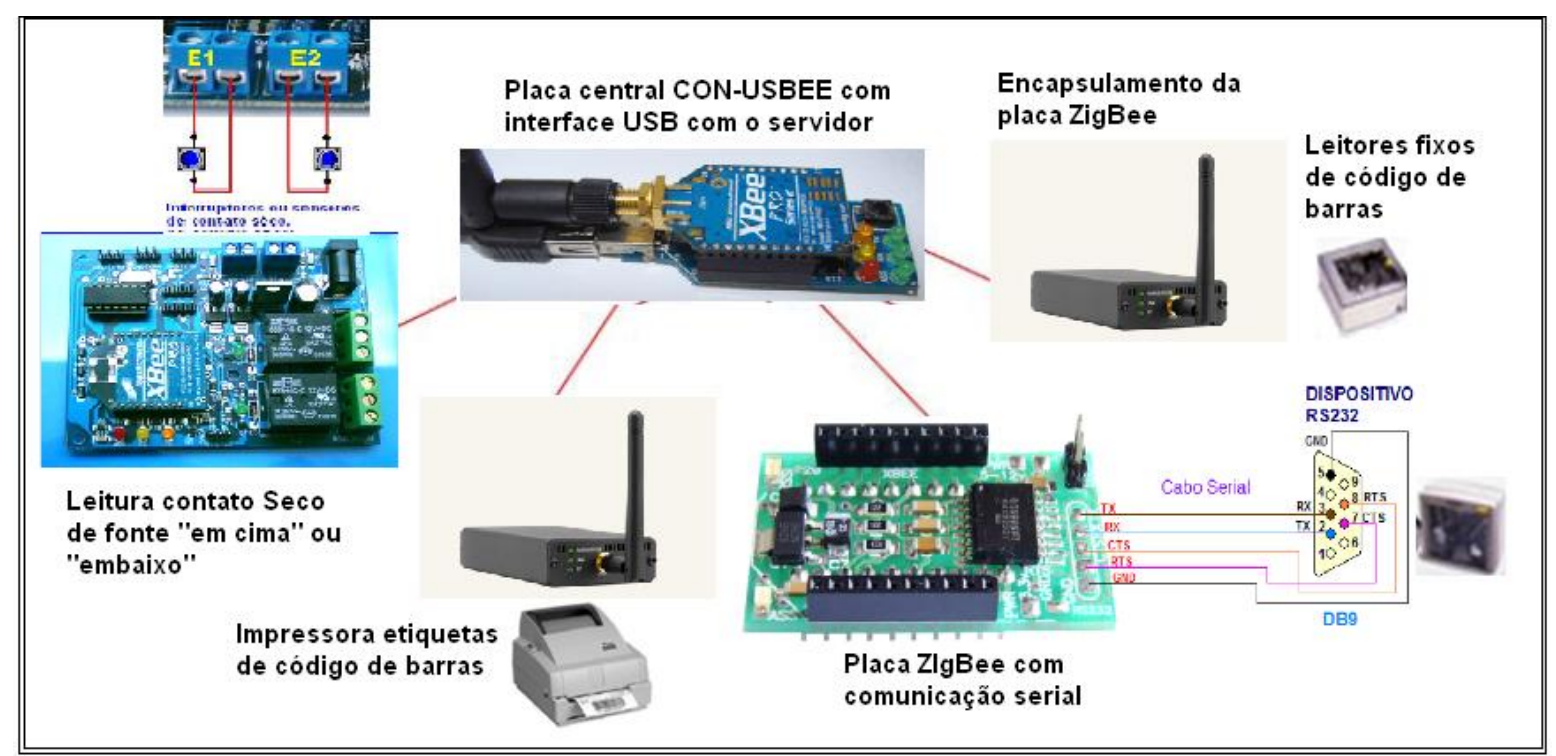

FIGURA 4.7 - Arranjo típico da rede de comunicação de coleta e escrita do ambiente do irradiador gama.

A descrição dos equipamentos representados na FIG.26 são resumidas como seguem:

- Uma placa CON-USBEE (ROGERCOM $\left.{ }^{12}\right)$, como um coordenador de rede e conecta até quatro placas (topologia ponto-multiponto) RCOM-HOMEBEE ou placa PROTO_BEE;

- Uma placa (entrada) RCOM_HOMEBEE com interface serial RS232 para leitura de posição da fonte: "em cima" para fonte exposta; "embaixo" para fonte guardada na piscina;

- Três placas PROTO-BEE com interface serial RS232:

- Duas placas (entrada) para leitores fixos de código de barras Symbol modelo LS6700 com interface RS232;

- Uma placa (saída) para a impressora Zebra-Eltron TL2642 termo transferência com interface serial RS232.

A leitura de código de barras dos diversos relacionamentos: produto do cliente, código de barras OS/Lote, Caixa de Irradiação, é feita por equipamento portátil (notebook), conectado à WEB e ao sistema TPI, por um roteador WiFi.

\footnotetext{
${ }^{12}$ WWW.rogercom.com
} 
Por sua vez, o equipamento portátil tem conectado um coletor manual, industrial, de código de barras Seal modelo P302FZY com interface serial-USB.

A leitura dos equipamentos fixos: leitores de entrada e saída de caixas no irradiador, e posição das fontes, são feitos por programas que ficam lendo as portas (COM) do servidor de aplicação destinadas à conexão de cada ponto. Esses programas têm características especiais. São denominados daemon. São robôs com missão de "ler" as portas de entrada associada aos dispositivos ZigBee. Cada dispositivo tem local fixo de leitura, portanto, os dados coletados alimentam tabelas específicas do modelo de dados. 


\section{CONCLUSÕES}

Os objetivos deste trabalho foram atingidos. As práticas de irradiação de produtos estão transformadas em Boas Práticas de Irradiação ou Good Irradiation Practice (GIP), mais propriamente Good Radiation Practice (GRP) de acordo com TECDOC 539, apoiadas nos controles proporcionados com a criação do sistema TPI - Tracking de Produtos Irradiados.

Também atende às normas da ANVISA: RDC-275/2001 e RDC21/2001 para produtos alimentícios, RDC-59/2000 para produtos médicos. Entretanto, ainda não há a preocupação em obter certificação da ANVISA.

As especificações de qualidade no processo definidas nas normas ISO-11137:2006 que trata da esterilização de produtos de saúde e ISO13485:2003 que trata da sistema de qualidade de equipamentos médicos também são atendidas.

O objetivo do serviço de irradiação é a emissão do Certificado de Irradiação totalmente baseado nas informações presentes na base de dados do TPI. O sistema garante a rastreabilidade dos dados coletados dos processos nas suas diversas fases. Esses dados ficam disponíveis para qualquer auditoria interna ou externa com objetivo de certificar que os processos estão documentados e coerentes.

A sistemática aqui adotada mostrou-se totalmente viável a utilização de software livre de licença na construção de sistemas complexos, como é o TPI. A escolha das ferramentas de software, adotadas para o TPI, foram no sentido de que as interfaces (telas) sejam publicadas na WEB. Esse recurso permite grande disponibilidade de uso do sistema, podendo seus usuários, o acesso de qualquer equipamento conectado à rede Internet, a qualquer hora e de qualquer lugar.

Como objetivo indireto pode-se citar que o sistema atende ao anseio do governo federal na adoção de soluções baseadas em software livre. Essa iniciativa é incentivada pela Sociedade de Software Livre da qual o governo federal é patrocinador. Com esse trabalho o IPEN/CNEN faz sua contribuição no contexto dos órgãos federais ao adotar sistema de software livre. 
Citando números do projeto pode-se dizer que nos quatro anos e três meses do projeto foram utilizadas cerca de 5.000 horas cobrindo todas as fases do projeto. Quanto aos valores, estimados, considerando o trabalho de um desenvolvedor (multiperfil) chegou-se a $\mathrm{R} \$ 722.350,00$. Se considerar o trabalho realizado por uma empresa o projeto teria 30 meses de duração e custos de $R \$$ 1.081.290,00, considerando $40 \%$ de impostos e margem de lucro. Ou, no pior caso, com $60 \%$ para impostos e margem de lucro, custos de $\mathrm{R} \$ 1.235 .760,00$. Qualquer das duas alternativas demonstra quão caro é o desenvolvimento de sistemas de computação.

Quanto aos equipamentos de comunicação e código de barras optouse por uma configuração simples com preço reduzido. Foi escolhida a tecnologia sem fio ZigBee que faz a comunicação serial RS232 dos equipamentos com o servidor de aplicação. O custo com os equipamentos de leitura de código de barras e posição de fontes ficou inferior a $R \$ 5.000,00$.

\section{PROJETOS FUTUROS}

Por se tratar de sistema aberto, este pode ser adaptado para outros departamentos do IPEN/CNEN, quanto às outras autarquias, escolas, institutos, etc. Basta que, para isso, outros pesquisadores se comprometam a desenvolver e adaptar o sistema às necessidades próprias de cada interessado.

A primeira sugestão é que o sistema seja transformado em multiempresa e multiirradiador. Ou seja, possa ser utilizado como um centralizador de serviços a clientes de diversas empresas de irradiação e estas com diversos modelos de irradiadores. Essa possibilidade abre a perspectiva de se ter uma empresa prestadora de serviço de irradiação que tenha como parceiras as empresas de irradiação. Para o cliente é visto como convergência de serviço. Os clientes farão uso de um único sistema para obter seus serviços. Mas a manutenção e operação do sistema mantido de forma única como redução de custos e riscos. 


\section{APÊNDICE - Principais Fluxos do Sistema TPI}

\section{APÊNDICE A1 - Solicitar Orçamento}

Fluxo das atividades no qual o Cliente inicia o processo 1- SolicitarOrcamento para obter um orçamento do serviço de irradiação. O fluxo apresentado é a representação gráfica que do editor Proed utilizado pelo desenvolvedor da aplicação.

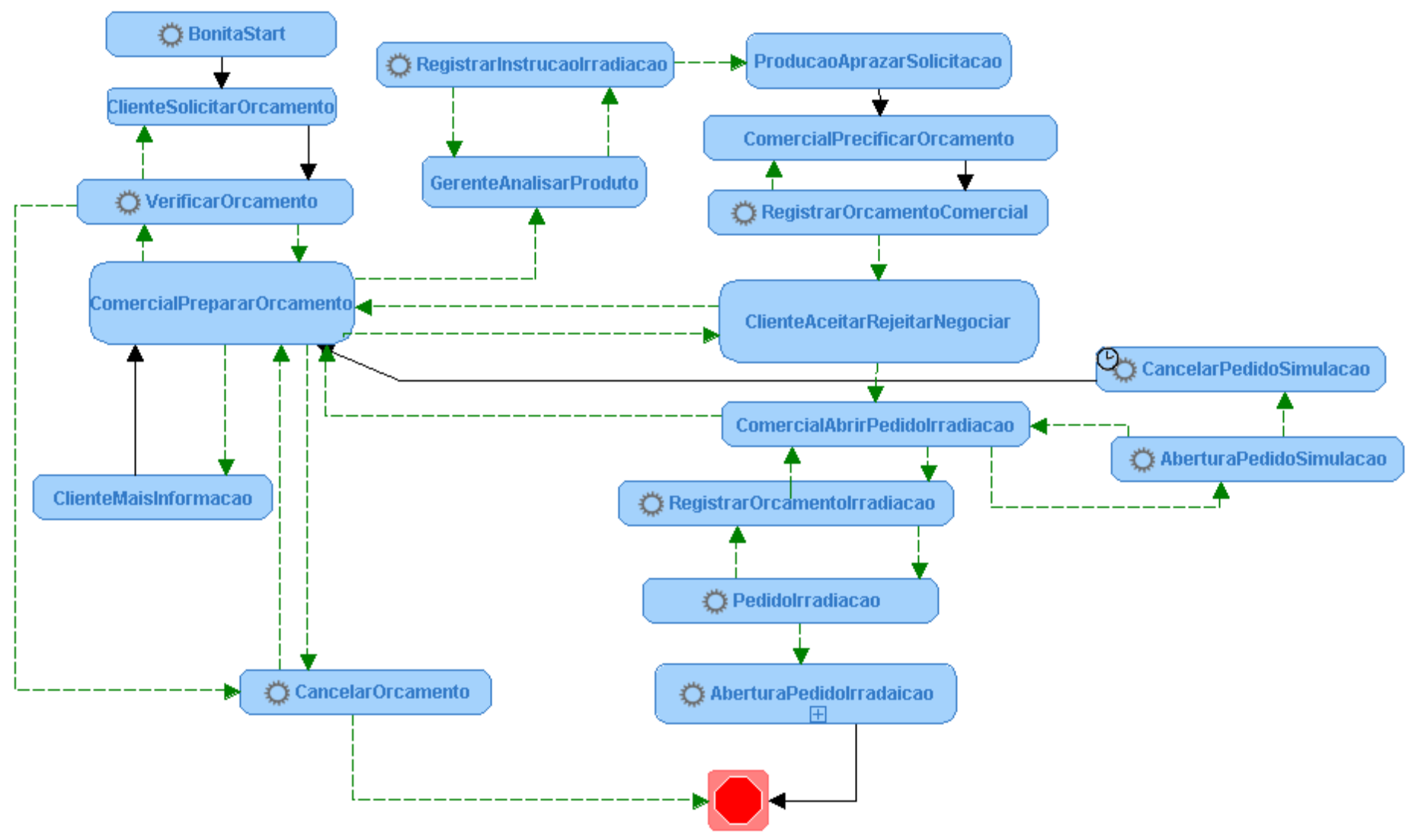


As transições entre as tarefas são sempre aderentes ao modelo lógico do processo. Por decisão do setor Comercial, fluxo do orçamento inicia-se o subprocesso de Abertura de Pedido de Irradiação

Para os testes foram criados vários usuários fictícios. Um deles é o usuário Palmer que pertence à empresa MangasJanjao. A seguir as FIG.A.1.1 e A1.2 mostram a sequência de acesso ao sistema pelo usuário palmer (senha: palmer01) e a página que ele acessa.

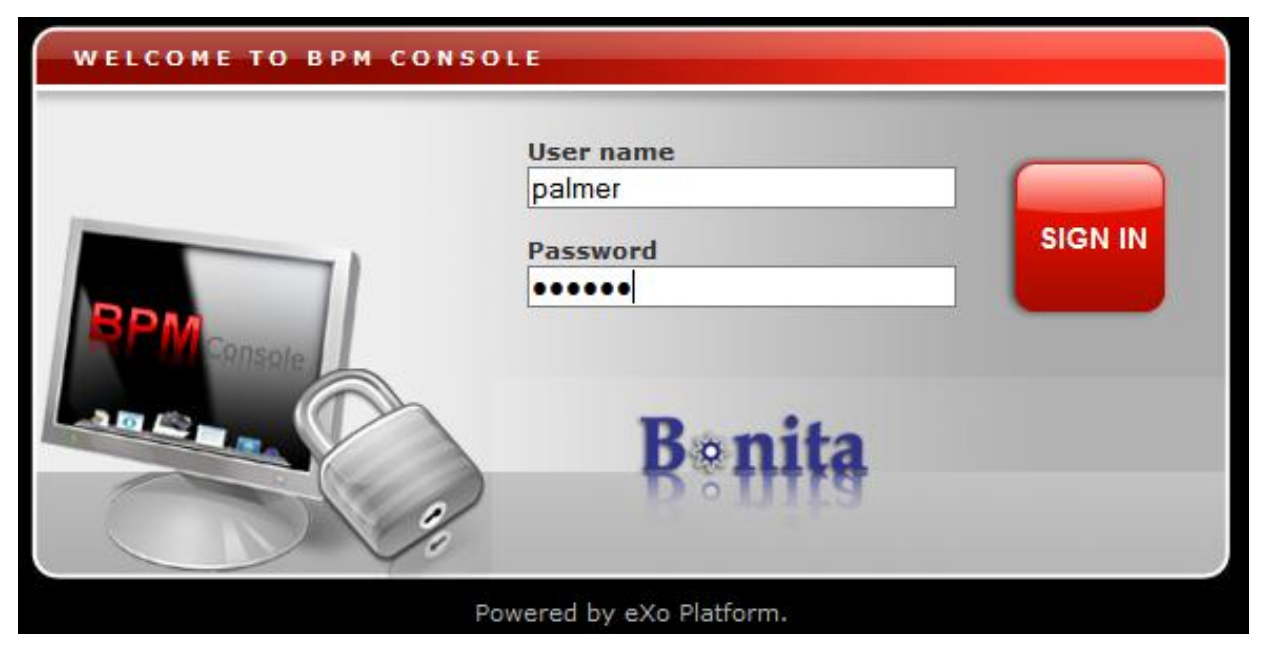

FIGURA A1. 1 - Página do Bonita que o usuário palmer faz acesso à página do sistema para iniciar a solicitação de Orçamento.

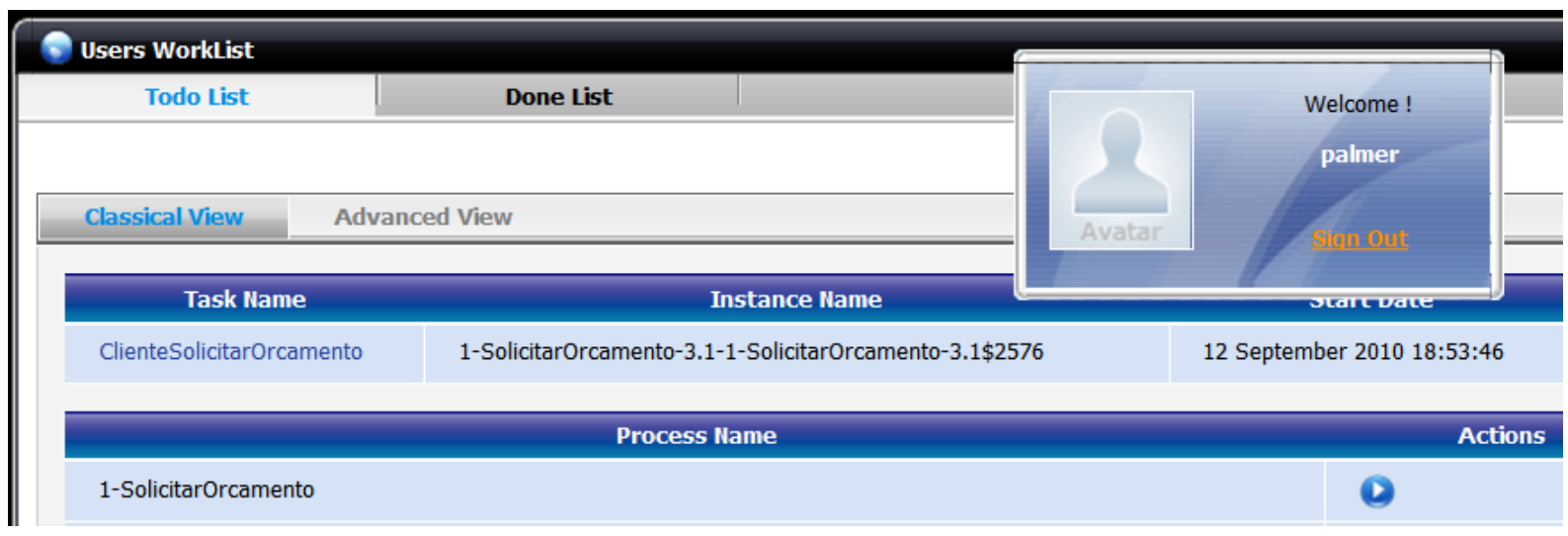

FIGURA A1. 2 - Página do Bonita que o usuário palmer faz acesso à página do sistema para iniciar a solicitação de Orçamento. 
Do grupo MangasJanjão estão habilitados os usuário: palmer, kate e tomy. Qualquer um deles poderá acessar qualquer atividade referente grupo.

Todos os outros usuários também têm acesso a esta página. Cada usuário poderá iniciar uma página para o qual ele ou o seu grupo tem acesso. $O$ sistema não iniciará nenhum processo para a qual ele não tenha permissão de visualizar ou alterar a tarefa.

De acordo com a FIG.A1.2 o usuário poderá iniciar um novo processo: "1SolicitarOrçamento" ou continuar com o processo já iniciado, tarefa "ClienteSolicitarOrçamento".

O Cliente ao acessar a atividade de Solicitar Orçamento recebe a tela referente à $1^{\underline{a}}$ Etapa do Fluxo: Cliente Solicitar Orçamento. A FIG.A1.3 ilustra esta tela. O Cliente pode preencher todos os campos, ou se não for o primeiro acesso ele pode optar por "RecuperarDadosOrcamentoAnterior". Nessa opção o sistema recupera os dados do orçamento anterior, e a partir deste, o Cliente faz seu novo Pedido de Orçamento. 


\section{Ciente Solicitar Orçamento}

Identificaşa da Orçamento Anterior: 215567890

Identificaçăa do Orçamento Atusl:

Origem das Dodas da Orçamenta:

Stusçăa do Orçamenta:

Tipo da Orçamenta:

Observoğa:

Comentários:

F

RecuperarDadosOrcamentoAnterior

InlcloOrcamento

1-Comerclal

Nome da Clente ou Razăa Social: * Mangasjanjao

Identificoşă do Ciente: * 12345678

Tipo de Identificsęăo do Cliente: 1-CNPJ

Códiga da Pedida da Ciente: $567 a 90$

Responsável pela Orçamento:

Palmer

Telefone: 23233434

Fax: 23233434

Email: palmervermelna goobahto60.00m. br

Tipo de Serviça: Irradlacaocontinua

Dats Prevista Inicial: $08 / 31 / 20100000000$

Dots Prevists Finsl: 09/13/2010 0000000

Produto: Manga99

Deseriçăa da Serviça: Irradlar

Volume do Produto (m3): 3240

Pesa do Produto (kg): 234.0

Quantidode de Embolsdos: 34

Quantidode de Lote: 2

Tipo de Processamento Produta:

Códiga de Instruç̄a de Irradisçăa: no

Dose Mínims (KGy): 44.0

Dose Msxims (KGy): 45.0

Tempo de Passagen Total (horss): 240

Valor Unitário da Serviço (R\$//hara): 28.0

Valor Total do Serviça: 543.0

Ocarrêncis do Orçamenta:

Emiar

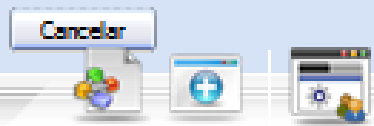

FIGURA A1. 3 - Tela que o Cliente faz acesso à página do sistema para iniciar a Solicitação de Orçamento. 


\section{APÊNDICE A2 -Pedido de Irradiação}

Fluxo das atividades no qual o Comercial abre o Pedido de Irradiação e a partir desse são percorridas as etapas até a conclusão do serviço.

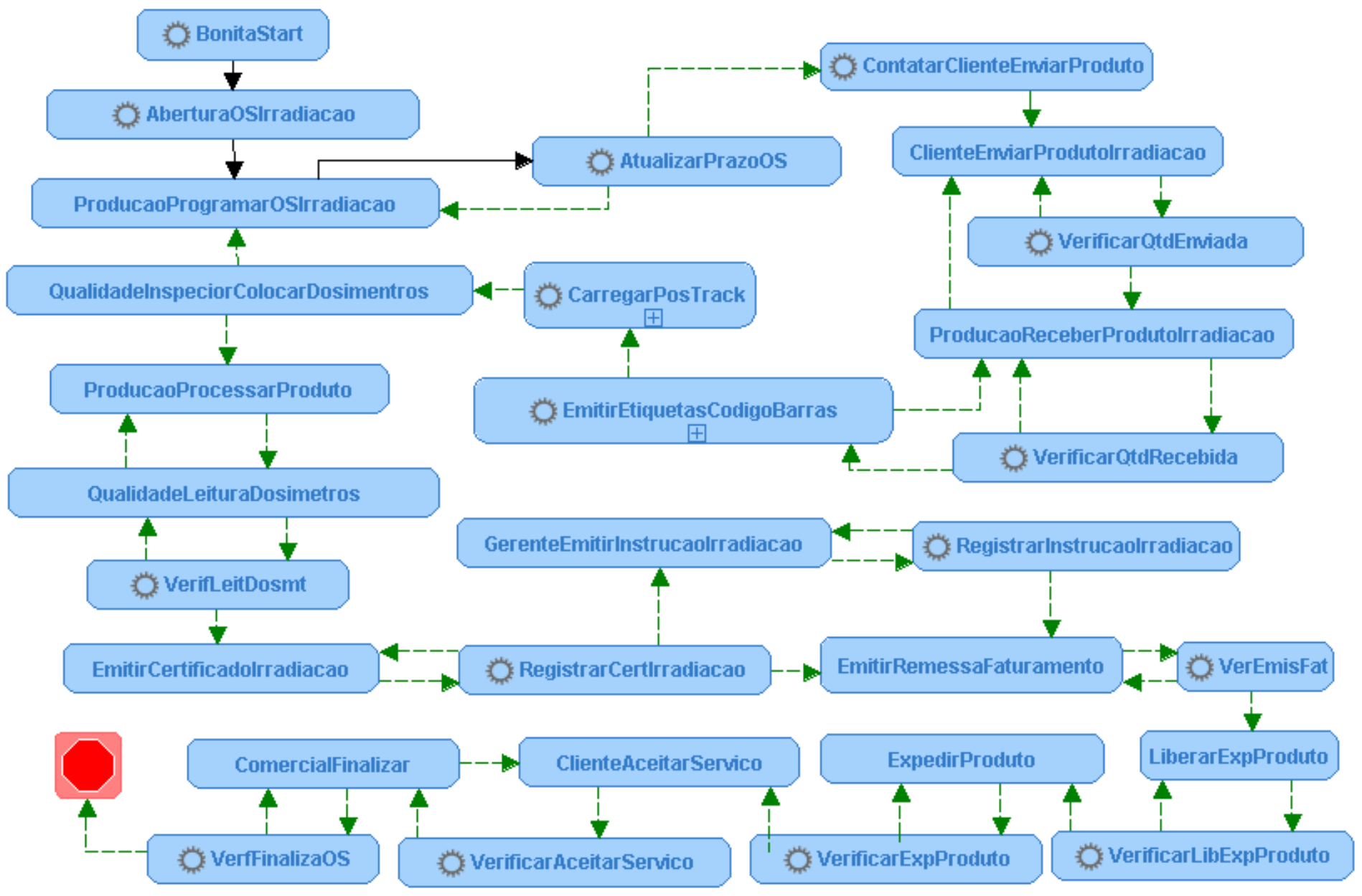




\section{APÊNDICE B1 - Emitir Instrução de Irradiação}

A Instrução de Irradiação é o documento que orienta o operador no processo de irradiação. Compreende a disposição dos embalados dentro das caixas de irradiação (processo contínuo) ou ao redor das fontes (processo estático). Também a colocação dos dosímetros: posição e quantidades.

A título de testes foram criados alguns usuários no grupo Gerente da Planta: júpiter, marte e saturno.

A FIG.B1.1 mostra o desenho do processo desenvovido no editor Proed. São previstos alguns estados:

- Encerrar: encerrar o processo;

- RecuperarInstrucaolrradiacao: recuperar uma instrução anterior para facilitar a definição de uma nova instrução;

- IncluirInstrucaolrradiacao: incluir uma nova instrução de irradiação;

- AlterarInstrucaolrradiacao: alterar o conteúdo de uma instrução de irradiação cadastrada;

- CancelarInstrucaolrradiacao: cancelar uma instrução de irradiação. O cancelamento não a exclui da base.

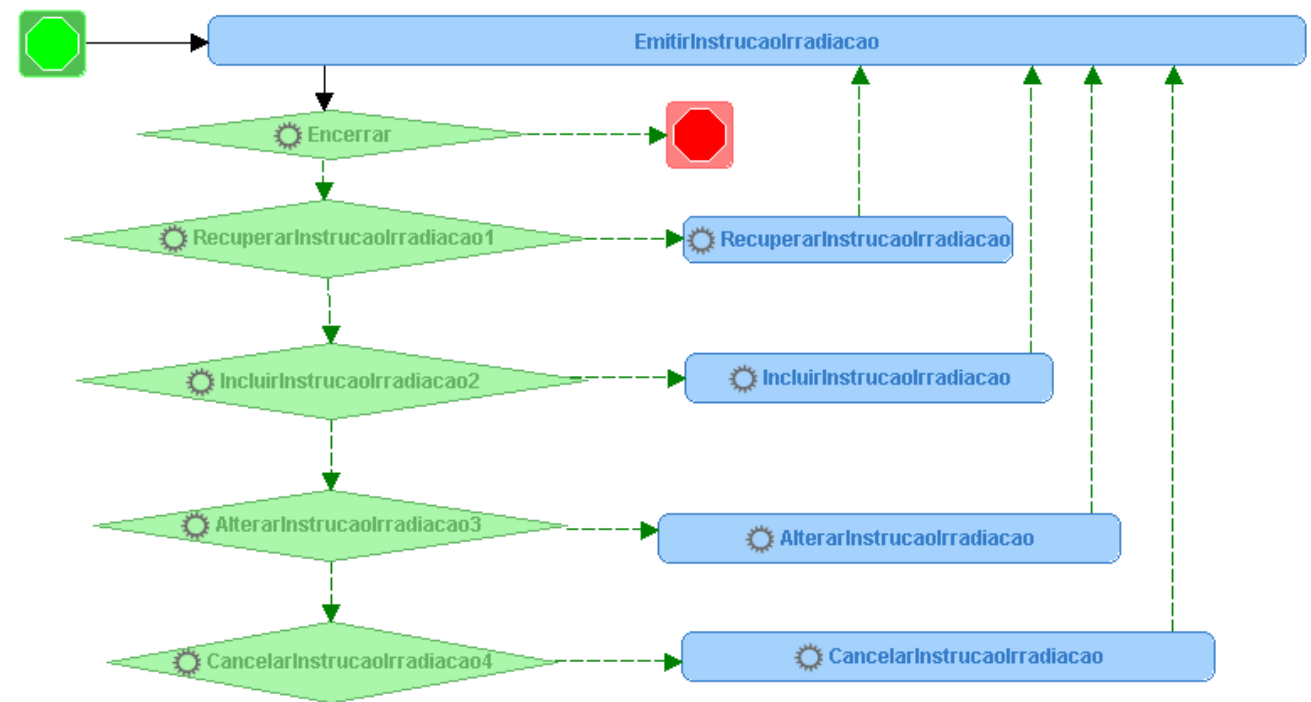

FIGURA B1. 1 - Fluxo do processo de Emitir Instrução de Irradiação. 
O Gerente da Planta ao entrar no processo de Emitir Instrução de Irradiação recebe a tela mostrada na FIG. B1.2 e B1.3 na qual estão as instruções para o operador.

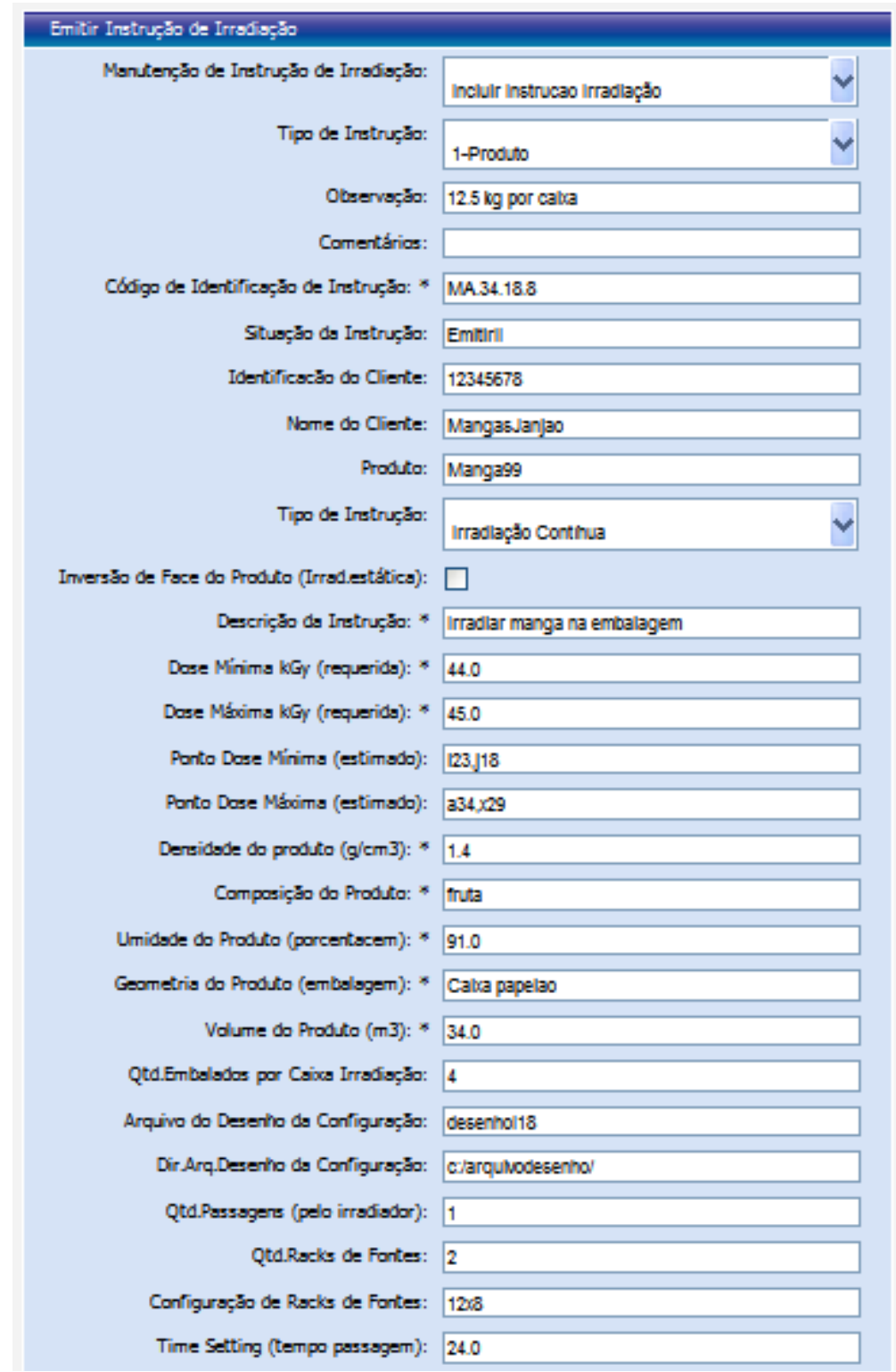

FIGURA B1. 2 - Tela do processo de Emitir Instrução de Irradiação (visão parcial). 


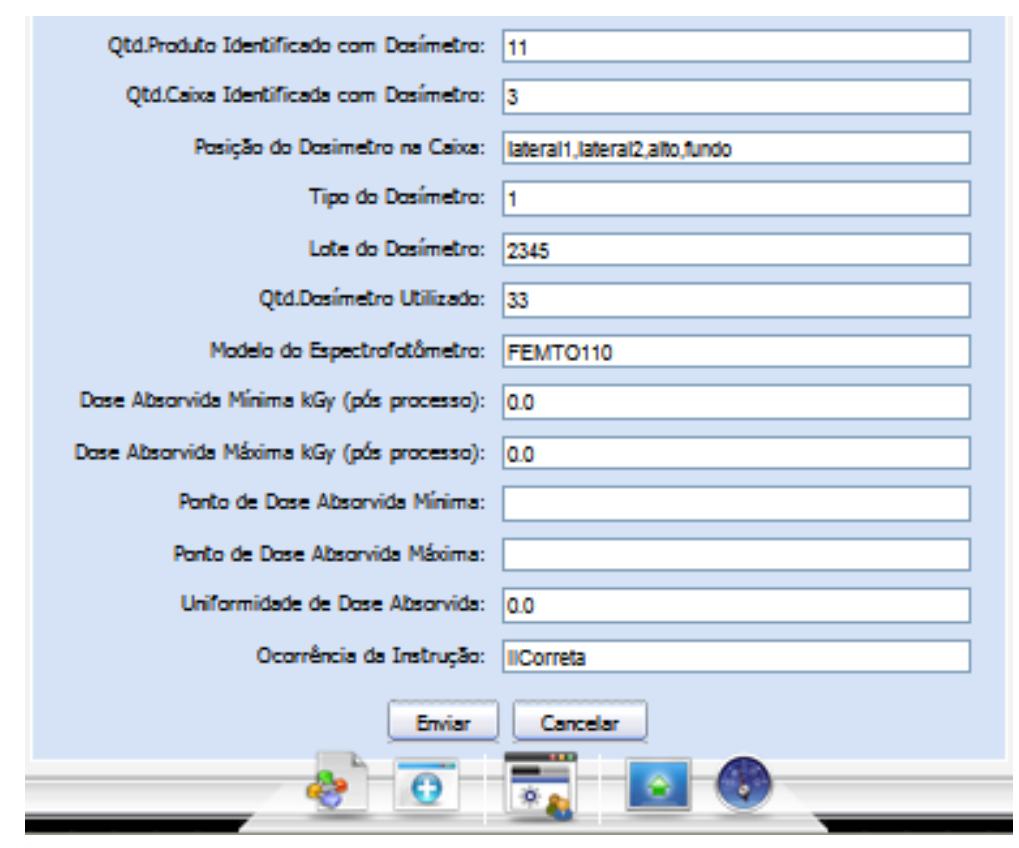

FIGURA B1. 3 - Tela do processo de Emitir Instrução de Irradiação (visão parcial).

Uma das informações que o Gerente da Planta deve informar é o diretório e o nome do arquivo que contém o desenho, ou fotos, da configuração dos embalados na caixa de irradiação, e também, o local de colocação dos dosímetros, tanto na caixa de irradiação, quanto no embalado. 


\section{APÊNDICE C1 - Cadastrar Dosímetros}

O setor de Qualidade tem importante papel no ciclo de irradiação dos produtos. Foram cadastrados, para testes, os seguintes usuários da Qualidade: gato, leão, tigre.

A FIG.C1.1 mostra o fluxo do processo de Cadastrar Dosímetros. O usuário pode optar por cadastrar os dosímetros individualmente ou em lote. A Instrução de Irradiação é o documento que orienta o operador no processo de irradiação. Compreende a disposição dos embalados dentro das caixas de irradiação (processo contínuo) ou ao redor das fontes (processo estático). Também a colocação dos dosímetros: posição e quantidades.

A título de testes foram criados alguns usuários no grupo Gerente da

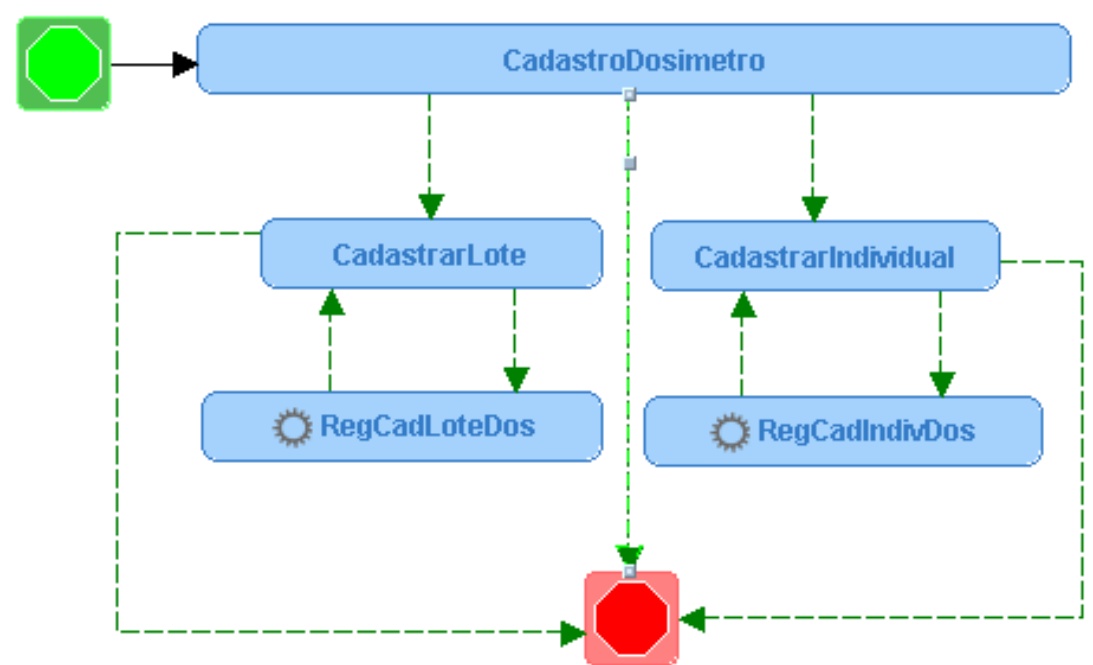

FIGURA C1. 1 Fluxo do processo de Cadastrar Dosímetros no editor Proed.

A FIG.C1.2 mostra a tela que o usuário da Qualidade recebe ao entrar no processo Cadastrar Dosímetro.

No campo de tela Escolher ele pode optar por:

- Cadastrar em Lote: os dosímetros são cadastrados obedecendo a sequência de primeiro e último do lote;

- Cadastrar Individual: o usuário faz o cadastro dosímetro a dosímetro.

No campo Continuação, ele pode optar por duas situações: 
- Encerrar: encerrar o cadastramento de dosímetros

- MaisCadastro: o sistema posiciona a tela da FIG.C1.3 caso ele optou por cadastrar os dosímetros individualmente.

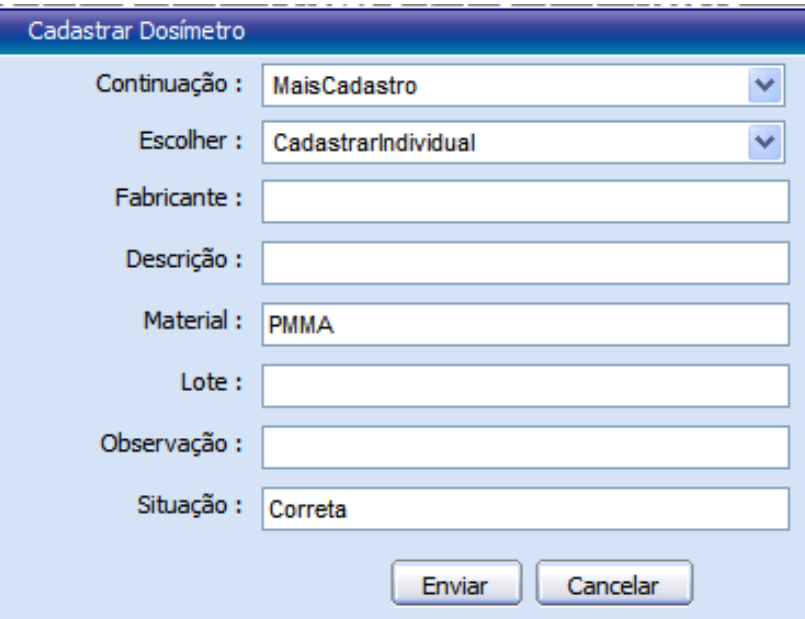

FIGURA C1. 2 - Tela do processo de Cadastrar Dosímetros.

A FIG.C1.3 mostra a tela para o usuário cadastrar os dosímetros individualmente.

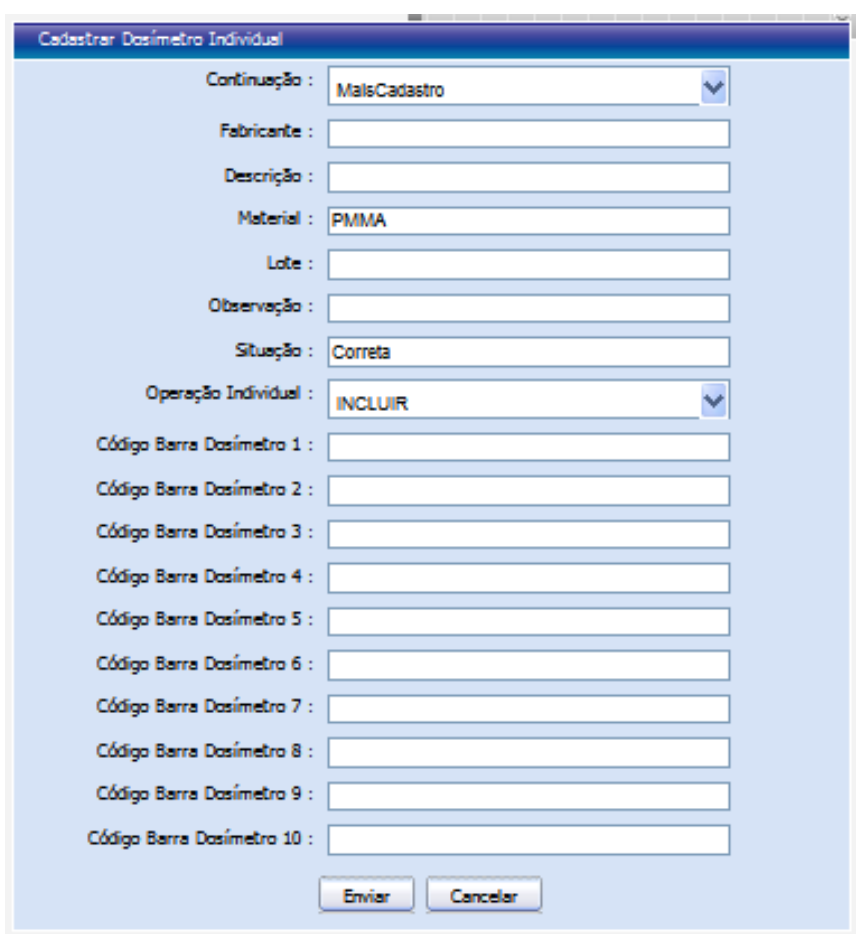

FIGURA C1. 3 Tela do processo de Cadastrar Dosímetros Individualmente. 


\section{APÊNDICE C2 - Leitura de Dose do Dosímetro}

Quando o produto é submetido ao irradiador são instalados dosímetros nos produto e nas caixas de irradiação (processo contínuo).

Após o ciclo de irradiação o usuário da Qualidade faz a leitura do dosímetro e faz o seu registro.

A FIG.C2.1 mostra o fluxo do processo de Leitura de Dose absorvida pelo dosímetro. Após a inserção da leitura da dose o usuário recebe uma tela com informações da dose acumulada no dosímetro

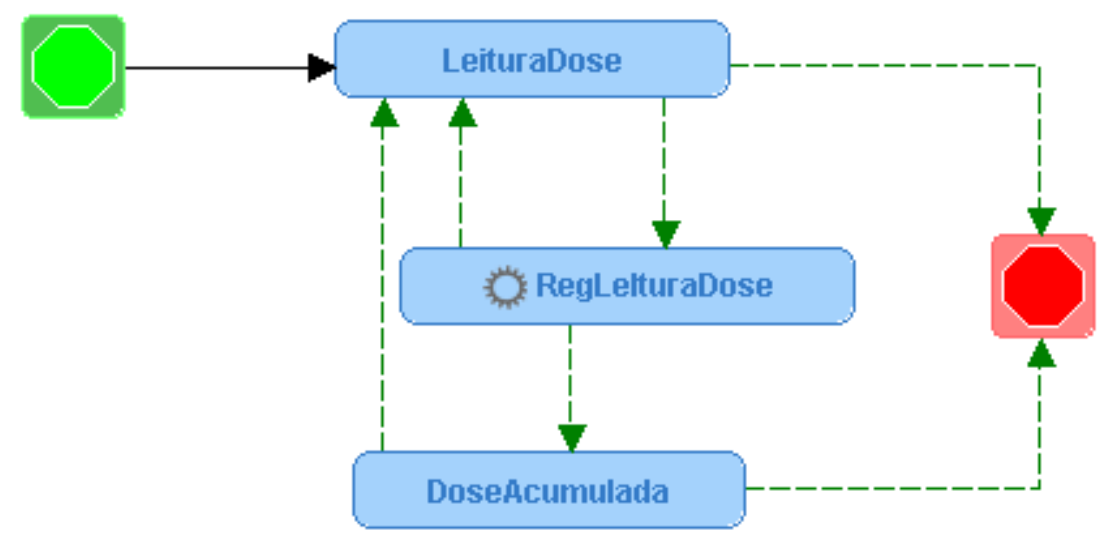

FIGURA C2. 1 - Fluxo do processo de Leitura de Dose no editor Proed.

A FIG.C2.2 mostra a tela que o usuário da Qualidade recebe ao entrar no processo para registrar a dose absorvida.

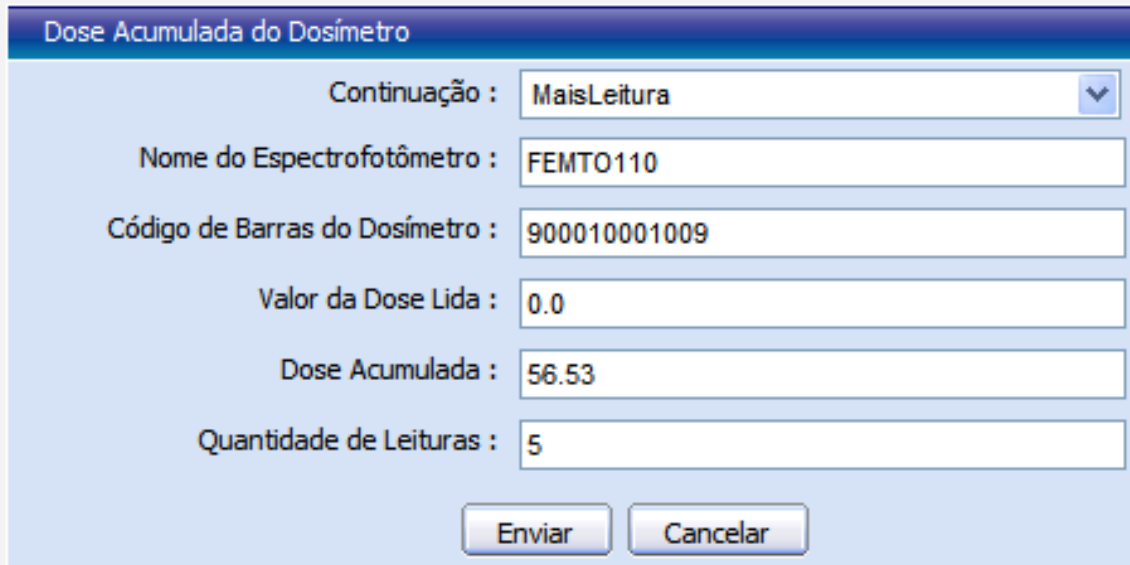

FIGURA C2. 2 - Tela de registro de Leitura de Dose. 
Nota que na FIG.C2.2 o usuário atribuiu o valor zero para a dose com o propósito de conferir o registro do dosímetro. A FIG.C2.3 mostra o posicionamento do dosímetro e o estado do mesmo.

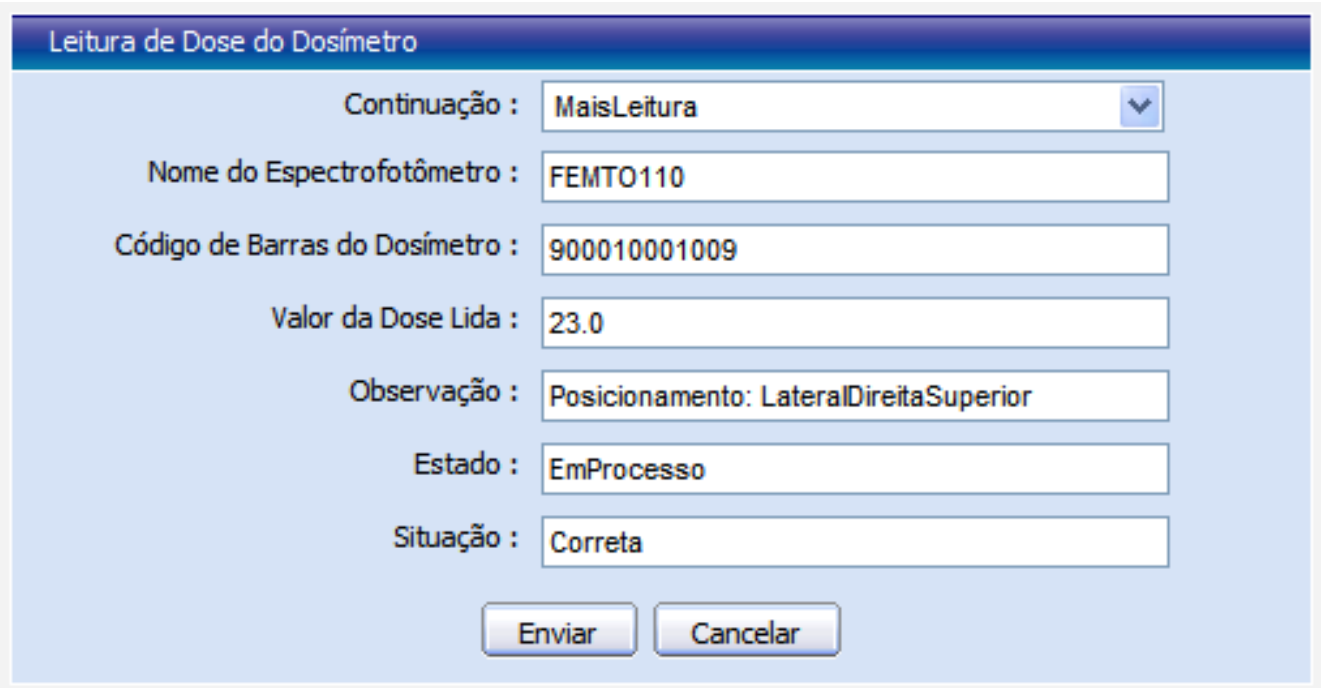

FIGURA C2. 3 - Tela mostra o posicionamento e a situação do dosímetro.

A FIG.C2.4 mostra a dose acumulada no dosímetro e a quantidade de leituras realizadas.

\section{Dose Acumulada do Dosímetro}

$\begin{aligned} \text { Continuação : } & \text { MaisLeitura } \\ \text { Nome do Espectrofotômetro : } & \text { FEMT0110 } \\ \text { Código de Barras do Dosímetro : } & 900010001009 \\ \text { Valor da Dose Lida : } & 23.0 \\ \text { Dose Acumulada : } & 56.53 \\ \text { Quantidade de Leituras : } & 4 \\ & \text { Enviar Cancelar }\end{aligned}$

FIGURA C2. 4 - Tela mostra a dose acumulada no dosímetro e as quantidades de doses realizadas. 


\section{APÊNDICE C3 - Consultar Dosímetro}

A qualquer momento o usuário da Qualidade poderá consultar os dados de um dosímetro.

A FIG.C3.1 mostra o fluxo do processo de Consulta de Dosímetro. Essa consulta é útil para o usuário saber se a dose mínima ou a máxima foram atingidas.

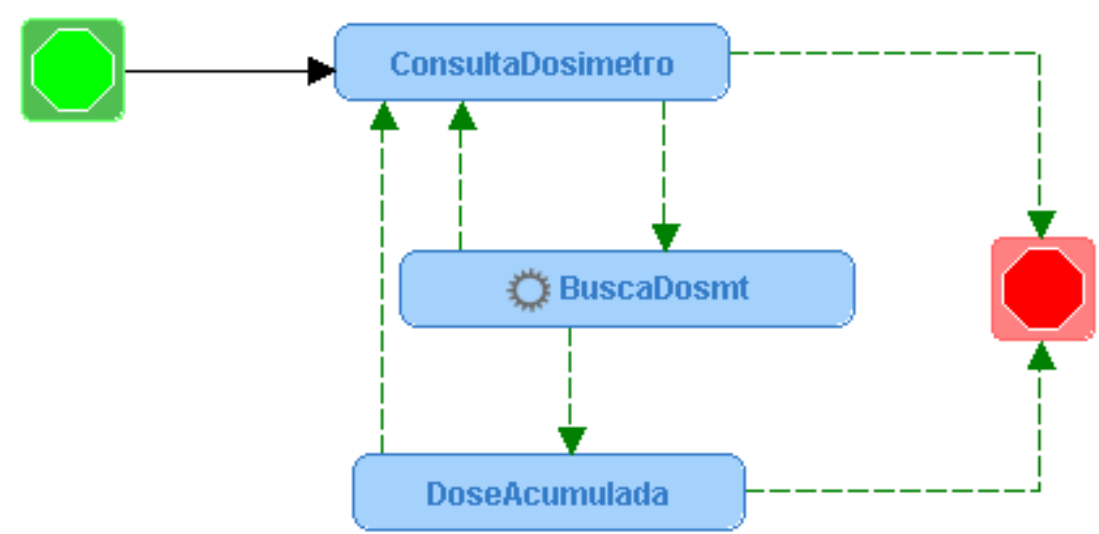

FIGURA C3. 1 - Fluxo do processo de Consultar Dosímetro no editor Proed.

A FIG.C3.2 mostra a tela que o usuário da Qualidade recebe ao entrar no processo para consultar o estado atual do dosímetro.

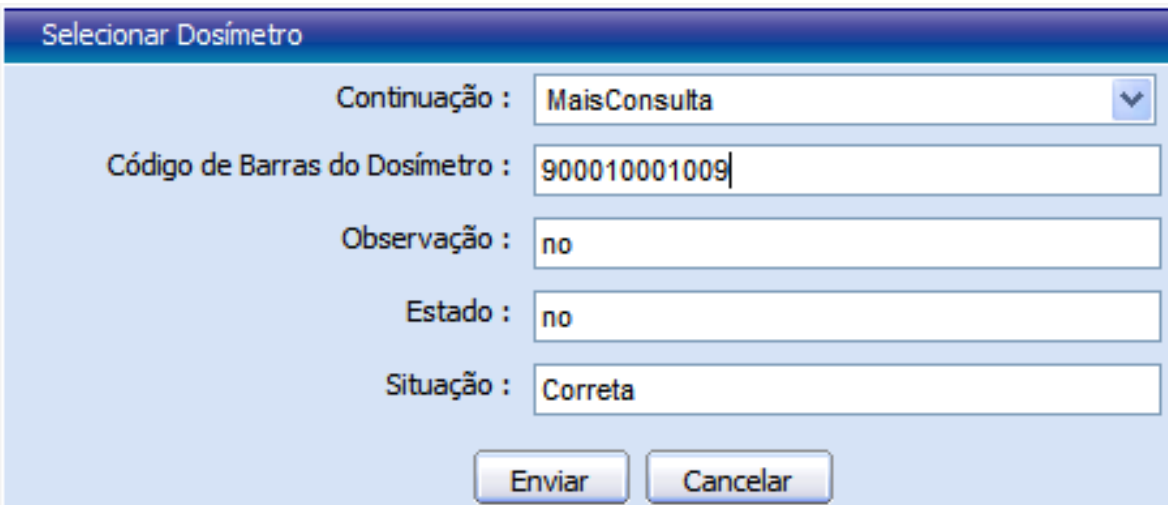

FIGURA C3. 2 - Tela de Consulta do Dosímetro. 
A FIG.C3.3 mostra o estado atual do dosímetro..

$\begin{aligned} \text { Dados do Dosímetro } & \\ \text { Continuação : } & \text { MaisConsulta } \\ \text { Código de Barras do Dosímetro : } & 900010001009 \\ \text { Dose Acumulada : } & 56.53 \\ \text { Quantidade de Leituras : } & 5 \\ \text { Data Última Leitura : } & 2010-09-13 \text { 11:15:43.171 } \\ \text { Item Associado : } & 8000095000153013 \\ \text { Tipo do Item Associado : } & 8 \text {-lteLote } \\ \text { Dose Mínima do Item : } & 33.000000 \\ \text { Dose Máxima do Item : } & 45.000000 \\ \text { Observação : } & \text { Posicionamento: LateralDireitaSuperior } \\ \text { Estado : } & \text { EmProcesso } \\ \text { Situação : } & \text { Correta } \\ & \text { Enviar }\end{aligned}$

FIGURA C3. 3 - Tela mostra o estado atual do dosímetro.

Entre as informações constam:

- Dose lida para o dosímetro

- Item associado;

- Tipo do item

- Posicionamento do dosímetro;

- Estado atual; 


\section{APÊNDICE C4 - Colocar Dosímetro}

O usuário da Qualidade da Qualidade poderá faz a colocação de dosímetro nos itens de lote ou na caixa de irradiação.

A FIG.C4.1 mostra o fluxo do processo de Colocar Dosímetro. Essa etapa é realizada seguindo a Instrução de Irradiação para o produto.

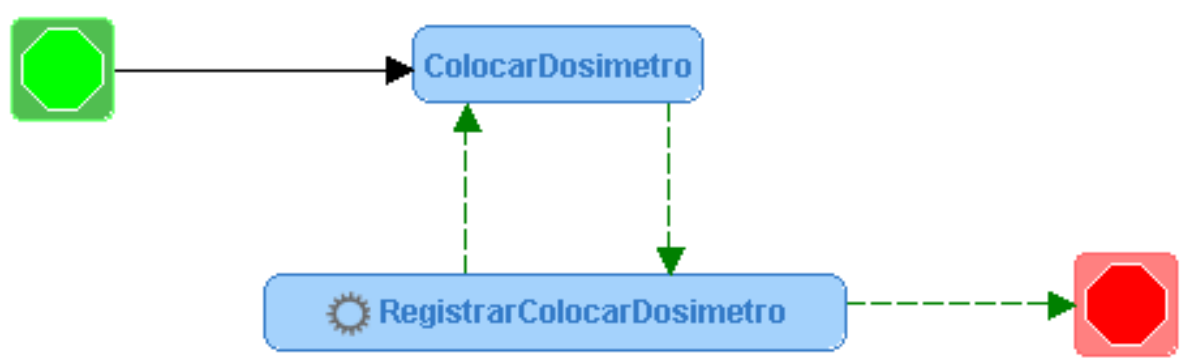

FIGURA C4. 1 - Fluxo do processo de Colocar Dosímetro no editor Proed.

A FIG.C4.2 mostra a tela que o usuário da Qualidade recebe ao entrar no processo para colocar dosímetros nos itens de lote ou caixa de irradiação.

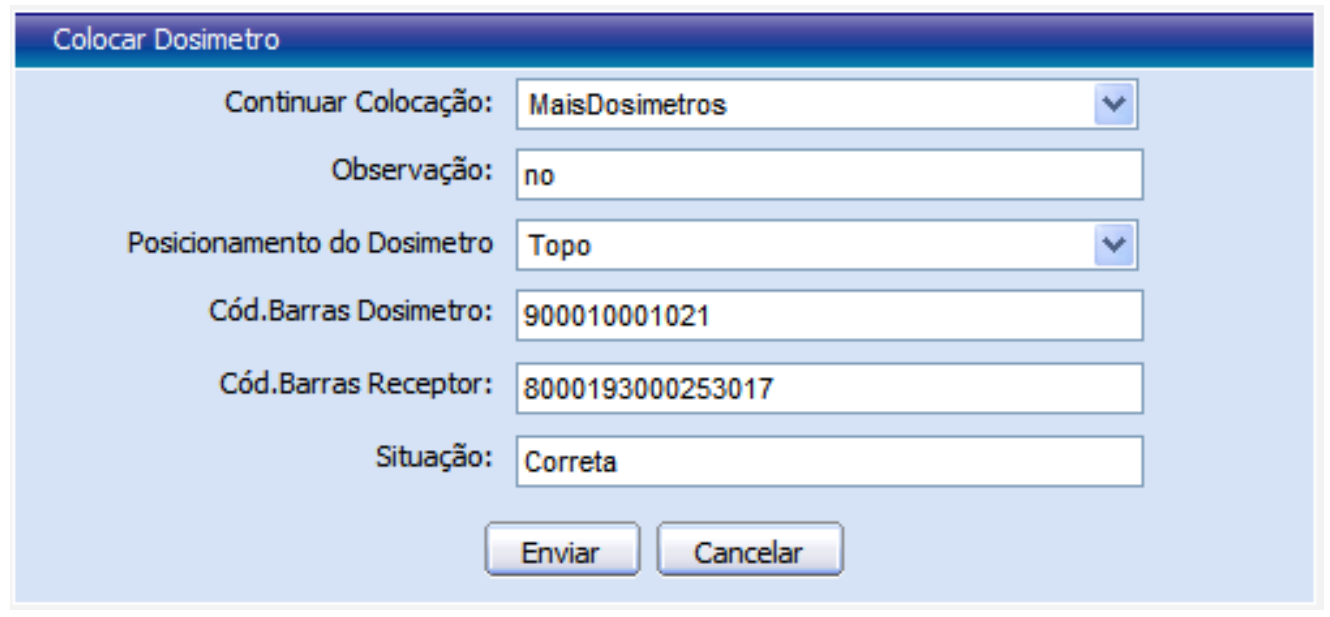

FIGURA C4. 2 - Tela de Colocar do, referente ao posicionamento do dosímetro.

A FIG.C4.2 apesar de ser simples, o processo produz um relacionamento importante entre o dosímetro e o item que irá recebê-lo. 


\section{APÊNDICE D1 - Carregar Caixa}

O usuário da Produção faz o carregamento das caixas de irradiação (processo contínuo) com os produtos para serem irradiados.

Foram criados alguns usuários para teste: pardal, sabiá e canário. A FIG.D1.1 mostra o fluxo do processo de Colocar Dosímetro. Essa etapa é realizada seguindo a Instrução de Irradiação para o produto.

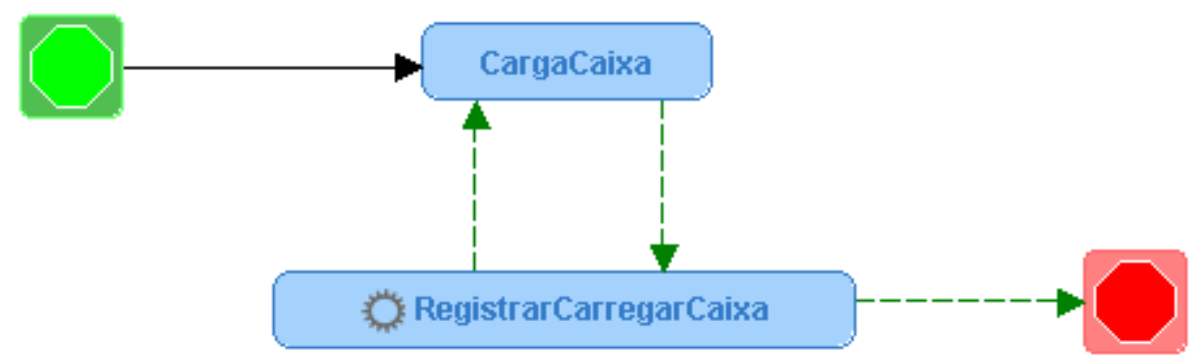

FIGURA D1. 1 - Fluxo do processo de Carregar Caixas de Irradiação.no Proed.

A FIG.D1.2 mostra a tela que o usuário da Produção recebe ao entrar no processo para colocar itens de lote na caixa de irradiação..

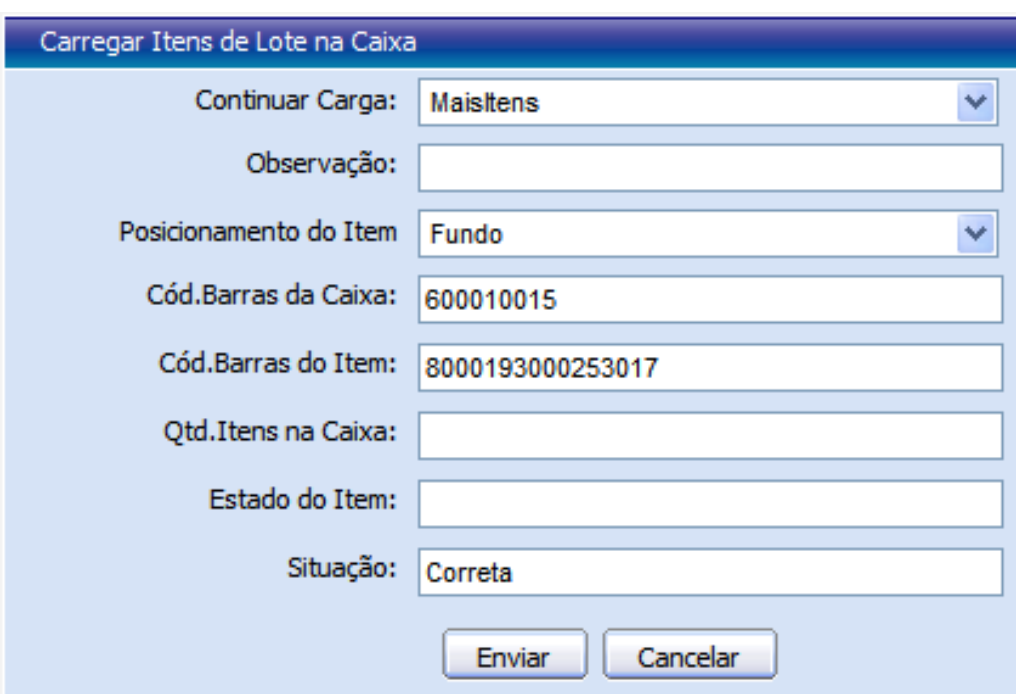

FIGURA D1. 2 - Tela de Carregar Caixa de Irradiação com itens de lotes. 
A FIG.D1.2 é de importância crucial para o tracking do item de lote ser rastreado no irradiador. Antes de serem carregados na caixa alguns itens de lote receberam dosímetros de teste.

A FIG.D1.3 mostra o estado atual do item anterior caso o operador escolher Carregar Mais Itens .

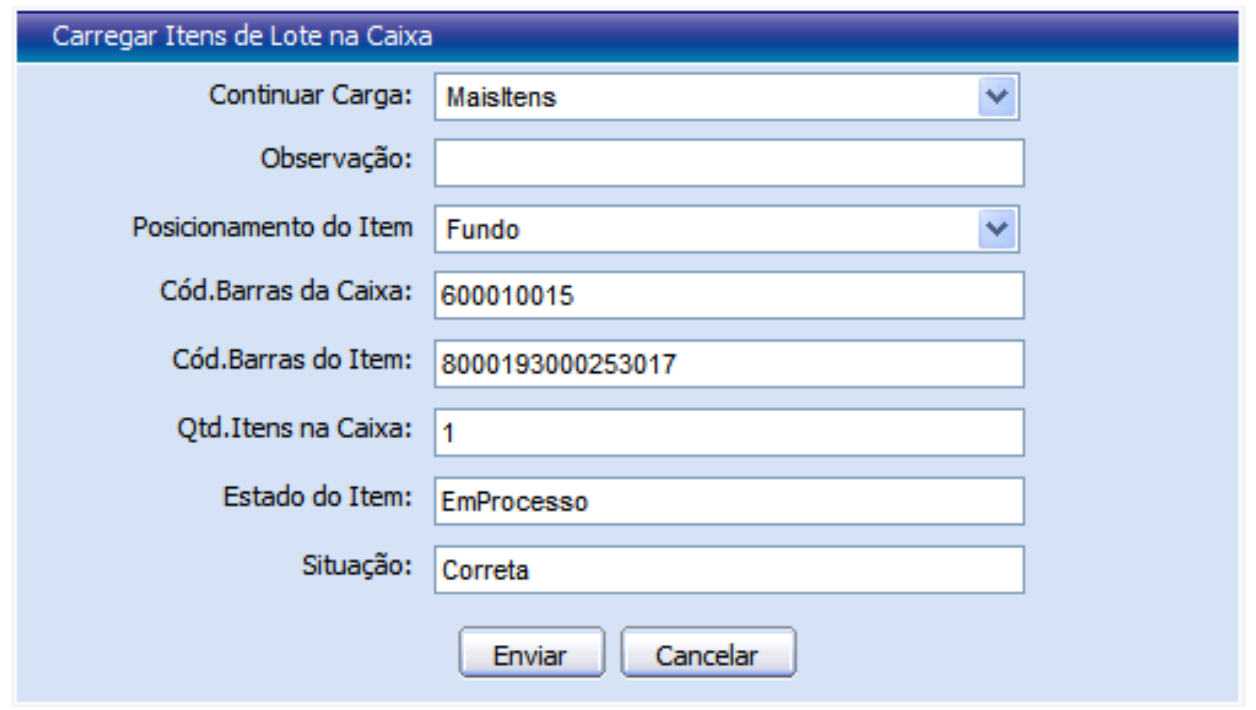

FIGURA D1. 3 - Tela mostra a efetivação da carga do item de lote na Caixa de Irradiação. 


\section{APÊNDICE D2 - Consultar Caixa}

O usuário da Produção a qualquer momento poderá consultar a situação de uma caixa de irradiação.

A FIG.D2.1 mostra o fluxo do processo de Consultar Caixa de irradiação.

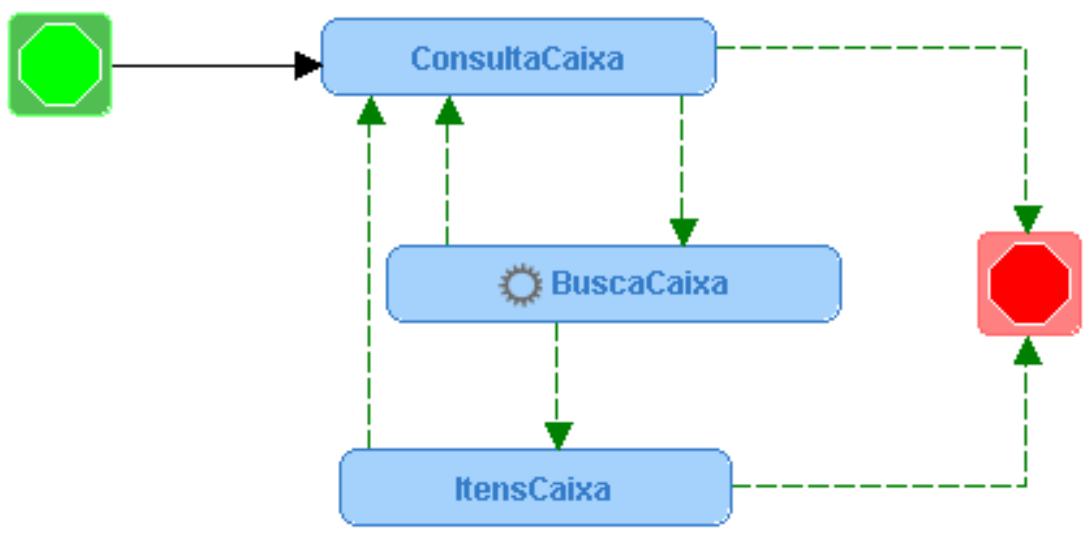

FIGURA D2. 1 - Fluxo do processo de Consultar Caixa de Irradiação.no Proed.

A FIG.D2.2 mostra a tela que o usuário da Produção recebe ao entrar no processo para consultar itens de lote na caixa de irradiação..

$\begin{aligned} \text { Consultar Itens na Caixa } & \\ \text { Continuação : } & \text { MaisConsulta } \\ \text { Código de Barras da Caixa : } & 600010015 \\ \text { Qtd.Itens na Caixa } & \\ \text { Observação : } & \\ \text { Situação : } & \text { Correta } \\ & \text { Enviar Cancelar }\end{aligned}$

FIGURA D2. 2 - Tela de Consultar Itens na Caixa de Irradiação. 
A FIG.D2.3 mostra o estado atual da caixa de irradiação. A data de carregamento dos itens de lote. Os itens de lote com as respectivas posições na caixa. Pode-se observar alguns detalhes nos campos mostrados:

- Observação:

- ST=EmProcesso: a caixa está em processo;

- POS=5-PosIrrad_1: caixa foi carregada na posição 1 do irradiador;

- $\quad \mathrm{DT}=2010-09-13$ : data em que foi carregada.

- Item de Lote1:

- 8000193000253017/Fundo/Realocado: o item foi carregado no Fundo da caixa e foi Realocado (logicamente) para a posição 1 do irradiador.

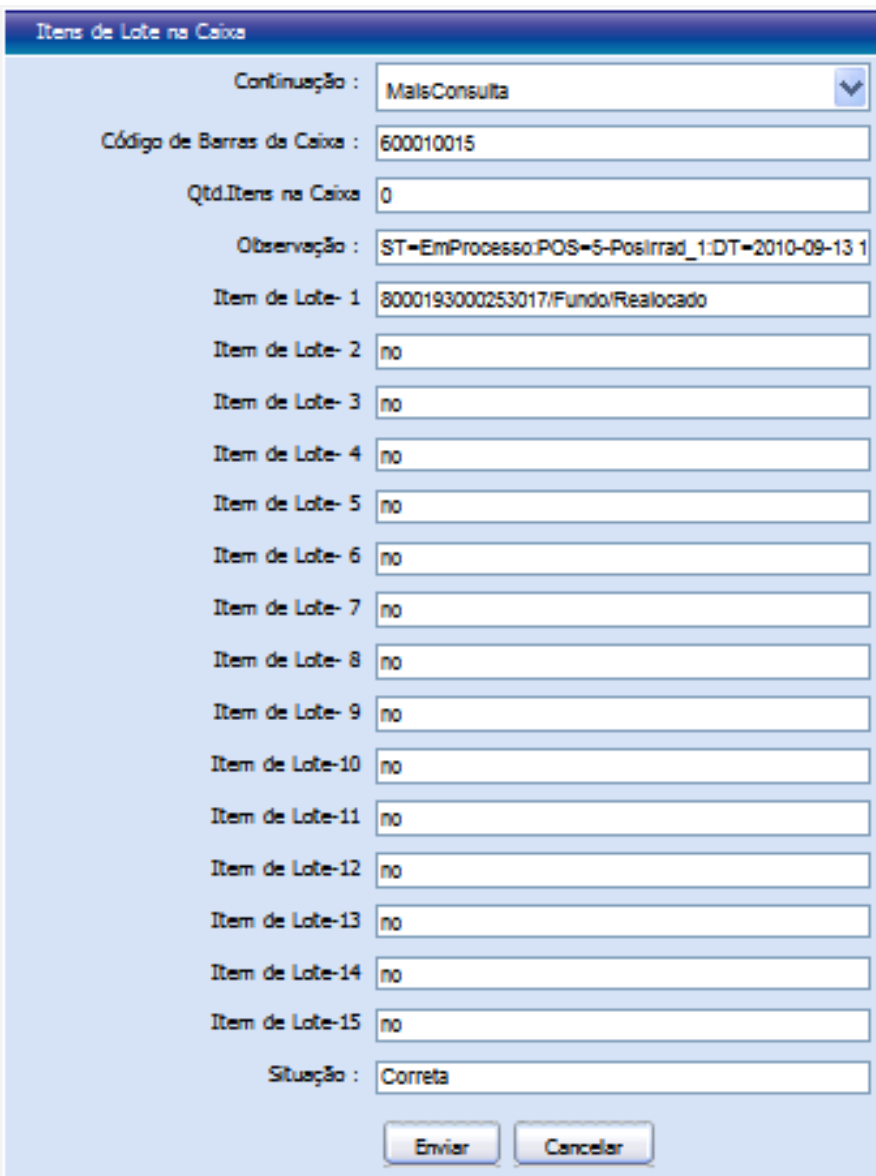

FIGURA D2. 3 - Tela mostra a efetivação da carga do item de lote na Caixa de Irradiação. 


\section{APÊNDICE D3 - Carregar Caixa Posição Irradiador Contínuo}

O usuário da Produção a qualquer momento poderá consultar a situação de uma caixa de irradiação.

A FIG.D3.1 mostra o fluxo do processo de Carregar Caixa na posição do irradiador.

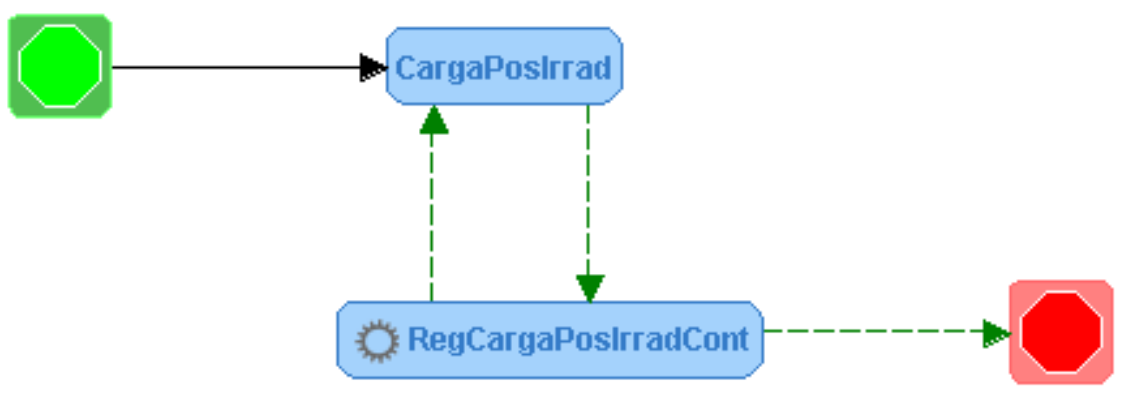

FIGURA D3. 1 - Fluxo do processo de Carregar Caixa de Irradiação na Posição do Irradiador no editor Proed.

A FIG.D3.2 mostra a tela que o usuário da Produção recebe ao entrar no processo para carregar caixas nas posições de irradiação do irradiador.

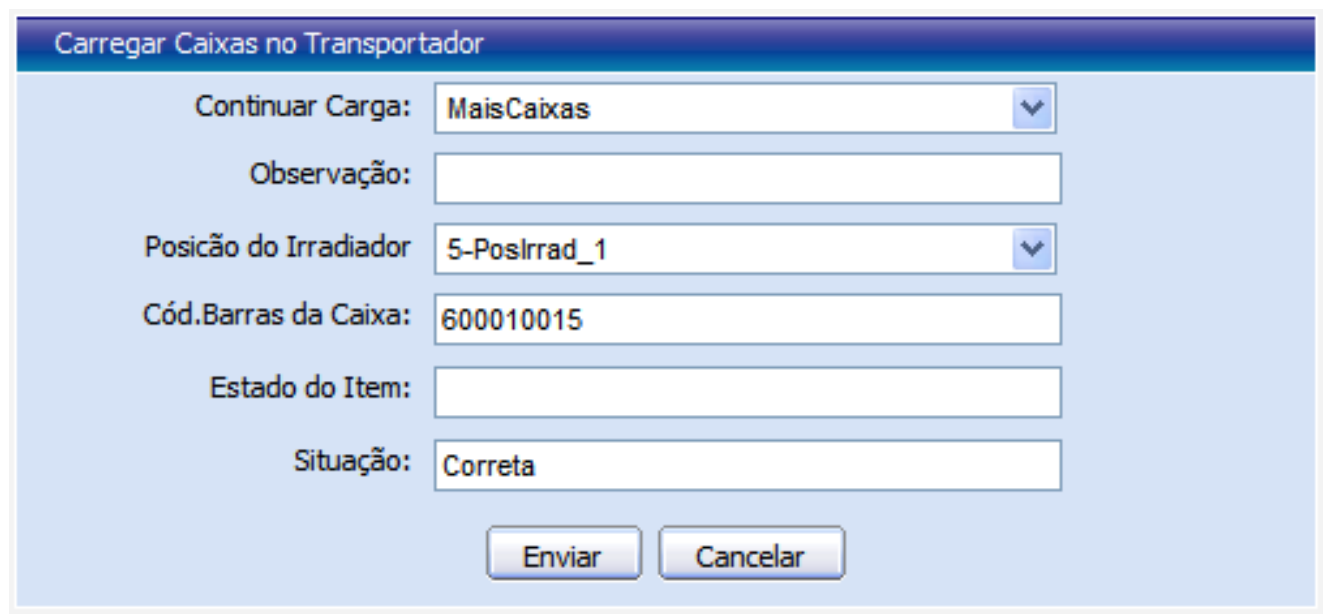

FIGURA D3. 2 - Tela de carregar caixas nas posições do irradiador. 


\section{APÊNDICE D4 - Carregar Posição do Track}

O usuário da Produção utiliza esse processo para carregar as outras posições do track. Considera-se posição de track qualquer posição que o produto é encontrado durante a permanência no ambiente do irradiador.

A FIG.D4.1 mostra o fluxo do processo de Carregar Posição do Track no ambiente do irradiador.

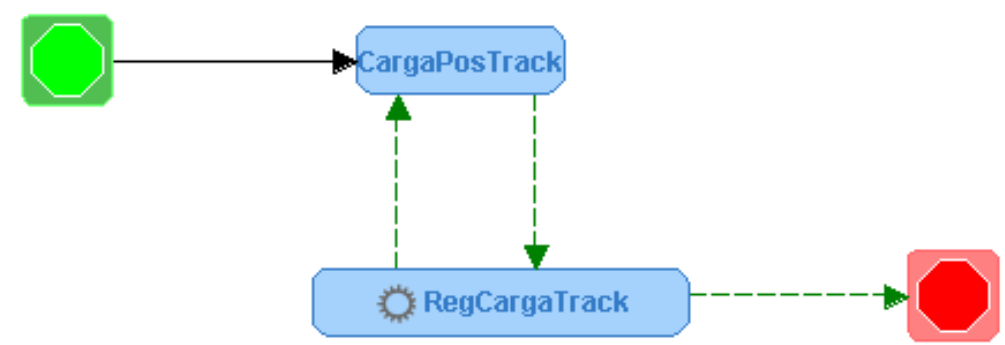

FIGURA D4. 1 - Fluxo do processo de Carregar Posição do Track no ambiente do irradiador no editor Proed.

A FIG.D4.2 mostra a tela que o usuário da Produção recebe ao entrar no processo para carregar itens nas posições do track do irradiador.

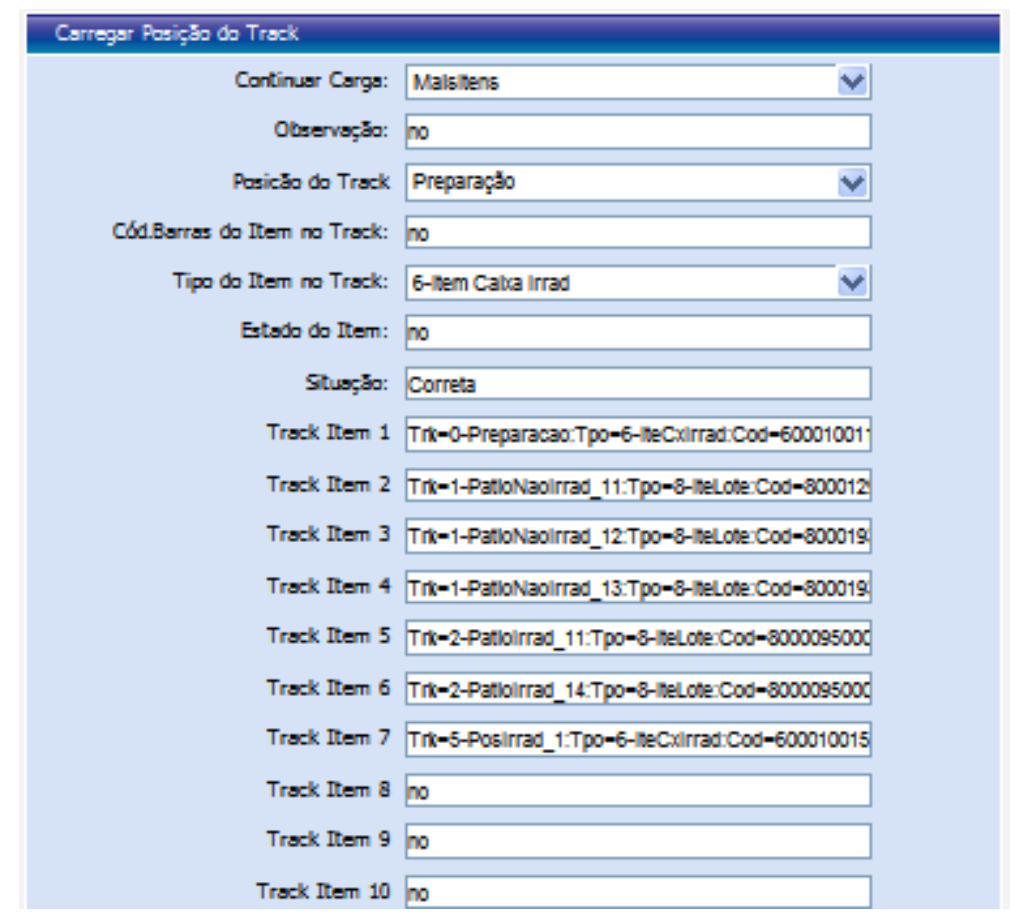

FIGURA D4. 2 - Tela de carregar posições de track nas posições do irradiador. 
A FIG.D4.2 mostra a tela de entrada de itens no track e deve ser entendida em dois momentos:

- Primeiro: o sistema mostra ao operador as posições já ocupadas com seus respectivos itens. A tela mostra de 30 em 30 itens.

- Segundo: o usuário pode optar por incluir dois tipos de itens:

○ 6-Item Caixa Irrad: itens de caixa de irradiação, ou

- 8-Item de lote de produto

As posições de track que podem serem escolhidas são:

- Preparação: posição na qual as caixas ficam estacionadas antes de entrarem no irradiador com os produtos alojados segundo a Instrução de Irradiação;

- Pátio de produtos Não Irradiados: local que os produtos ficam armazenados antes da irradiação. Nesse espaço o operador faz a identificação dos produtos e coloca dosímetros:

- Pátio Não Irradiado 1:1

- Pátio Não Irradiado 1:2

- Pátio Não Irradiado 1:3

- Pátio Não Irradiado 1:4

- Pátio Não Irradiado 1:5

- Pátio Não Irradiado 2:1

- Pátio Não Irradiado 2:2

- Pátio Não Irradiado 2:3

- Pátio Não Irradiado 2:4

- Pátio Não Irradiado 2:5

- Pátio Não Irradiado 3:1

- Pátio Não Irradiado 3:2

- Pátio Não Irradiado 3:3

- Pátio Não Irradiado 3:4

○ Pátio Não Irradiado 3:5

- Pátio de produto irradiados: local onde os produtos ficam armazenados após a liberação do processo. Ficam a disposição do cliente para sua retirada:

- Pátio Irradiado 1:1

- Pátio Irradiado 1:2

- Pátio Irradiado 1:3

- Pátio Irradiado 1:4

- Pátio Irradiado 1:5

- Pátio Irradiado 2:1

- Pátio Irradiado 2:2

- Pátio Irradiado 2:3

- Pátio Irradiado 2:4 
- Pátio Irradiado 2:5

- Pátio Irradiado 3:1

○ Pátio Irradiado 3:2

- Pátio Irradiado 3:3

- Pátio Irradiado 3:4

○ Pátio Irradiado 3:5

- As Câmaras frias seguem os mesmo conceitos dos pátios citados acima:

- Câmara Não Irradiado 1:1

- Câmara Não Irradiado 1:2

- Câmara Não Irradiado 1:3

- Câmara Irradiado 1:1

- Câmara Irradiado 1:2

- Câmara Irradiado 1:3

- Posição Estática do Irradiador: posições ao redor das fontes nas quais os produtos ficam estáticos enquanto são irradiados:

- Posição Estática Irradiador 10a13

- Posição Estática Irradiador 15a17

Pode-se notar que estão de fora as posições do irradiador. Estas são carregadas no processo CarregarPosIrradCont.

Note também que as posições estáticas do irradiador são carregadas utilizando-se desse processo. 


\section{APÊNDICE D5 - Consultar Lote}

O usuário da Produção utiliza esse processo para Consultar Lote de produto para irradiação.

A FIG.D5.1 mostra o fluxo do processo de Consultar Lote.

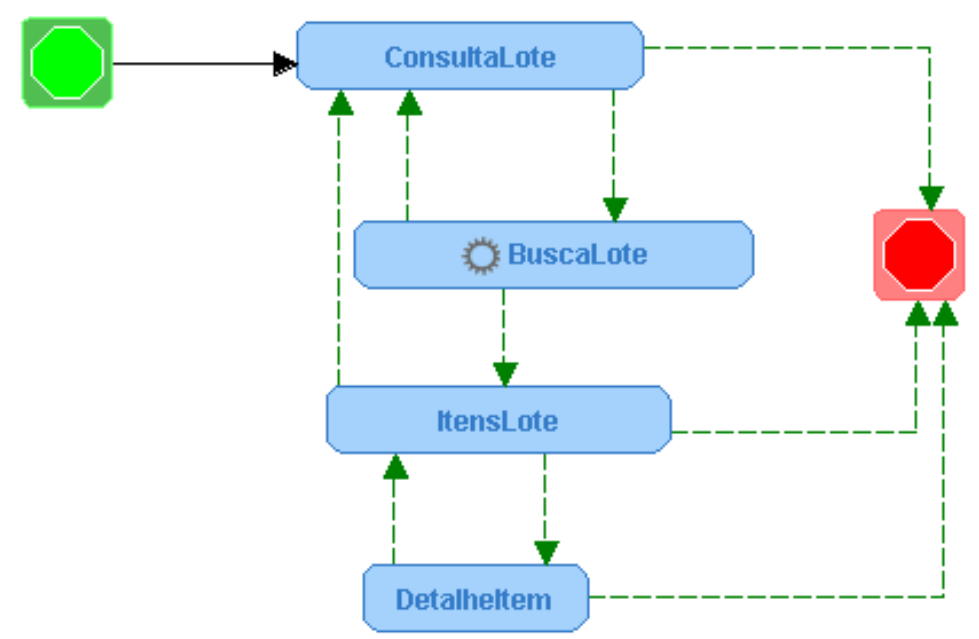

FIGURA D5.1 - Fluxo do processo de Consultar Lote de produto para irradiar no editor Proed.

A FIG.D5.2 mostra a tela que o usuário da Produção recebe ao entrar no processo para consultar lote. O usuário pode alterar o estado (status) do lote. Essa providência é no sentido de deixar coerente o estado do lote. Esse estado deve refletir o atual estado dos seus itens. Pode ser:

- Ativo

- EmProcesso

- Negociando

- Aprovado

- Concluido

- Suspenso

- Inativo

- Cancel

- ClienteEnviarMat

- ClienteEnviouMat

- MaterialRecebido

- InspecaoMatRecebido

- ReprovadolnspRecepcao

- ClienteTrocarMat

- LiberadolnspRecepcao 
- IdentMatRecebido

- PrepararMaterial

- InspPreparacao

- LiblnspPreparacao

- ReprovinspPreparacao

- ColocarDosimetro

- LibProcesso

- ProcesEstatico

- CargaManual

- ProcesContinuo

- CargaAutomatica

- MedirDosagem

- AprovDosagem

- ReprovDosagem

- ReciclarDosagem

- EmitirCertif

- Emitirll

- EmitirDocFat

- LibExpedicao

- Expedido

- Encerrado

- PatioNI

- CamaraNI

- Patiolrrad

- Camaralrrad 


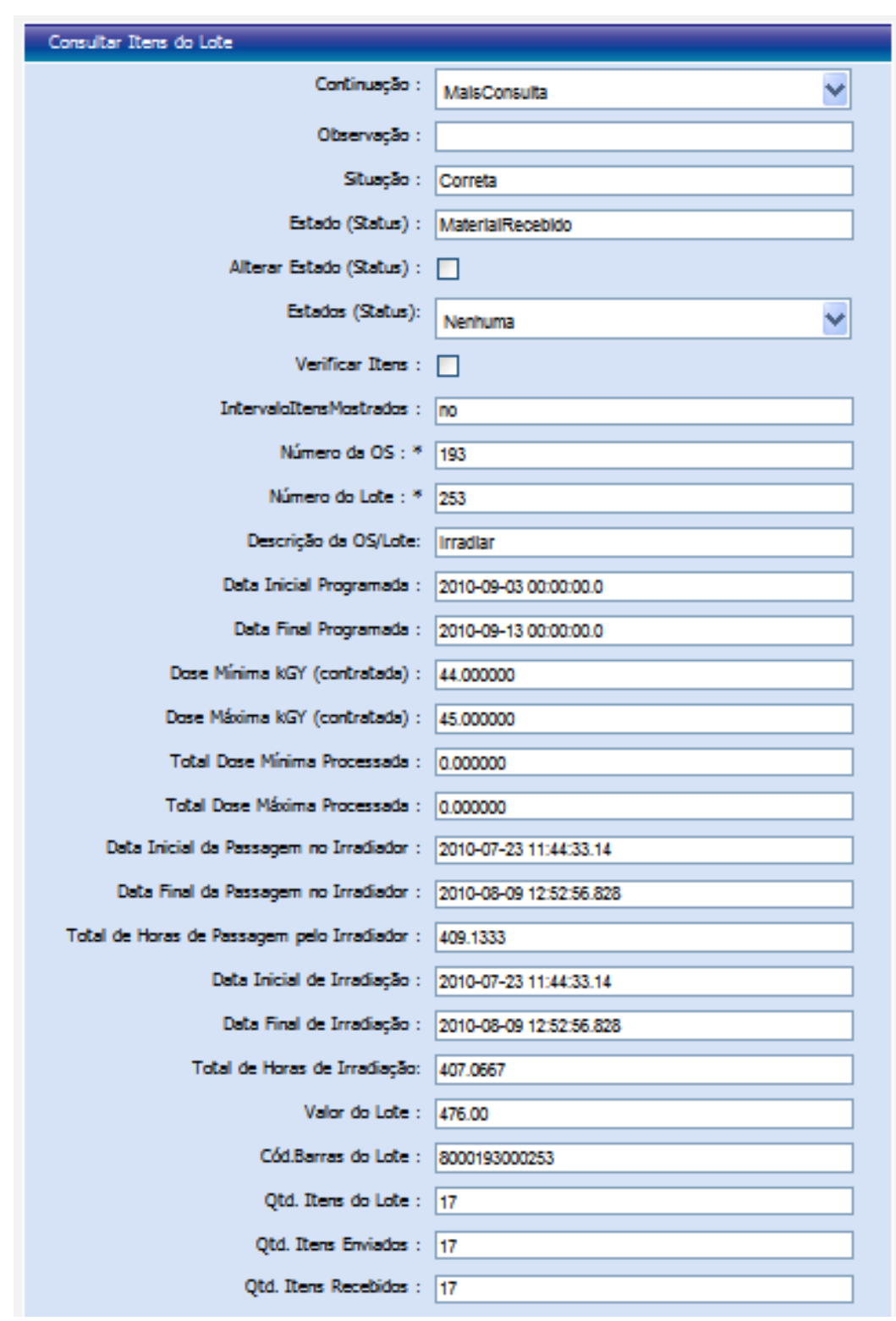

FIGURA D5.2 - Tela de Consultar Lote e seus itens.

Outra possibilidade é o usuário verificar os itens do lote. Nesse caso o sistema apresenta outra tela mostrado na FIG.D5.3. 


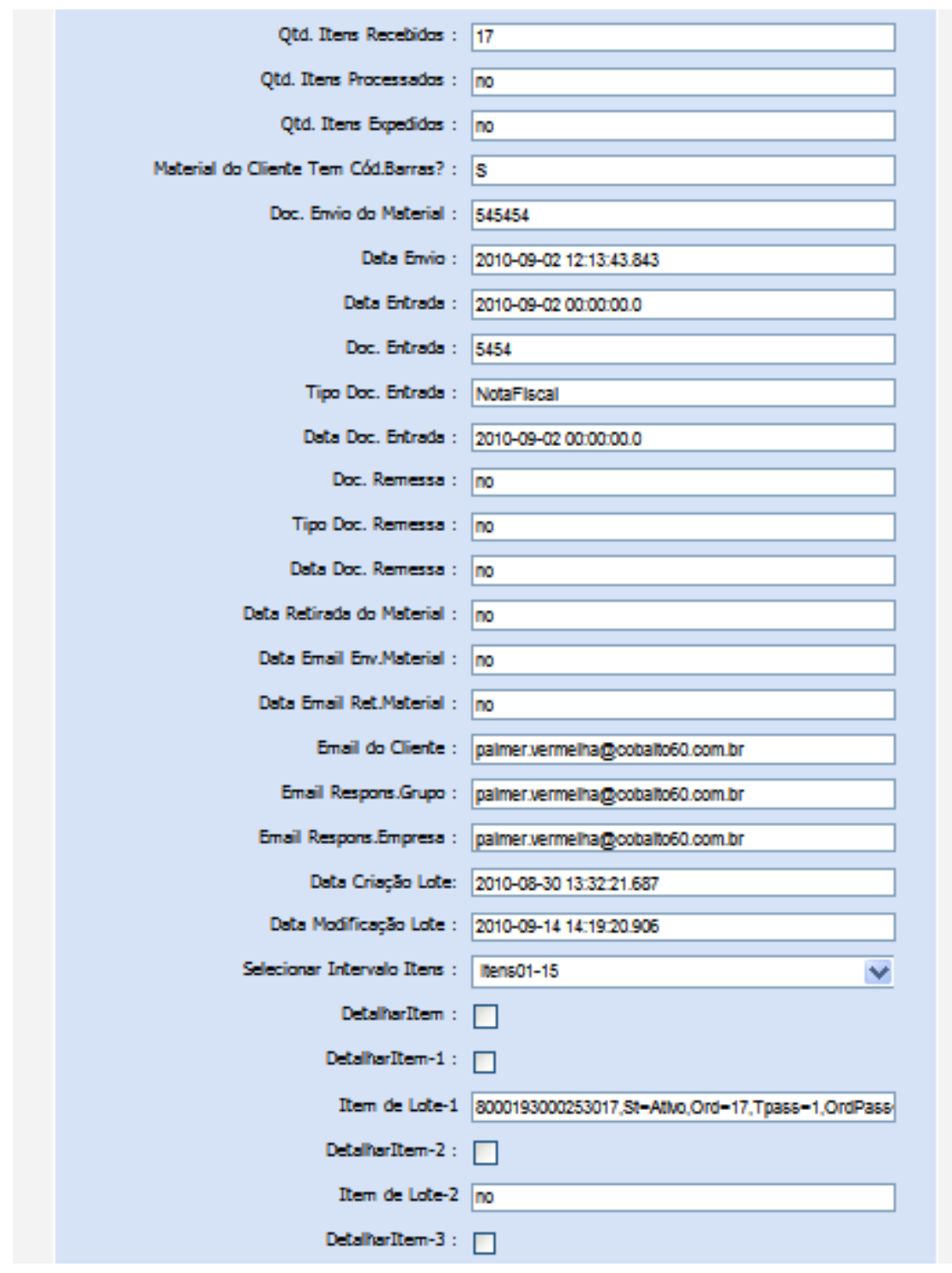

FIGURA D5.3 Tela de Consultar Lote e são detalhados os seus itens.

Na FIG.D5.3 foi aberto espaço para mostrar os itens 01 a 15 . O usuário ainda pode abrir o detalhe de algum item em particular.

O chekbox Detalharltem em conjunto com o chebox Item de lote-x faz com que o sistema apresente uma nova tela.

A FIG.D5.4 mostra o detalhamento do item-1 com todas suas características de processo e estados que já transitou. 


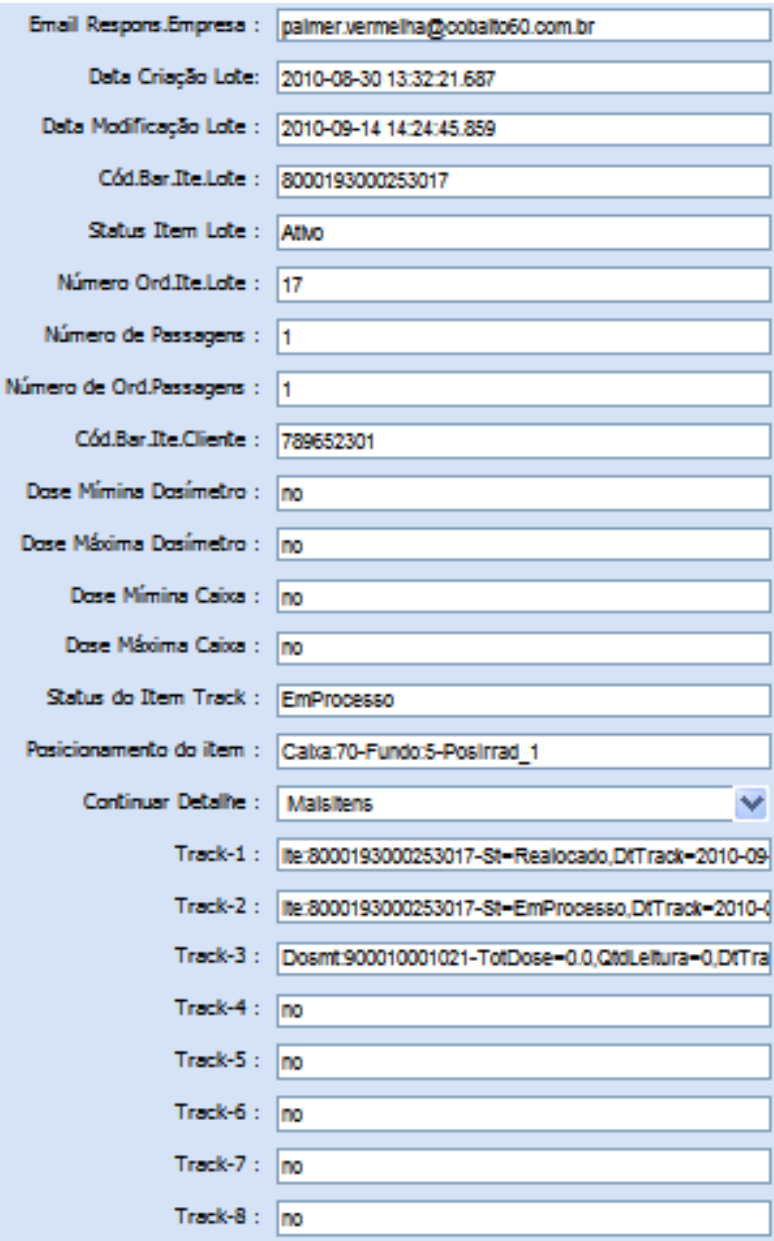

no
no
no
no
no

FIGURA D5.4 - com o detalhamento do item-1 com seu respectivo tracking. 
APÊNDICE E1 - Tela dos Processos do TPI no Bonita

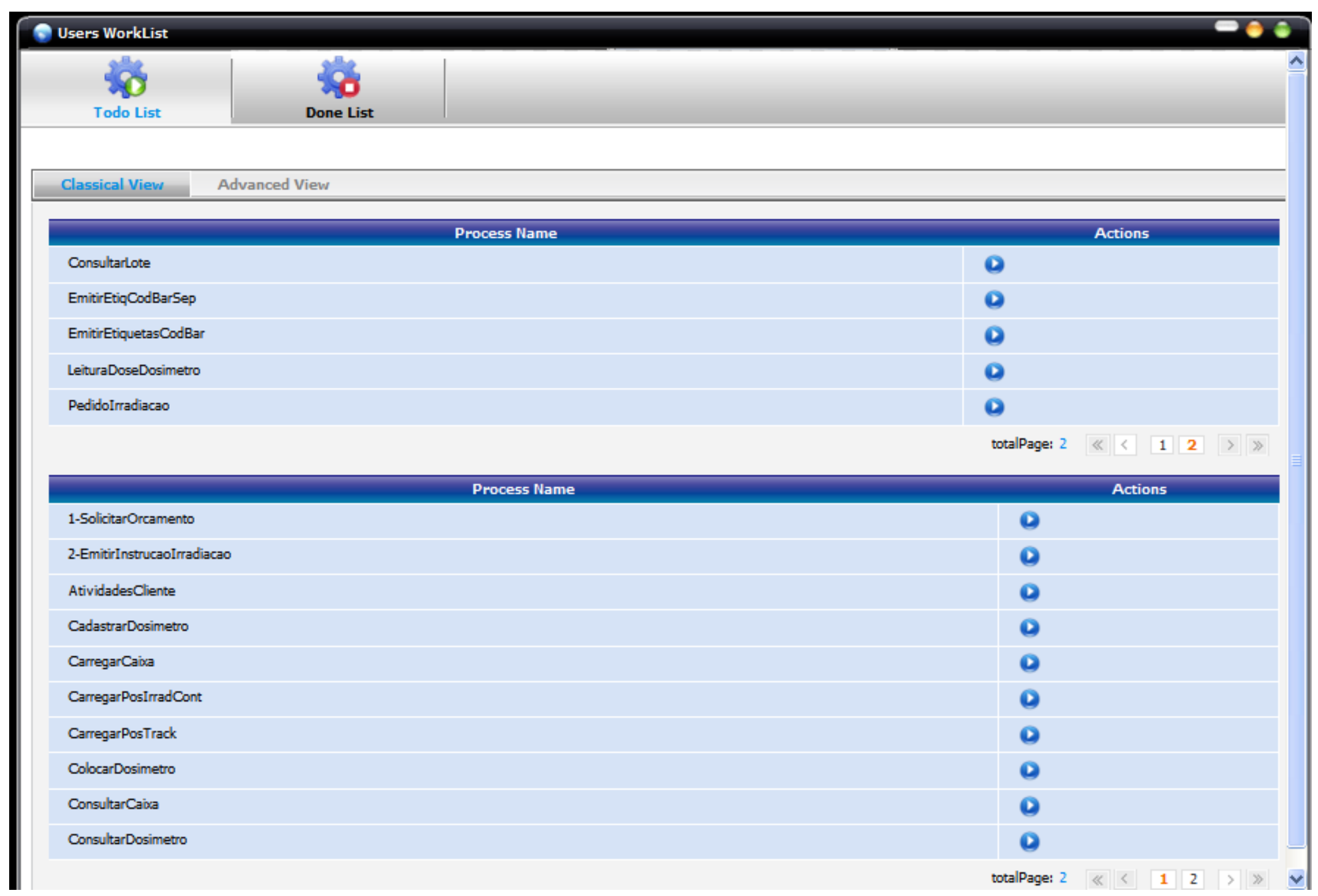




\section{APÊNDICE F1 - Modelo de dados do Sistema TPI}
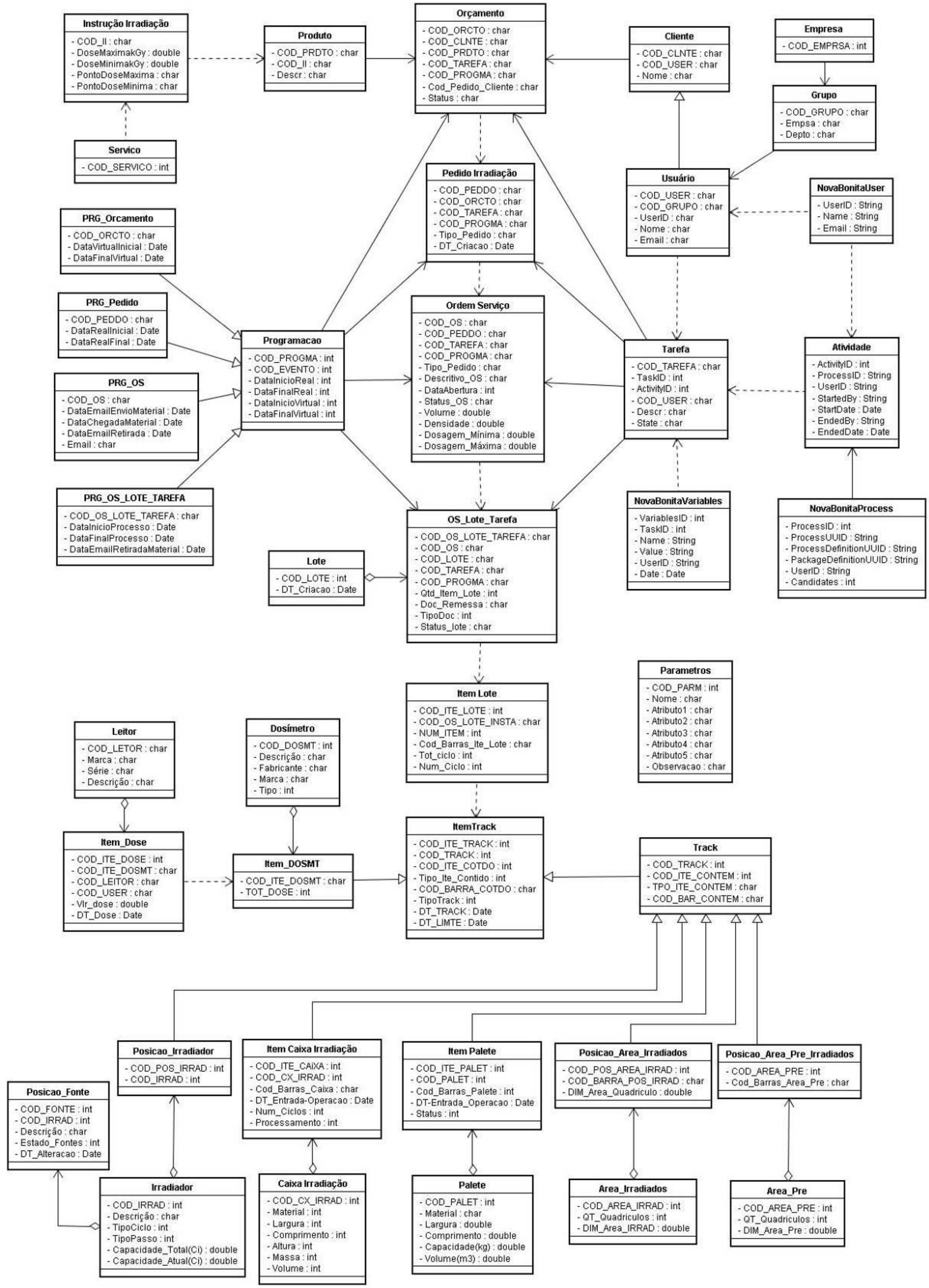
APÊNDICE G1 - Modelagem do fluxo do processo de Solicitação de Serviço (FIG.3.1)

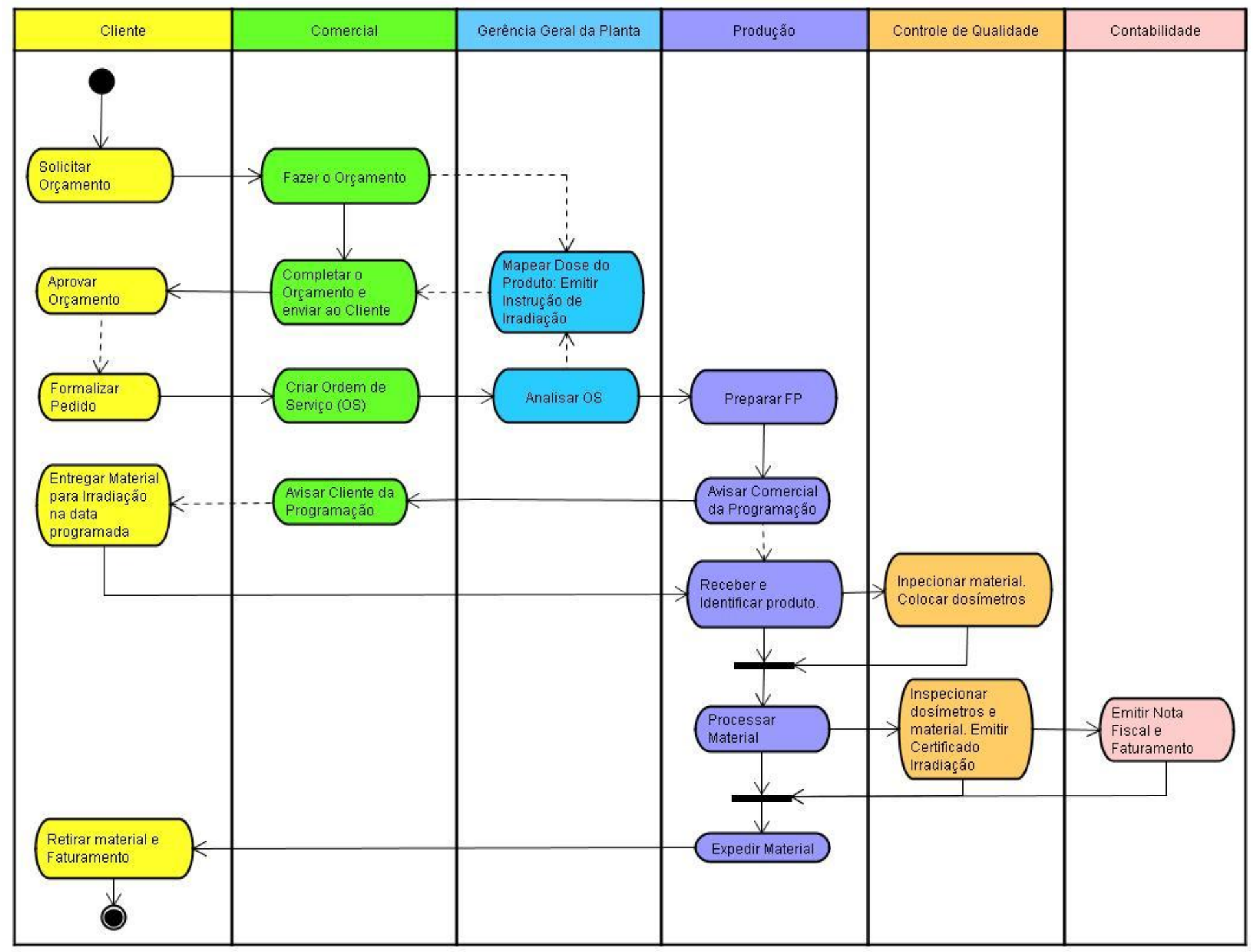




\section{REFERÊNCIAS BIBLIOGRÁFICAS}

BONITA. Nova Bonita versão 4.1.1. Disponível em http://forge.objectweb.org/projects/bonita. Acesso em: 10 nov.2010.

BRASIL. ANVISA Agência de Vigilância Sanitária. Disponível em < http://elegis.anvisa.gov.br/leisref/public/form.php?lang=pt>. Acesso em: 30 mai.2007.

BRASIL. Comunidade de Software Livre do Governo Federal. Disponível em http://www. softwarelivre.gov.br acesso em 10 nov.2010.

BRASIL. Ministério da Justiça. Código de Defesa do Consumidor. Lei № 8.078 de 11 de setembro de 1990 .

BORGES, M. BPM - Gerência de Processos de Negócios. Disponível em http://chord.nce.ufri.br/cursos/sctci2004/documentos/aula\%20BPM.pdf. Acesso em: 25 mar.2008.

CALVO, Wilson A.P. Desenvolvimento Do Sistema De Irradiação Em Um Irradiador Multipropósito De Cobalto-60 Tipo Compacto. 2005. Tese (Doutorado) - Instituto de Pesquisas Energéticas e Nucleares, São Paulo.

CREDE, Ricardo Gandara, Estudos dos efeitos da radiação gama e de Aceleradores de elétrons na detecção de grãos de Milho (zeamays) geneticamente modificado. 2005. Dissertação (Mestrado) - Instituto de Pesquisas Energéticas e Nucleares, São Paulo.

ECLIPSE - Eclipse Foundation - IDE for Java EE Developers . Disponível em http://www.eclipse.org/downloads/packages/release/galileo/sr2. Acesso em: 10 nov.2010.

FAO-AIEA, INTERNATIONAL CONSULTIVE GROUP and FOOD IRRADIATION. Facts about food irradiation. 1999: ICGFI.. Viena-Austria .

GNU Lesser General Public License - Disponível em http://www.opensource.org/licences/gpl-3.0.htm Acesso em: 10 nov.2010.

H2 - The Java SQL Database. Disponível em http://www.h2database.com/html/main.html. Acesso em: 10 nov.2010.

IAEA, INTERNATIONAL ATOMIC ENERGY AGENCY Guidelines for industrial radiation strerilization of disposable medical products (Cobalt-60 Gamma Irradiation). TECDOC-539. IAEA-Vienna-1990. Austria: January 1990.

IAEA, INTERNATIONAL ATOMIC ENERGY AGENCY. Gamma Irradiators for Radiation Processing. Institute of Nuclear Chemistry and Technology, Warszawa, Poland, July 2005.

ISO-9001:2008 Quality Management System - Requirement. 2008. 
ISO-11137:2006 Sterilization of Health Care Produts - Requirements for Validation and Routine Control - Radiation Sterilization. Association for the Advancement of Medical Instrumentation. 2006.

ISO-13485:2003 Medical devices -- Quality management systems -Requirements for regulatory purposes. 2003/Cor 1:2009

JAVA - Java Platform, Standard Edition (Java SE). Disponível em: http://www.oracle.com/technetwork/java/javase/downloads/index.html. Acesso em: 10 nov.2010.

JONAS - Java On Application Server Versão 4.8.6 - disponível em http://forge.objectweb.org/ projects/jonas Acesso em: 10 nov.2010.

JUDE -COMMUNITY. Free UML Modeling Tool. Disponível em: http://jude.change-vision.com/jude-web/index.html. Acesso em: 10 nov.2010.

KARAN JUNIOR, D. Estudo de Aplicação da Tecnologia "Fieldbus" nos Sistemas de Controle e Segurança de uma Planta de Radioesterilização. 2000. Dissertação (Mestrado) - Instituto de Pesquisas Energéticas e Nucleares, São Paulo.

LINUX - Linux is a free Unix-type operating system. Disponível em http://www.linux.org/. Acesso em: 10 nov.2010.

LACY, Miguel K. O'BRIEN De. O sistema de workflow e BPM Bonita: Fluxo sincronizado. Linux Magazine, Edição número 45. Agosto de 2008.

LORIDAN, Christophe, ROSELL, Jordi A. Bonita - WorkFlow patterns support. 2006. Bull R\&D versão V1.1. Disponível em http://www.workflowpatterns.com/vendors/documentation/bonita patterns.pdf.

Acesso em: 17 dez.2009.

RELA, P. R., SAMPA, M. H. O. Present Status On Development Of Industrial Radiation Process Plants In Brazil. - 2005. Instituto de Pesquisas Energéticas e Nucleares, São $\quad$ Paulo. Disponível em http://www.ipen.br/biblioteca/2005/inac/10673.pdf. Acesso em: 10 set.2007.

RELA, P. R.. TNA - 5783 Utilização da Radiação lonizante na Esterilização de Produtos - Radioesterilização. 2006. Curso. IPEN-SP. São Paulo.

RESHEF, N.A.. Message Brokers and Workflows. In Advanced Web Applications Development Technion CS 236606 Spring 2003, Class 10. IBM Labs, Haifa. 2003. Disponível em webcourse.cs. technion.ac.il/ 236606/ Spring2003/ho/WCFiles/ 236606\%20 Lecture10.ppt -.Acesso em 17 dez. 2010.

SIQUEIRA CAMPOS, Carlos Frederico Pereira de. Estudo e especificação de um sistema de instrumentação para unidades de elevação de petróleo utilizando tecnologia sem fio. 2006. Dissertação (Mestrado) - Universidade Federal do Rio Grande do Norte, Natal. 
SOFTWARE LIVRE BRASIL, FISL11 - 11웅rum Internacional Software Livre A tecnologia que liberta. Porto Alegre - RS, 21 a 24 de julho de 2010. Centro de Eventos da PUC-RS8. Disponível em http://softwarelivre.org/fisl11. Acesso em: 10 set.2010.

TOMEI, Thiago, Acelerados de Partículas. 2009. Disponível em http://www.sprace.org.br/Twiki/pub//Main/CursoParticulas/Aceleradores de Partic ulas I.pdf. Acesso em 17 dez. 2010.

VRIES, René Penning de, The Bussiness of Innovation (Wireless Sensor Network). 2008. Taipei. IN Computex Taipei - June, 4, 2008.

ZIGBEE-ALLIANCE. Controle remoto e aquisição de dados via XBee/ZigBee (IEEE 802.15.4). 2008. Disponível em: <http://www.rogercom.com>. Acesso em: 11 mar.2009. 